The University of Southern Mississippi

The Aquila Digital Community

Dissertations

Spring 5-1-2018

\title{
The Effects of Organizational Commitment and Harmonious Passion on Voluntary Turnover Among Social Workers: A Mixed Methods Study
}

Ashley Scales

University of Southern Mississippi

Follow this and additional works at: https://aquila.usm.edu/dissertations

Part of the Organization Development Commons, Other Social and Behavioral Sciences Commons, and the Social Work Commons

\section{Recommended Citation}

Scales, Ashley, "The Effects of Organizational Commitment and Harmonious Passion on Voluntary Turnover Among Social Workers: A Mixed Methods Study" (2018). Dissertations. 1532.

https://aquila.usm.edu/dissertations/1532

This Dissertation is brought to you for free and open access by The Aquila Digital Community. It has been accepted for inclusion in Dissertations by an authorized administrator of The Aquila Digital Community. For more information, please contact Joshua.Cromwell@usm.edu. 
The Effects of Organizational Commitment and Harmonious Passion on

\title{
Voluntary Turnover Among Social Workers:
}

\author{
A Mixed Methods Study \\ by \\ Ashley Nicole Scales

\begin{abstract}
A Dissertation
Submitted to the Graduate School, the College of Science and Technology and the Department of Human Capital Development at The University of Southern Mississippi in Partial Fulfillment of the Requirements for the Degree of Doctor of Philosophy
\end{abstract}

Approved by:

Dr. H. Quincy Brown, Committee Chair

Dr. Heather M. Annulis

Dr. Cyndi H. Gaudet

Dr. Dale L. Lunsford

Dr. H. Quincy Brown

Committee Chair
Dr. Cyndi H. Gaudet

Department Chair
Dr. Karen S. Coats

Dean of the Graduate School

May 2018 


\section{COPYRIGHT BY}

Ashley Nicole Scales

2018

Published by the Graduate School

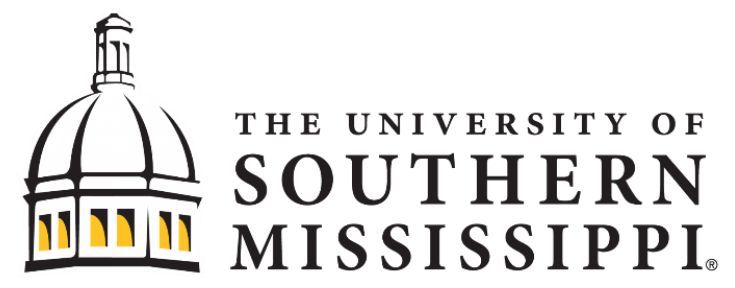




\begin{abstract}
The retention of Social Workers (SWs) is a concern that affects government and private organizations and the workforce. Voluntary turnover among SWs is increasing at an alarming rate. Not only is voluntary turnover rising, but organizational commitment and harmonious passion are declining (Wharton University of Pennsylvania, 2012). This study explored and examined the effect organizational commitment and harmonious passion have on voluntary turnover among Child Protective Services (CPS) SWs. The study used a concurrent mixed method design. Data collected during the quantitative phase provided information on the perceptions of SWs regarding organizational commitment, harmonious passion, and their intent to leave. The qualitative aspect of the study consisted of one-on-one interviews, which provided an opportunity for the SWs to tell their story in a meaningful way and provided a deeper explanation of their perceptions of organizational commitment, harmonious passion, voluntary turnover, and intent to leave. Two-hundred and twenty-six SWs completed the survey and twenty-nine SWs participated in an interview on organizational commitment, harmonious passion, voluntary turnover, and intent to leave. Although the literature suggested organizational commitment (affective, normative, and continuance commitment) and harmonious passion influences voluntary turnover. Results of the study did not support the prediction. However, the results of the study did indicate organizational commitment and harmonious passion levels are low among CPS SWs who participated in the current study. Participants noted low levels of organizational commitment and harmonious passion do contribute to turnover and has a negative impact on the clients and communities they serve. The SWs of this study feel undervalued and need support and
\end{abstract}


respect from CPS leaders to increase their levels of organizational commitment and harmonious passion. The retention of more qualified licensed SWs is critical in improving organizational commitment, harmonious passion, and the quality of care provided by the organization. 


\section{ACKNOWLEDGMENTS}

First, I am thankful to God through whom all is possible. Secondly, I would like to express my sincere gratitude to my chair, Dr. H. Quincy Brown for his continuous support of my study, his patience, weekly calls and text messages, motivation, and his immense knowledge. Dr. Brown's guidance has helped me enhance the way I analyze, research, think, write, and much more. I would also like to thank Dr. Cyndi H. Gaudet, Dr. Heather Annulis, and Dr. Dale Lunsford for believing in me and seeing me through to the end of this process. In addition, several people assisted me on my dissertation journey for which I will be forever grateful. Last, but not least, I would like to give special thanks my parents, Earl and Lottie Scales, for their leadership and patience as I completed my degree. I would also like to thank them for affording me the opportunity of an education and the support they have given me throughout my life. 


\section{TABLE OF CONTENTS}

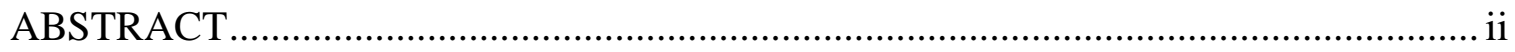

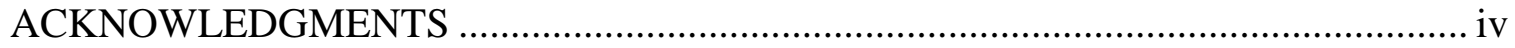

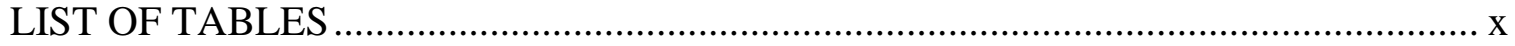

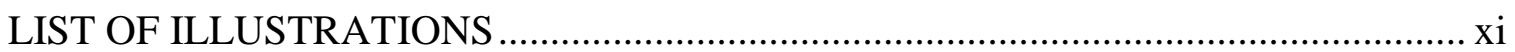

LIST OF ABBREVIATIONS ......................................................................... xii

CHAPTER I - INTRODUCTION .................................................................. 1

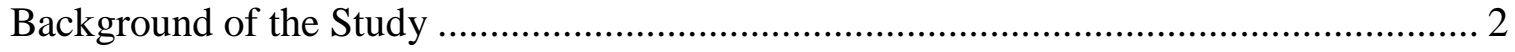

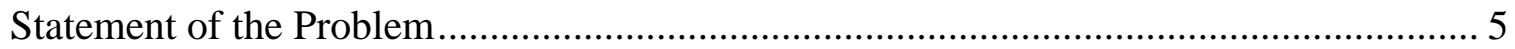

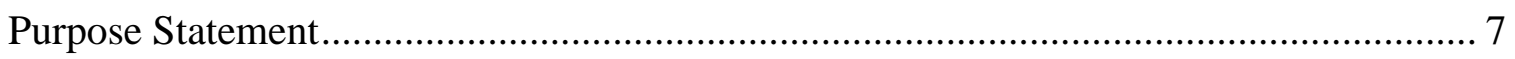

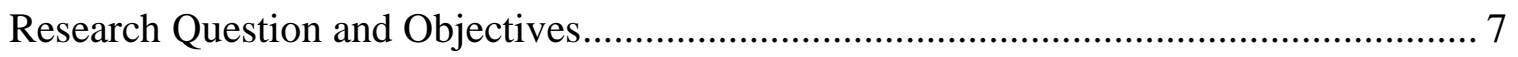

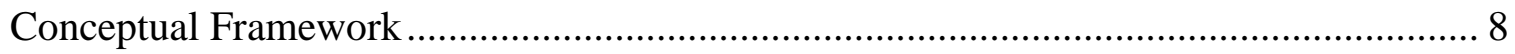

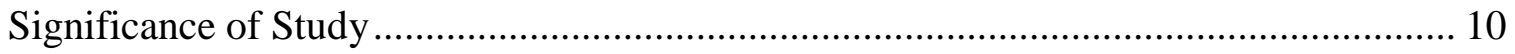

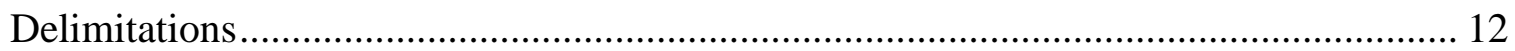

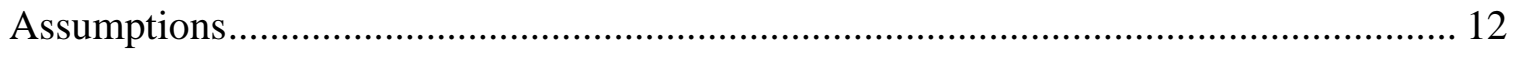

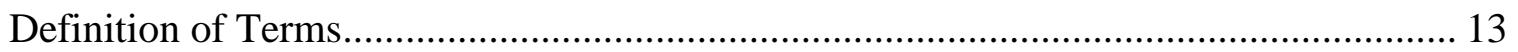

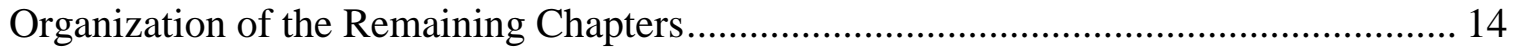

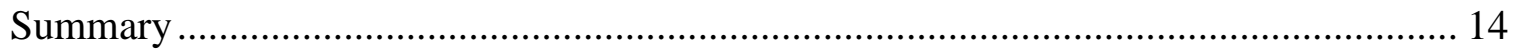

CHAPTER II - LITERATURE REVIEW ........................................................ 16 
Theory of Organizational Commitment. 16

Affective, Normative, and Continuance Commitment .......................................... 17

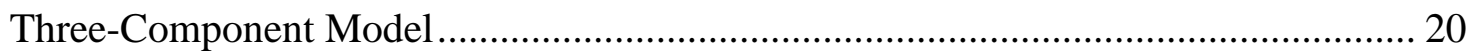

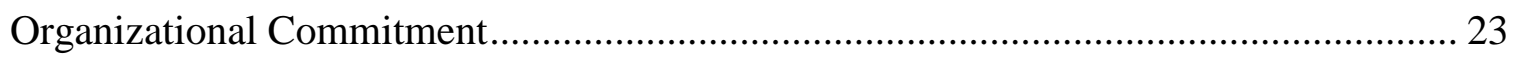

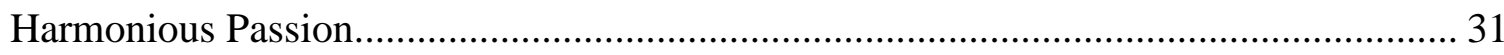

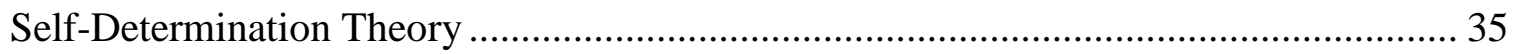

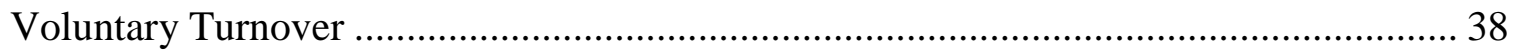

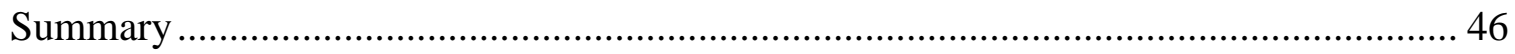

CHAPTER III - RESEARCH DESIGN AND METHODOLOGY ............................... 48

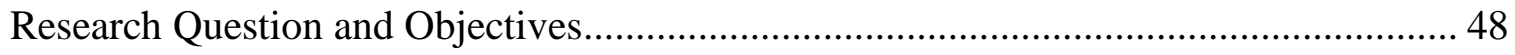

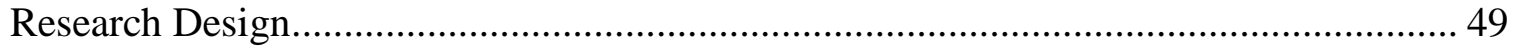

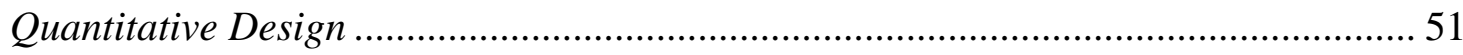

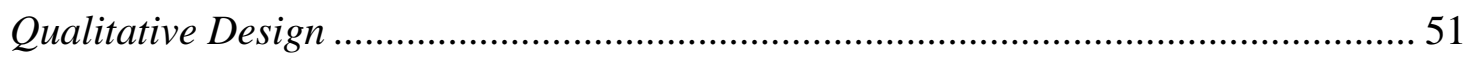

Institutional Review Board Approval ................................................................... 52

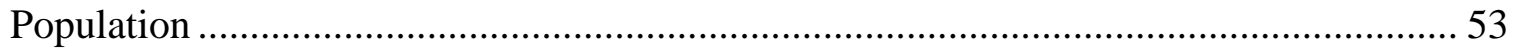

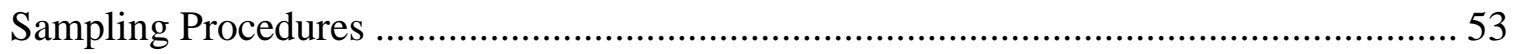

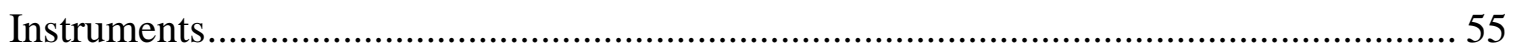

Three Component Model Employee Commitment Survey ..................................... 56

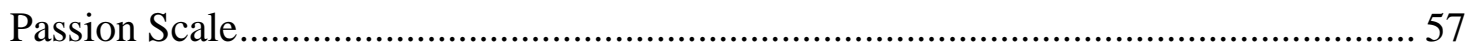

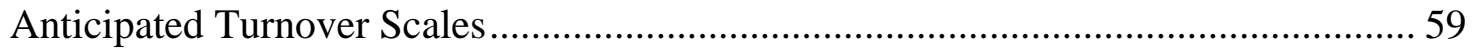




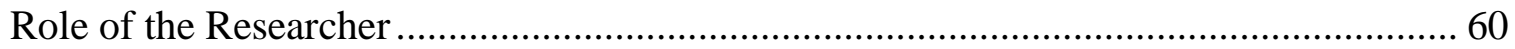

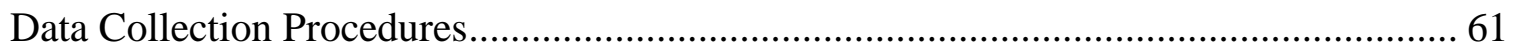

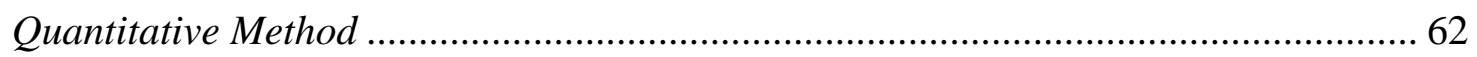

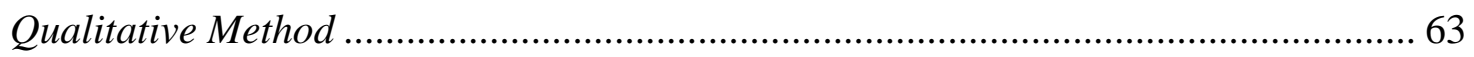

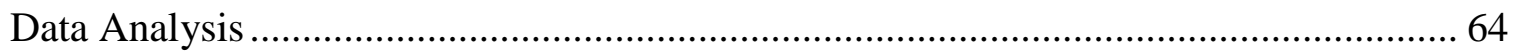

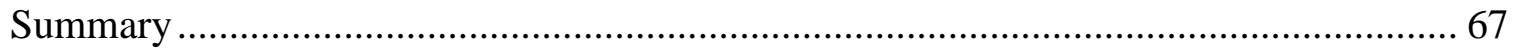

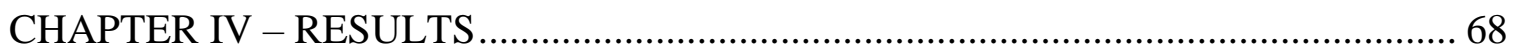

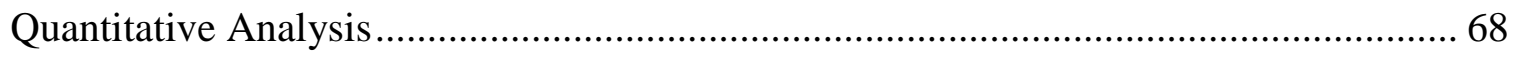

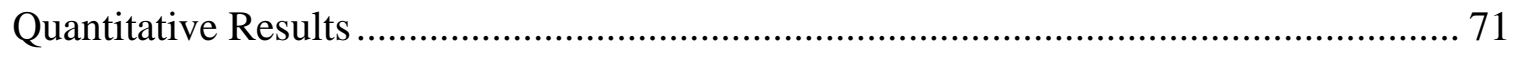

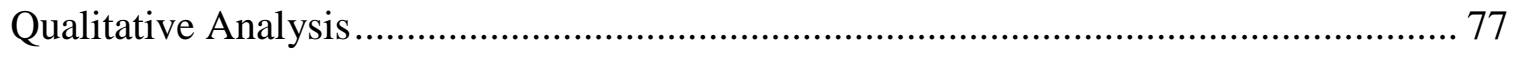

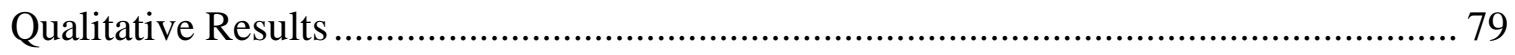

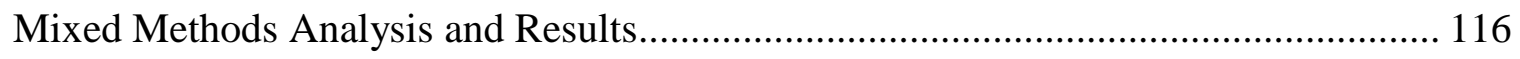

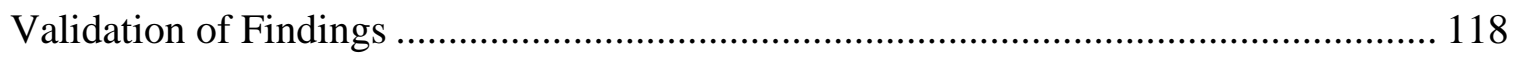

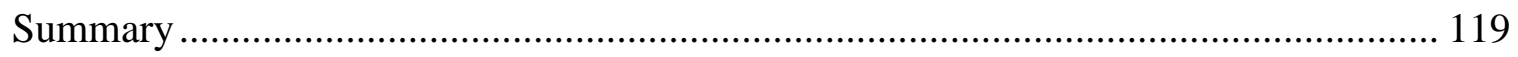

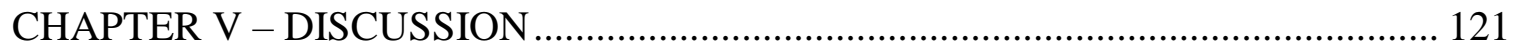

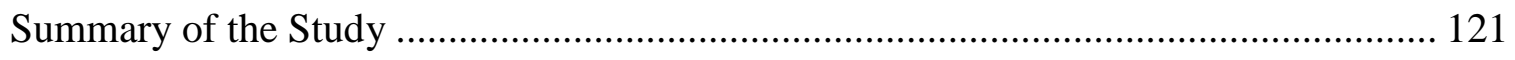

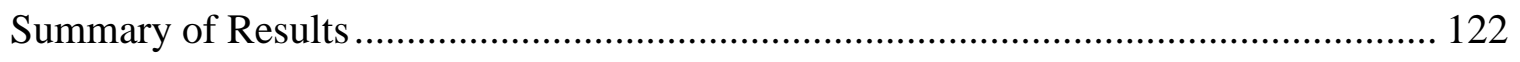

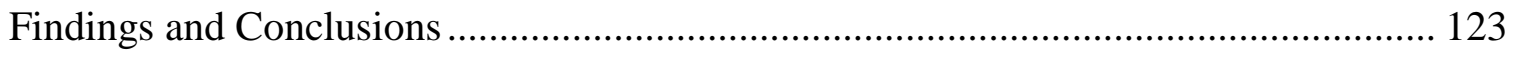

Organizational Commitment Perceptions ………..................................................... 123 
Finding. Valuing employees and support from leadership is vital to increasing organizational commitment among CPS SWs.

Conclusion.

Recommendations.

Harmonious Passion Perceptions

Finding. Boosting morale is critical for increasing harmonious passion among CPS

SWs.

Conclusion.

Recommendations.

Voluntary Turnover Perceptions

Finding. Voluntary turnover among CPS SWs negatively impacts the agency and the

clients they serve.

Conclusion.

Recommendations.

Implications of the Study 128

Limitations

Recommendations for Future Research . 130

Discussion 130

Summary 133

APPENDIX A - IRB Approval 135

viii 
APPENDIX B - Permission to Access Population

APPENDIX C - Authors' Permission to Use Instrument

APPENDIX D - Interview Protocol

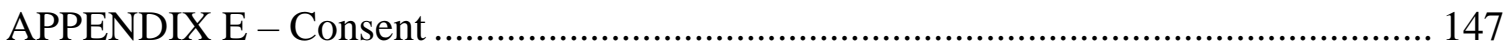

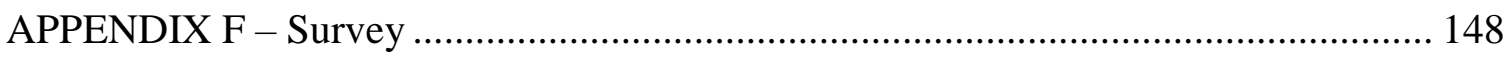

APPENDIX G - Recruitment Email................................................................... 152

APPENDIX H - Follow-Up Email to Participants........................................................ 154

APPENDIX I - Second Follow-Up Email to Participants................................................ 155

APPENDIX J - Interview Transcript Email ........................................................... 156

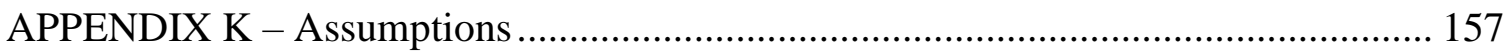

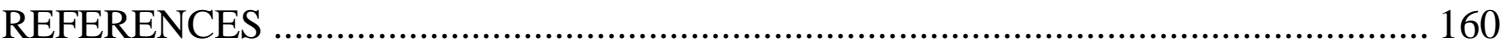




\section{LIST OF TABLES}

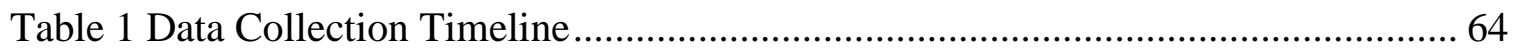

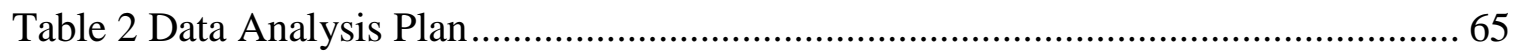

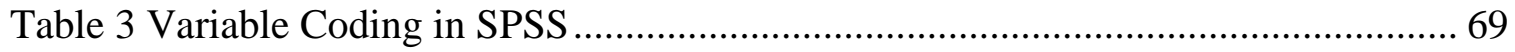

Table 4 Quantitative Frequency Distribution ...................................................... 71

Table 5 Results of ANOVA from the Multiple Regression......................................... 77

Table 6 Results from Multiple Regression Analysis Illustrating the Relationship between the independent variables (affective commitment, normative commitment, continuance commitment, and voluntary turnover) and the dependent variable (anticipated turnover).

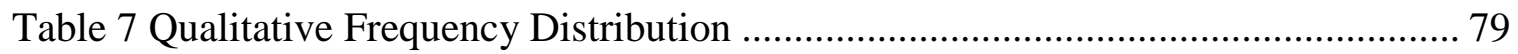

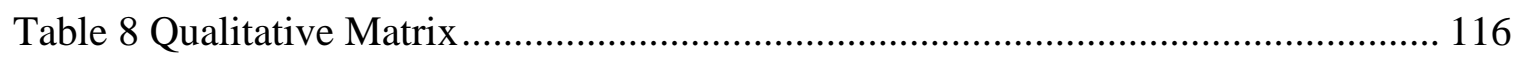

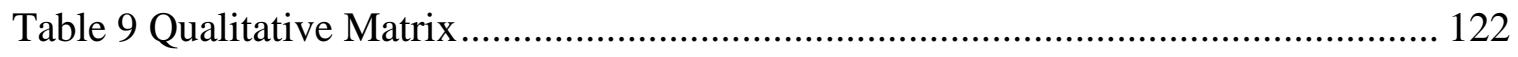




\section{LIST OF ILLUSTRATIONS}

Figure 1. Conceptual Framework ............................................................................. 10

Figure 2. Concurrent Mixed-Methods Design........................................................ 50

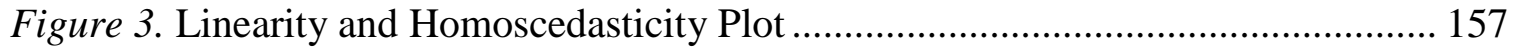

Figure 4. Affective Commitment Normality Plot.................................................... 157

Figure 5. Continuance Commitment Normality Plot ............................................ 158

Figure 6. Normative Commitment Normality Plot ................................................. 158

Figure 7. Harmonious Passion Normality Plot...................................................... 159 


\section{LIST OF ABBREVIATIONS}

$C P S$

DHS

SWs

ATS
Child Protective Services

Department of Human Services

Social Workers

Anticipated Turnover Scale 


\section{CHAPTER I - INTRODUCTION}

A national shortage of skilled social workers (SWs) plagues the United States.

Researchers predict that as time progresses the shortage will continue to expand (O'Neill, 2000). Child Welfare League of America (2004) states, "no issue has a greater effect on the capacity of the child welfare system to serve at-risk and vulnerable children and families than the shortage of a competent, stable workforce" (p. 1). State agencies across the United States face a crisis due to the increase in voluntary turnover (Newman, Ye, \& Leep, 2014). The ability to retain competent staff is problematic and may have a negative influence on the quality of services provided by the organization (Newman et al., 2014). In the absence of a properly staffed and competent workforce, the effectiveness of the organization will deteriorate (Newman et al., 2014).

Voluntary turnover produces a financial burden for the affected organization. The estimation of turnover cost is 50-200\% of the employee's salary (Newman et al., 2014). As an illustration, a supervisor earning $\$ 40,000$ per year could cost the organization between $\$ 20,000$ and $\$ 80,000$ to replace (Merhar, 2016). Because of depleted resources, the cost associated with turnover can be unbearable for human resource personnel (Merhar, 2016). Understanding organizational commitment and harmonious passion (individuals who can balance their work and personal life activities; Vallerand et al., 2003) may be the key to discovering why voluntary turnover continues to increase.

The focus of the current study is to examine and explore the effect of organizational commitment and harmonious passion on voluntary turnover among SWs. Chapter I introduces the present study and contains the background, problem, purpose, 
research objectives, and significance of the study. Chapter I also addresses the delimitations, assumptions, and operational definitions.

\section{Background of the Study}

Turnover within organizations persists as an ongoing problem; accordingly, retention of employees is a chief concern among executives (Chen, Park, \& Park, 2012). An audit conducted in 2015 at a state Child Protective Services (CPS) organization in the southern United States notes that voluntary turnover continues to rise (Deputy Executive Director of Programs, personal communication, June 20, 2016). The national turnover rate for all industries is $12.8 \%$ (Compensation Force, 2017). For SWs, the turnover rate ranges from $30-60 \%$ each year. The rate is considerably high for turnover, compared to the national turnover rate for registered nurses at 17.2\% (Chen et al., 2012; NSI Nursing Solutions, 2016; Reagh, 1994). Studies indicate individuals who enter their selected field of work are passionate toward their job; however, organizations continue to lose valuable employees (Bent-Goodley, 2014). Empirical evidence connects turnover to job satisfaction, pay, and burnout (Barth, Lloyd, Christ, Chapman, \& Dickinson, 2008; Strand \& Dore, 2009; Vinokur-Kaplan, 1991). Burnout research includes numerous studies of SW and nurse turnover in a hospital setting (Fillenbaum, Heyman, Peterson, Pieper, \& Weiman, 2000; Shinan-Altman, Werner, \& Cohen, 2015). However, researchers call for more studies to discover the continuing influence of voluntary turnover (Shinan-Altman et al., 2015), such as organizational commitment and harmonious passion.

Grimsley (2003) defines organizational commitment as "an individual's psychological attachment to the organization" (p. 1). The lack of organizational 
commitment significantly affects state agencies and human resource personnel (Larson \& Hewitt, 2012). Organizational commitment is important to an organization's success. Organizational commitment may influence whether an employee leaves the organization or works toward the vision, mission, and goals outlined in the business strategy (Phillips, Phillips, \& Zuniga, 2013). The three-component model designed by Meyer and Allen (1991) suggests that organizational commitment influence is attributable to the three types of commitment: (a) affective, (b) normative, and (c) continuance. Affective commitment is the individual's emotional attachment to the organization; normative commitment is a feeling of obligation to the organization; and continuance commitment is the financial impact leaving the organization will have on the individual (Meyer \& Allen, 1991).

Along the same lines, harmonious passion may influence an employee's intent to leave. The definition of harmonious passion is, "an autonomous internalization that leads individuals to choose to engage in the activity that they like" (Vallerand et al., 2003, p. 1). Research notes when an employee acquires harmonious passion, they invest and engage more with their work (Houlfort et al., 2015). Individuals are motivated when they possess harmonious passion and are ready to engage with other persons in the organization (Forest, Mageau, Sarrazin, \& Morin, 2011). Organizational commitment and harmonious passion accompany one another to create a successful, efficient, and effective organization. Yet, research that links organizational commitment and harmonious passion among different populations is lacking.

Literature suggests that the passion an individual possesses toward their job affects the behavioral outcomes of the organization (Houlfort et al., 2015). Harmonious 
passion can increase positive organizational commitment in the organization, which can lead to a decline in voluntary turnover (Houlfort et al., 2015). Individuals choose their career field based on passion, specifically SWs (Bent-Goodley, 2014); however, when people begin to lose harmonious passion, it will influence the future of the organization.

The decision of the employee to leave an organization is "a clear and deliberate choice by the employee to make a job change that they perceive will presumably provide a greater level of fulfillment and satisfaction" (Smith \& Hitt, 2005, p. 183). When voluntary turnover occurs, the loss of knowledge affects the entire structure of the organization. The loss of knowledge is due in large part to the knowledge holder leaving the organization without properly ensuring the knowledge remains (Newman et al., 2014). The organization becomes weaker as access to the knowledge possessed by the previous employee vanishes.

Voluntary turnover not only affects the organization, but the relationship the organization has with its clients. The relationship clients build with the employee of the organization unravels when the individual decides to leave the organization, which decreases the trust between not only the employee and client, but also the community they serve (Chen et al., 2012). Many clients who receive services from state agencies do not receive emotional support from home, which the employee often provides (Larson, Hewitt, \& Lakin, 2004).

McGregor (1988) states, "perhaps the most pervasive cost of turnover to an organization is the loss of human capital, which deprives the organization of productive capability and the knowledge, skills, and abilities embedded in an experienced workforce" (p. 39). The definition of human capital is "the skills, knowledge, and 
experience possessed by an individual or population, viewed in terms of their value or cost to an organization or country" (Human Capital, 2017). The human capital perspective of McGregor's (1988) statement is critical when examining the financial burden turnover causes an organization. The skills possessed by the employee who resigns and has to be replaced, can become a financial burden to the organization. A study conducted in 2012, shows there was a $16.4 \%$ turnover rate in all state and local government health departments (Newman et al., 2014). Voluntary turnover, such as the turnover experienced in state and local government, is costly and negatively affects the performance of the organization (Newman et al., 2014).

Human Resource expenditures consume the bulk of funds expended relative to the costly impact of turnover in an organization (Blankertz \& Robinson, 1997). Replacing employees who leave an organization is time consuming and financially prohibitive (Blankertz \& Robinson, 1997). Time-consuming references the time human resources and supervisors spend selecting and interviewing possible candidates. Time spent training a new employee, and making sure they are up to speed to perform their work duties effectively without supervision can be time consuming to fellow co-workers and supervisors. The next section will address the current problem of voluntary turnover and the potential outcome if the issue is not resolved.

\section{Statement of the Problem}

Research over the past decade has not focused on whether the employee has a psychological attachment (organizational commitment) to the organization (Scrima, Stefano, Guarnaccia, \& Lorita, 2015). Pyschological attachment determines the level of organizational commitment the individual possess (Richards \& Schat, 2011). Scrima et 
al. (2015) asserts that knowing what type of attachment, such as affective, normative, and continuance attachment an employee has to an organization is integral to determining the level of commiment they possess. The results from Scrima et al. (2015) suggests that psychological attachment is key to an employee forming a bond with the organiation. Furthermore, Vallerand (2008) emphasized that harmoniously passionate individuals are less likely to convey negative feelings toward their daily activities. He further explained that individuals with harmonious passion know when to focus on their work and when to enjoy their leisure activities (Vallerand, 2008). Harmonious passion is an excellent mediator in the workplace and is more effective than intrinsic and extrinsic motivational factors (Liu et al., 2011). Liu et al. (2011) notes that future research should further examine the influence harmonious passion has on voluntary turnover. To gain a greater understanding of the effect organizational commitment and harmonious passion have on an organization, researchers should continue studying the variables with a variety of populations (Forest et al., 2012; Zeitlin, 2014).

Voluntary turnover is one of the most critical problems organizations face in the 21 st century (Dess \& Shaw, 2001). Voluntary turnover negatively affects the quality of services provided by an organization caused by shortage of employees and increased caseloads (Barrett \& Greene, 2016; Dess \& Shaw, 2001). Voluntary turnover affects human capital and decreases the quality of services provided by an organization (Dess \& Shaw, 2001). Organizations need a competent and stable workforce to provide quality services to the communities they serve (Chen, Park, \& Park, 2012). If the issue of voluntary turnover continues unresolved, researchers predict a nationwide shortage of thousands of employees; for instance, there could be a shortage of 195,000 SWs by 2030 
if the issue is unresolved (Lin, Lin, \& Zhang, 2015). Gaining and retaining committed and harmoniously passionate employees is essential to a successful organization (Clark, 2013). The consequences of not gaining and retaining employees are low organizational commitment, decrease in passion towards work, and an increase in costs to the organization (Aydogdu \& Asikgil, 2011; Newman et al., 2014).

\section{Purpose Statement}

The purpose of this concurrent mixed methods study is to explore and examine the effect organizational commitment and harmonious passion have on voluntary turnover among CPS SWs. The quantitative survey provided insight into SW levels of commitment to CPS, SW harmonious passion, and SW intent to leave. The qualitative interviews explored the SWs perceptions of organizational commitment, harmonious passion, voluntary turnover, and their intent to leave by allowing the participant to tell their story. Combining the two methodologies aided in improving the understanding of how SWs view organizational commitment and harmonious passion.

\section{Research Question and Objectives}

Four research objectives guided the examination and exploration of organizational commitment and harmonious passion influence on voluntary turnover. The central research question the study answered is how does organizational commitment and harmonious passion contribute to the participants' intent to leave? The study addressed the following research objectives,

RO1 - Describe the demographics of the participants in terms of gender, age, educational attainment, and years of employment. 
$R O 2$ - Explore the participants' perspectives about how organizational commitment and harmonious passion affects voluntary turnover in the organization.

RO3 - Determine the relationship between organizational commitment and harmonious passion on voluntary turnover.

RO4 - Describe the effects of organizational commitment and harmonious passion on voluntary turnover.

\section{Conceptual Framework}

The conceptual framework provides a visual graphic that aligns and narrows the focus of the study (Roberts, 2010). To create the framework for the current study, Meyer and Allen's (1991) three-component model of organizational commitment along with, Deci and Ryan's (1985) self-determination theory structures the foundation of the framework. Meyer and Allen (1991) describe the commitment individuals have toward the organization using the three-component model. The three components are (a) affective commitment, (b) normative commitment, and (c) continuance commitment (Meyer \& Allen, 1991). Previous research acknowledges a strong determinate of voluntary turnover is organizational commitment (Chuebang \& Baotham, 2011; Mowday, Porter, \& Steers, 1982; Porter, Steers, Mowday, \& Boulian, 1974).

On the other hand, the self-determination theory involves harmonious passion (Deci \& Ryan, 1985) and typically associates with motivation. However, to have harmonious passion the individual must exemplify motivation (Deci \& Ryan, 1985). The self-determination theory links to outcomes such as turnover intentions, burnout, and organizational commitment (Guntert, 2014). Liu, Chen, and Yao (2011) notes that 
Vallerand incorporates the self-determination theory as a result of how harmonious passion translates the individuals' autonomy in an organization and their job creativity. The theory focuses on one's passion and creativity toward their job (Liu, Chen, \& Yao, 2011). Vallerand et al. (2003), whom developed harmonious passion, argues that selfdetermination theory brings out passion based on the motivation an individual has toward accomplishing an activity. Liu et al. (2011) argue that harmonious passion is another form of motivation, which is either extrinsic or intrinsic. The theory suggests that contextual and personal autonomy influence the level of harmonious passion an individual possesses (Deci \& Ryan, 2008; Vallerand et al., 2003). Self-determination theory is not only applicable to harmonious passion, but the theory coincides with organizational commitment, which can further assist in identifying if the constructs influence voluntary turnover. The intertwining of the variables in Figure 1 conveys the possible influence organizational commitment and harmonious passion may have on voluntary turnover. 


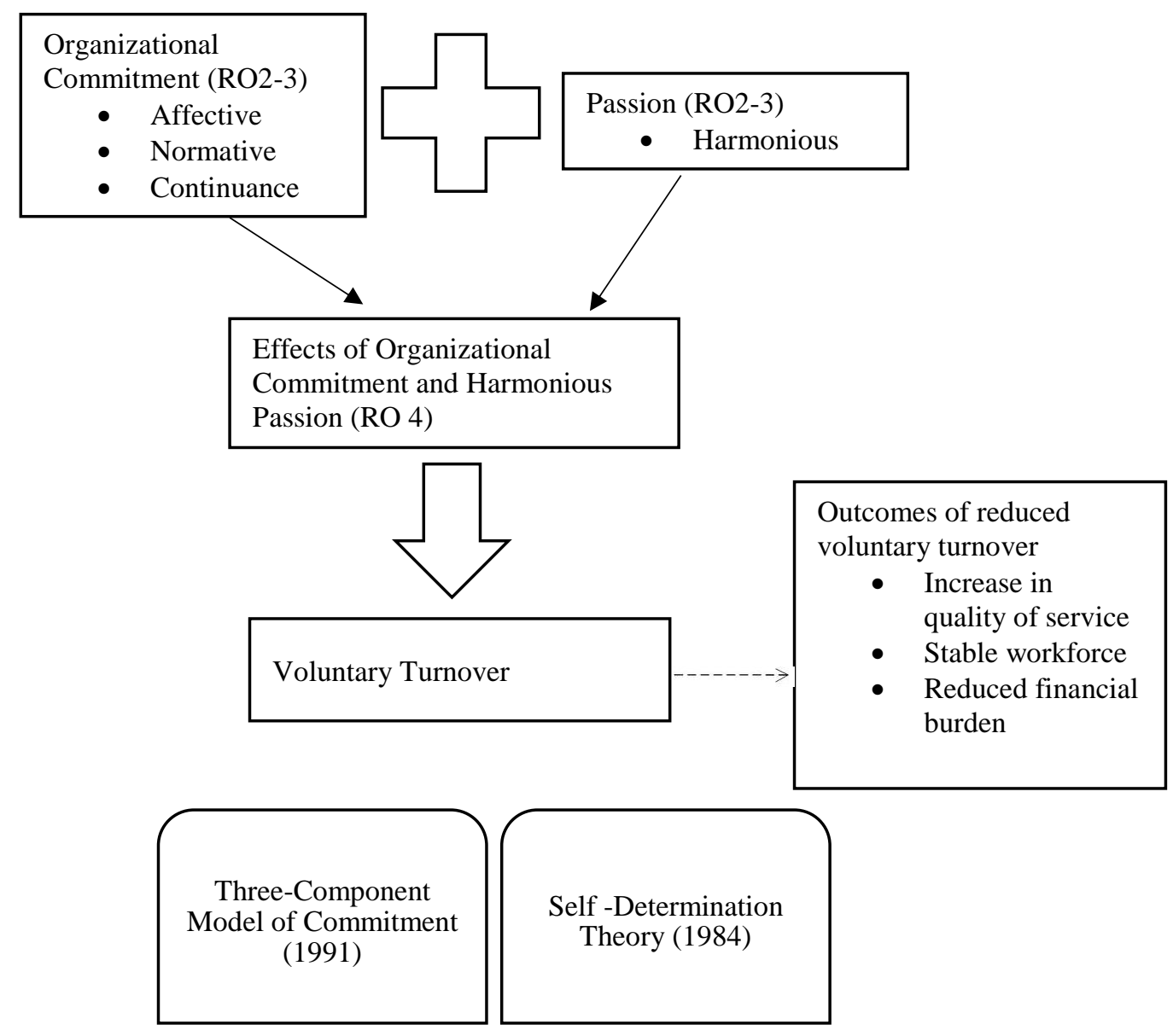

Figure 1. Conceptual Framework

\section{Significance of Study}

A critical issue for organizations is retaining a stable workforce, given the direct and indirect cost associated with turnover, along with the decrease in the quality of services provided by the organization (Weaver et al., 2006). The findings of the present study could benefit a variety of organizations, considering that employees have an important role in the daily operations of any organization. The present study may contribute to business practices by exploring strategies for reducing turnover rates within an organization. Numerous benefits exist associated with retaining committed and passionate employees. Example of benefits include the following: (a) an increase in the 
number of qualified individuals employed, (b) reducing the shortage of employees across the United States, (c) meeting of communities' needs, and (d) an increase in human capital development (Weaver et al., 2006).

Research suggests when employees are committed to an organization they take more responsibility and actively participate on an ongoing basis (Nehmeh, 2009). The more committed employees are, the higher chance the organization will achieve high performance, and other companies will have difficulty attracting the current employer employees (Nehmeh, 2009). Furthermore, when an employee is harmoniously passionate there is an increase in desire toward the activity, along with the individual finding the activity important and worth investing their time and energy into (Vallerand et al., 2003).

Therefore, the results of the current study provide leadership and human resource personnel with insight on how current employees perceive organizational commitment and harmonious passion toward the organization; in addition, they will also know the employees' intent to leave. The study heightens the awareness of organizational commitment and harmonious passion to equip organizations with an enhanced systematic process for decreasing voluntary turnover, and increasing the quality of services provided by the organization. The current research contributes to improving human capital by providing knowledge regarding the influence of organizational commitment and harmonious passion on voluntary turnover, which could potentially aid in reducing turnover rates in a variety of industries. The researcher's goal is to disseminate findings to organizations on the employees' perception of organizational commitment and harmonious passion as it relates to voluntary turnover. The researcher surveyed SWs, asked probing questions, and listened to the participants to gain a deeper understanding of 
their perceptions. The study adds to the existing literature regarding employee turnover, specifically among of SWs.

\section{Delimitations}

Delimitations of a study are elements that emerge from boundaries outlined by the researcher (Simon \& Goes, 2013). In view of the choices made by the researcher, the current study has two delimitations. The first delimitation is the examination and exploration of only SWs at CPS. The current study did not include other occupations of CPS. Considering the researcher is limiting the population to SWs, the study may not show how organizational commitment and harmonious passion effect other populations at CPS. The second delimitation links to the problem, question, and research objectives of the study, the researcher will only focus on the influence that organizational commitment and harmonious passion have on voluntary turnover. Simon and Goes (2013) notes that there may be other problems the study could address, besides the problem outlined by the researcher; therefore, the problem of the study is a delimitation.

\section{Assumptions}

The present study has two assumptions; the primary assumption is that the participants will be honest in their responses to the questionnaire and interview questions (Wargo, 2015). The researcher assumes participants who volunteer to participate in the study will respond to the questions with the best of their ability and in a truthful manner. To encourage honesty from the participants, the researcher will maintain their privacy. The second assumption of the study is that the participants will understand the terms (Wargo, 2015) organizational commitment and harmonious passion; the researcher described these terms to the participant and checked for understanding. Although 
participants in the study are SWs who have similar educational backgrounds, the researcher assumes that common themes may emerge by reason of their experience as SWs at CPS (Wargo, 2015).

\section{Definition of Terms}

Operational definitions narrow the research and place a focus on the terms emphasized throughout the study (Roberts, 2010). Specific terms chosen for this research are defined below.

1. Affective Commitment - The emotional attachment an individual has to the organization (Meyer \& Allen, 1991).

2. Continuance Commitment - The extrinsic need to stay with the organization, such as salary and benefits (Meyer \& Allen, 1991).

3. Intent to Stay - "An employees' intention to stay in the present employment relationship with their current employer on long term basis" (Ekety \& Edeh, 2015, p. 29).

4. Organizational Commitment - A psychological attachment to the organization, depending on the attachment, it can affect the intent to stay with the organization (Grimsley, 2003).

5. Harmonious Passion - A routine daily activity that the individual chooses freely based upon the pleasure, typically associated with intrinsic motivation (Vallerand, Houlfort, \& Forest, 2014).

6. Normative Commitment - The feeling of obligation an individual has to the organization (Meyer \& Allen, 1991). 
7. Self-Determination Theory - The support of healthy trends, such as the daily activities of an individual's life, but in efficient ways and is researched thoroughly and practiced around the United States (Deci \& Ryan, 1985).

8. Social Work - "A practice-based profession and an academic discipline that promotes social change and development, social cohesion, and the empowerment and liberation of people" (Social Worker, 2014, p. 1).

9. Voluntary Turnover - When an employee willingly leaves the organization (Society for Human Resource Management, 2008).

\section{Organization of the Remaining Chapters}

The dissertation will comprise five chapters. Sections within the dissertation are: literature review, methodology, analysis plan, results, findings, conclusions, and recommendations. Chapter I, introduction, includes the foundation for the study and presents the purpose and significance of the study. Chapter II, literature review, is a review of relevant and current literature connecting the affect organizational commitment and harmonious passion have on voluntary turnover. Chapter III, methodology and analysis, outlines the research methodology and provides an analysis plan. Chapter IV, results, displays the results for the data analysis along with an explanation of the results. Chapter V consists of findings, conclusions, and recommendations; the researcher will explain their findings, conclusions drawn from the study, and recommendations for future research.

\section{Summary}

Researchers acknowledge that state governments spend millions of dollars in training and retraining employees (Borysenko, 2014; Merhar, 2016). Despite the large 
investment, employee passion continues to decline, which hinders the quality of service provided by the organization. Organizations need the expertise of their employees to care for clients the organization serves daily, and places a heavy financial burden on Human Resources to acquire and retain a stable and a skilled workforce (Newman et al., 2014). High voluntary turnover has a negative influence on the workforce, organization, and the individual (Houlfort et al., 2015; Shinan-Altman et al., 2015). Past research targets several factors, including organizational commitment, which can influence voluntary turnover. However, the present study explored and examined if organizational commitment and harmonious passion influence voluntary turnover among SWs. Understanding the influence of organizational commitment and harmonious passion on voluntary turnover could result in effective strategies for decreasing voluntary turnover. 


\section{CHAPTER II - LITERATURE REVIEW}

Organizational commitment and harmonious passion are necessary for a robust workforce of SWs (Forest et al., 2012; Meyer, Becker, \& Vandenbergh, 2004).

Administrators appreciate when employees demonstrate organizational commitment; however, few administrators have put emphasis on developing harmonious passion (Meyer, Becker, \& Vandenbergh, 2004). Organizations' desire to retain SWs stems from the high turnover rates that affect the quality of service (Cho \& Song, 2017). The purpose of the current study is to explore and examine the affect organizational commitment and harmonious passion have on voluntary turnover among CPS SWs. The researcher will provide the foundation for the current study through a review of existing evidence-based literature. The literature review will include historical origins as well as contemporary research and findings.

\section{Theory of Organizational Commitment}

More than 50 years ago, Howard Becker presented the side-bet theory of commitment (Becker, 1960). Becker defined side-bets as "[the] commitment [that] come[s] into being when a person, by making a side-bet, links extraneous interests with a consistent line of activity" (p. 1). The purpose of Becker's research was to provide an analysis of how the side-bet theory increases commitment. The side-bet theory of commitment is not a stand-alone theory, but is a major influential component of the Meyer and Allen (1991) three-component model (Powell \& Meyer, 2004). The three components represent different psychological states, which are affective, continuance, and normative. The three-component model is a diverse model that incorporates different forms of attitudinal commitment, in which each element has some form of influence on 
turnover (Meyer \& Allen, 1997). Thus, researchers have termed the model employee retention; meaning employees remain with the organization for the reason that they want to (affective), they need to (continuance), or feel obligated to (normative; Meyer, Allen, \& Smith, 1993). Wong and Tong (2014) examined the effects of opportunity on organizational commitment in the information technology industry in China. They found that the three-component model is the best-suited model to study organizational commitment. A detailed description of each component is in the next section. Affective, Normative, and Continuance Commitment

Affective commitment is the employee's emotional attachment to the organization, which is the desire to remain with the organization (Meyer \& Allen, 1991). When the employee commits to the organization and aligns with the agencies goals, they tend to remain with the organization for a longer period. Individuals that have affective commitment are likely influencing others in the organization to become more productive (Slack, Orife, \& Anderson, 2010). Individuals that exude affective commitment have a more positive work experience and assist with strengthening the workforce, inside and outside of the organization (Slack et al., 2010). Employees who have a high level of affective commitment are brand ambassadors of the organization since they can assist with increasing other employees' affective commitment levels by reason of their positive relationship with the organization (Slack et al., 2010).

Culpepper (2011) examined, in detail, the relationship between the organizational commitment theory and turnover. He surveyed 366 employees from a chain of retail stores located throughout the Southeastern United States. He found that enhancing affective commitment in an organization decreases voluntary turnover. Culpepper (2011) 
proclaimed that affective commitment is more pertinent to turnover than normative and continuance commitment. Furthermore, researchers report the noteworthy reduction in affective commitment and job satisfaction when an employee is getting ready to depart from the organization (Dickter, Roznowski, \& Harrison, 1996). When employees begin searching for other jobs, they have a desire to leave the organization. The desire to leave turns affective commitment, which is positive, into a negative association because the employee no longer feels attached to the organization. When affective commitment declines among employees, there is an increase in voluntary turnover (Dicker et al., 1996).

Normative commitment is the employee feeling obligated to stay with the organization (Meyer \& Allen, 1991). For instance, the employee may feel obligated to stay with the organization based on the resources expended on their training; therefore, they feel a sense of obligation to remain with the business. The sense of obligation also derives from the employee having a positive experience that is attributed to the organizations showing an interest in them as an employee and a person (Rodrigo, 2012). Normative commitment is greater in the organization when there are incentives of being an employee in the organization (Meyers \& Allen, 1991; Slack et al., 2010). Normative commitment increases when there are affective committed employees as well, considering they are the most fitting example of committed employees (Slack et al., 2010). Per Slack et al. (2010), when an employee commits to the organization, the chance of the organization striving for success elevates; which in turn leads to greater organizational commitment and reduces voluntary turnover (Slack et al., 2010). Meyer and Allen (1991) have theorized normative commitment as a steady predictor for 
turnover. A high level of normative commitments conveys that the employee is only staying with the organization for the reason that they feel obligated, versus staying for the sake of the strong relationship they have with the organization (Grimsley, 2003).

Some researchers believe normative commitment is repetitive of affective commitment, this opinion comes mostly for organizations outside of North America (Meyer et al., 2002). Normative and affective commitment coexists in much of the literature on organizational commitment through the similar psychological attachments the individual have toward the job. Many researchers note that affection for your job and sense of obligation to stay is similar in many ways, and at times seen as one. However, researchers, such as Meyer et al. (2002), note that other countries are finding that normative and affective are similar, but examination should be separate. Further research should convey results of the influence that normative commitment has on turnover (Culpepper, 2011). Culpepper (2011) acknowledges that there needs to be more research on the three components using a more diverse population. Literature surrounding the three-component model and turnover has not addressed either the theoretical perspective of the model or how the components affect each other (Culpepper, 2011).

Continuance commitment is the extrinsic need to stay with the organization, such as salary and benefits (Meyer \& Allen, 1991). At the continuance stage, the employee is deciding if they should commit to the organization based on economic and social cost (Becker, 1960). Having a high level of continuance commitment is not seen as positive, but, as a result, of the high cost of leaving the organization (Meyer \& Allen, 1991). In addition, with a decrease in desire and the cost of leaving being too high, the employee only performs the minimum, which decreases the quality of service provided to the 
community they serve (Meyer \& Allen, 1991). Those who embody continuance commitment are less likely to motivate others to stay, as they are not happy in their own job setting. If the employee perceives the organization as positive and supportive, it will lead to a higher value of organizational commitment (Slack et al., 2010). Continuance commitment is an influential factor in organizational commitment from the perspective of the employee. Employees who have low affective and normative commitment, and lack other opportunities of exploring work elsewhere have high levels of continuance commitment (Saygan, 2011). A high level of continuance commitment proposes that the employee is only staying as long as they feel that they must for financial or other benefits, such as healthcare insurance (Grimsley, 2003). The next section contains a discussion of the three-component model.

\section{Three-Component Model}

The three-component model is the theoretical foundation for studying commitment (Davis, 2014). The three-component model is the most dominant model representing organizational commitment, which is often used as a predictor of turnover (Solinger, Van Olffen, \& Roe, 2008). The model suggests that affective, normative, and continuance commitment, even though dissimilar, describes the connection between the organization and the employee (Allen \& Meyer, 1990). Allen and Meyer (1990) states, "employees with strong affective commitment remain because they want to, those with strong continuance commitment because they need to, and those with strong normative commitment because they feel they ought to do so" (p. 3). The three components reflect a psychological state that an employee has toward the organization. The components relate to the company by initiating the thought that commitment is a behavior that has the 
organization as its object, which can simultaneously be present as a result of organizational commitment being a sum of all three components (Allen \& Meyer, 1990; Solinger et al., 2008). However, each component of organizational commitment is distinguishable by cause of the behavior displayed at work (Meyer \& Allen, 1991, 1997). Meyer, Stanley, Jackson, McInnis, Maltin, and Sheppard (2012) notes that prior research from Meyer and Allen $(1991,1997)$ expects that all three forms of organizational commitment would reduce voluntary turnover. However, Meyer et al. (2012) acknowledges that researchers should examine each component individually, as each one can have a different impact on an employee and the organization, such as turnover. They concluded that affective and normative commitment was higher in countries with employees that have a collectivist mindset, in other terms, weaker individualist values.

Meyer et al. (2002) study expresses that affective commitment relates to job performance, this relationship also involves normative commitment. Interestingly, continuance commitment did not correlate with job performance (Meyer et al., 2002). In previous literature, studies have focused on affective and normative commitment and how the two constructs work together to increase organizational commitment; however, research has not focused on continuance commitment as extensively (Casper, Harris, Taylor-Bianco, \& Wayne, 2011). Research indicates that affective commitment is the only component needed to increase organizational commitment; but no further examinations validated those findings (Casper et al., 2011). Casper et al. (2011) observed organizational commitment among Brazilian professionals, and emphasized the importance of affective commitment concerning supervisor support. However, Meyer and Allen (1991) projected that the willingness of employees to abide by the 
organizational goals and values would affect their level of commitment to the organization. Therefore, individuals that possessed affective commitment were more susceptible when applying effort to perform their job duties than the persons that possessed normative and continuance commitment (Meyer \& Allen, 1991).

Meyer et al. (2002) research showed a correlation between continuance and affective commitment, and affective and normative commitment. Affective and continuance commitment correlated with antecedent variables of job satisfaction and job involvement (Meyer et al., 2002). Normative commitment had a weak correlation to theses antecedent variables (Meyer et al., 2002). Affective commitment is in the center of the correlations; this relationship indicates affective is one of the most important components of the three-component model. Solinger et al. (2008) acknowledges that affective commitment is an attitude toward the organization, whereas continuance and normative commitment signify different concepts, such as anticipating when an employee intends to leave.

Meyer and Smith (2000) provide examples on how the human resource department can increase an employee's commitment to the organization. For instance, human resource can provide training opportunities for employees. Greater training opportunities lead to affective commitment, which then leads to normative being that it is the benefit factor, and lastly continuance in that training is an asset (Meyer \& Smith, 2000). Herscovitch and Meyer (2002) recognized that employees at any given time could experience any of the three components concurrently or sequentially. Each component of three-component model has an impact on the length of time an employee stays with an 
organization (Werf, 2016). Nonetheless, the three-component model plays a vital role in understanding organizational commitment.

\section{Organizational Commitment}

Grimsley (2003) defines organizational commitment as “an individual's psychological attachment to the organization" (p. 1). Organizational commitment is the topic of many studies conducted over the past few decades, and is important to examine regarding employees and employers (Yousef, 2016). Organizational commitment affects turnover intentions, attitudes toward changes in the organization, and job satisfaction (Yousef, 2016).

Organizational commitment can affect an employee's decision to terminate their employment with the company (Coomber \& Barriball, 2007). The possibility of the employee seeking employment elsewhere heightens when an employee becomes uncommitted to the organization. Coomber and Barriball (2007) conducted a systematic literature search to study shortages among nurses in the United Kingdom. The authors identified four themes that reoccur throughout research: leadership, educational attainment, pay, and stress. Surprisingly, the findings over time related to Coomber and Barriball's study stressed the importance of organizations reassessing the influence of the employees' intent to leave and turnover. Reassessment of job satisfaction is vital for ongoing changes that occur throughout time regarding the sources that influence voluntary turnover intentions among certain populations, such as nurses in the Coomber and Barriball study.

The controversy of whether organizational commitment has influence on turnover has existed since the 1980s (Reichers, 1985). Reichers (1985) examined worldwide 
approaches that organizations had in place to observe their global ideas regarding organizational commitment. The purpose of his study was to suggest a way commitment can be reconceptualized. Reichers (1985) presented reconceptualization as a design to apprehend a person's experience of organizational commitment and steer the attention to the separate pieces of the construct. He acknowledges that there was a problem emerging from the commitment literature of the 80 's, in view of the lack of emphasis placed on the individual's involvement of being committed to the organization.

The foundational work provided by Reichers (1985) clearly outlines that future researchers should not just study the literature, but ask the participants directly or indirectly of their perception of organizational commitment. Therefore, to develop research on the topic of commitment, researchers should understand commitment from the viewpoint of the committed (Reichers, 1985). Contemporary researchers on commitment, such as Aydogdu and Asikgil, took Reichers advice, and focused on organizational commitment among the production and service sector.

Commitment has become increasingly important to sustaining a healthy organization (Sharma, Mohapatra, \& Rai, 2014). Meyer and Parfyonova (2010) suggest that organizational commitment is an intriguing paradox to examine among the $21 \mathrm{st}$ century workforce. The employee's commitment to the organization affects the employee on an organizational level as well as on an individual level; whether high or low, the level of organizational commitment can influence the quality of work produced by the employee (Aydogdu \& Asikgil, 2011). According to Aydogdu and Asikgil (2011), when employees are committed to the organization, positive behaviors increase. With greater commitment comes higher productivity, which benefits the organization and the 
society. Aydogdu and Asikgil examined 182 employees from the production and service sector. They studied the relationship between job satisfaction, organizational commitment, and turnover. Aydogdu and Asikgil (2011) found that the intent to leave had a negative correlation with organizational commitment and job satisfaction. The researchers stressed the importance of organizations addressing organizational commitment among their employees. Likewise, a study conducted among mental-health direct-care staff members found that variables such as lower job satisfaction could affect organizational commitment, and therefore increase turnover (Barak, Nissly, \& Levin, 2001). Retention of staff in the community-based mental health workforce is an ongoing challenge (Aarons, Sommerfeld, Hecht, Silovsky, \& Chaffin, 2009). Aarons et al. (2009) discuss turnover intentions in the workforce and the influence organizational commitment has on turnover intentions. They determined that poor organizational climate could affect organizational commitment.

Barak et al. (2001) notes that an effective way to predict turnover is by examining organizational commitment, professional commitment, burnout, and job satisfaction (Barak et al., 2001). Their study included a meta-analysis of 25 articles regarding the correlation amongst demographic variables, perceptions, organizational environment, and turnover. They concluded that the lack of social support, increased burnout, increased stress, and other factors are robust predictors of intention to leave.

Many of the studies conducted on organizational commitment have used the organizational commitment questionnaire, developed by Porter et al. (1974), to measure affective, continuance, and normative commitment (Llobet \& Fito, 2013; Suma \& Lesha, 2013). Their focus was to examine patterns found in commitment and job satisfaction 
among psychiatric technicians. The researchers concluded that organizational commitment influences the employee's decision to remain with the company (Llobet \& Fito, 2013; Suma \& Lesha, 2013).

Starnes and Truhon (n.d.) examined the subject of organizational commitment and its effect on efficiency. Starnes and Truhon (n.d.) pointed out how vital organizational commitment is to a functioning organization, and suggested that leaders focus on developing employees that identify with the goals of the organization to produce high performing work. They concluded that gaining commitment from employees is important in how efficient and effective a functioning organization runs. Organizational commitment has a significant influence on the effectiveness and efficiency of the business (Harter, Schmidt, Asplund, Killham, \& Agrawal, 2010). The significant effect is seeing how the employee perceives their work conditions, engagement, and how committed the organization is to them.

Organizational commitment affects the morale of the employee, short-term and long-term output, and the efficiency of the organization (Aarons, Sommerfeld, \& Willging, 2011). Aarons et al. (2011) studied several constructs in their research, such as organizational climate, staff turnover intentions, leadership, and voluntary turnover within a behavioral health system. The researchers studied 190 safety-net institution workers, ranging from administrators to social workers. A safety-net institution is a facility that houses low-income populations, such as individuals on Medicaid and suffering from serious mental health issues. Aarons et al. (2011) study assisted with making conversations easier when addressing techniques to improve engagement and retention among staff members. Even though the study is part of a larger 5-year mixed- 
methods study, a weakness in the research was that they did not possess turnover data from the agencies in which they were examining (Aarons et al., 2011). Aarons and Sommerfeld (2011) notes future studies should research the influence organizational commitment has on voluntary turnover.

Persistence is fundamental to keeping employees engaged, since engagement allows the worker to push through an activity that they enjoy. Organizations should engage employees early in the process and continue to keep them engaged throughout their tenure. By keeping employees engaged, the organization will convey to the employee that they value their contribution to the organization; therefore, increasing the opportunity to have employees commit to the goals and values of the business (Testa, 2008). Engagement will not only reduce turnover, but will also allow the employees to continue to grow and develop their skills. Personal growth regarding engagement will make the organization a more desirable place to work for future employees (Testa, 2008).

Employees that embody organizational commitment have a more positive attitude toward the work they do and the organization itself (Porter et al., 1974). When the level of commitment is high, the employee identifies with the organization's vision, mission, and goals; their desire to stay with the organization increases (Porter et al., 1974). Blau (1986) studied organizational commitment and job involvement influence on absenteeism and tardiness among 82 registered nurses at a large hospital. His research used a questionnaire to gather data from nurses. The small population limited the study and turnover was not as much of an issue as in today's workforce. The results of the study conveyed that the decline in absenteeism and tardiness was due to high levels of 
organizational commitment and job involvement, and those who possessed low levels of the constructs increased in absenteeism and tardiness (Blau, 1986).

Studies linked to organizational commitment involve organizational behavior, job search activity, and turnover (Bateman \& Strasser, 1984). Previous research concludes that with the decline of innovative employee behavior, there was a decline of organizational commitment (Ng, Feldman, \& Lam, 2010). Attitudes are shaped around how committed the employee is to the organization; therefore, when the commitment is high, the more likely the attitude toward the job is positive (Bateman \& Strasser, 1984). Bateman and Strasser (1984) collected data from nurses. Their study concluded that organizational commitment was an antecedent to job satisfaction instead of an outcome (Bateman \& Strasser, 1984). The findings of their study suggest that commitment is neither simulataneous with nor a result of job satisfaction (Bateman \& Strasser, 1984).

Recent theories and examinations of organizational commitment have evolved the meaning of commitment to fit with the 21 st century generation of workers. The most current definition of organizational commitment is a phenomena that increases and decreases on the account of the positive or negative experiences employees have on the job (Solinger, Hofmans, \& Van Olffen, 2015). Maia, Virgilio, Bastos, and Solinger (2016) added that commitment naturally declines over time, specifically during the first few years on the job. Maia et al. (2016) acknowledged that with older (seasoned) individuals, the organization gains more commitment. Organizational commitment increases as the individual has positive experiences on the job, and spends more time with the company (Maia et al., 2016; Solinger et al., 2015). 
Mathieu and Zajac (1990) summarized emperical research on organizational commitment using 48 meta-analysis and 26 variables. The results of the work showed that the more challenging the job is to the employee, the higher their commitment is to the organization. The attitude that an employee has is a psychological connection, which can affect how they align themselves with the strategic goals and values set forth by the organization (Meyer \& Allen, 1991). The literature focuses on the relationship between voluntary turnover and commitment, job burnout, and stress (Peng et al., 2016). Peng et al. (2016) notes that the greater the sense of belonging and commitment an employee has to an organization, the chance of the employee leaving lessens. Peng et al. also acknolwedges the more active an employee is in their job, the more committed they become to the organization. Therefore, organizaitonal commitment mediates the effect voluntary turnover has on an organization.

Proper leadership increases organizational commitment and employee retention (Lapointe \& Vandenberghe, 2017). Mosadeghrad and Ferdosi (2013) researched commitment and job satisfaction amongst leadership in the healthcare field. The researchers declare that human resource departments drive commitment and loyalty (Mosadeghrad \& Ferdosi, 2013). Committed human resource departments can have a substantial influence on employee and customer satisfaction (Mosadeghrad \& Ferdosi, 2013). Similarly, when employees do not commit to the organization, the quality of services begin to decline, which can affect the organization and lower client satisfaction (Mosadeghrad \& Ferdosi, 2013). Research in previous literature indicates that high job satisfaction and strong organizational commitment are major influences on employee turnover (Gieter et al., 2011). 
A study conducted in China found that if employers evaluate their employees more often, there might be a chance that they can discover the employees level of commitment (Froese \& Xiao, 2012). By conducting evaluations more frequently, employers can understand their employees ambitions, which in turn the employee becomes more committed to the organization (Gong \& Chang, 2008). A similar study conducted in 2013 by Zhang, $\mathrm{Wu}$, and Miao found that self-evaluations can aid in predicting voluntary turnover; but, the most popular group for organizaitonal commitment research are nurses. Evaluations aid in organizaitons learning more regarding their employees, and how the company can assist with ensuring the employee remains with the organizaiton (Zhang, $\mathrm{Wu}, \&$ Miao, 2013).

The lack of organizational commitment among employees can be detrimental to an organization. Poor performance, reduced effort put into work assignments, absenteeism, and turnover are consequences of low organizational commitment (Aydogdu \& Asikgil, 2011). Poor performance at work increases as organizational commitment decreases, which results in a major decline in the quality of services provided by the organization (Aydogdu \& Asikgil, 2011). When low motivation is present among a group of employees, the effort placed on work assignments becomes miniature; low motivation is a significant of not having organizational commitment (Aydogdu \& Asikgil, 2011). Aydogdu and Asikgil (2011) stress that organizational commitment is a pressing role on the quality of services provided by an organization. Not only does organizational commitment play a role in voluntary turnover, but also harmonious passion. The next section discusses this connection 


\section{Harmonious Passion}

Phillippe, Vallerand, Houlfort, Lavigne, and Donohue (2010) define harmonious passion as a "desire to engage in the activity that remains under the person's control" ( $\mathrm{p}$. 5). Vallerand et al. (2003), the theorist of harmonious passion, acknowledges that passion fuels and enhances peoples' everyday life. The major purpose of the studies conducted in their research was to validate the scale used for harmonious and obsessive passion (Vallerand et al., 2003). The researchers had 900 participants from a variety of populations to conduct the empirical quantitative study. Their research findings suggest that engaging in an activity through harmonious passion has positive effects on psychological adjustment, by reason of the recurrent experience of positivity with that activity (Vallerand et al., 2003). Vallerand stressed the importance to recognize the meaning of obsessive passion. Many acknowledge obsessive passion as non-beneficial in the interest of the individual not being able to focus on more than one thing and if they choose to, they can become obsessed and cause themselves anxiety when too much is on their plate (Vallerand et al., 2003). For example, when an obsessive individual tries to balance home and work life, they focus on their own self-esteem and their ability to please others. The obsessive individual does not understand how to properly balance their life responsibilities; therefore, they become overwhelmed and lose their self-esteem.

For harmonious passion to exist, an individual must view what they do as a part of their identity (Phillippe et al., 2010). Now that the attraction to the activity is robust, the harmonious passion increases the individuals' motivation to continue to do their daily activity longer. When individuals go to work, it typically brings them some form of happiness, on the grounds that they feel in control of their work and themselves 
(Kaufman, 2011). In other words, employees find harmony with their job when they can balance other activities as well (Kaufman, 2011). The positive emotion that surfaces from harmonious passion supports individuals in achieving greatness (Kaufman, 2011). Harmonious passion decreases work burnout, which can in turn assist with voluntary turnover. Kaufman (2011) stressed the importance of employees possessing passion in an organization, specifically so the organization can see an increase in performance and creativity. A person can accomplish the work they are doing and balance their personal life; the overall individuals' quality of work improves. When an employee possesses harmonious passion, they could stay with the organization longer, on behalf of the alignment of their personal values and the mission of the organization (Tran, 2014).

Vallerand et al. (2003) pointed out that for an individual to achieve their highest attainment; they must possess passion. Yet, one must be in control of their passion to be successful with retaining harmonious passion. Studies regarding harmonious passion among SWs are critical, seeing communities are familiar with SWs being passionate toward their career; however, research has not defined the type of passion they have or need to possess to be successful in their role. Organizations that foster harmonious passion are more likely to sustain long lasting employees if they continue to invest in them (Ho et al., 2011). An excellent example of harmonious passion in the workplace would be two employees discussing the holiday break over lunch, but once they return to work they can fully concentrate on their job duties with positive energy arising from the engagement in their job (Zigarmi, Nimon, Housin, Witt, \& Diehl, 2009).

Ho et al. (2011) proposes a model of job passion that linked to harmonious passion. They studied 509 employees from an insurance company, and the responses 
from the passion scale indicated that employees with harmonious passion perform their job duties more successful than individuals that do not possess harmonious passion (Ho et al., 2011). The large sample size and use of reported data from supervisors was a strength of the study. Ho et al. (2011) research concludes harmonious passion has a positive relationship with work commitment and job satisfaction. They recommend that future studies should examine other outcomes of harmonious passion, such as voluntary turnover (Ho et al., 2011).

Since individuals spend a large amount of time pursuing their passion, organizations must become aware of what type of passion their employees possess (Caudroit, Boiche, Stephan, Le Scanff, \& Trouilloud, 2011). In the interest of individuals being passionately involved in daily activities, the activity becomes a part of their routine (Mageau \& Vallerand, 2007). The existence of harmonious passion aids with decreasing burnout and increasing work satisfaction; nevertheless, if these factors do not exist in the workplace, an undesirable effect on organizational commitment can occur (Vallerand, 2012). Persons who possess harmonious passion will terminate their passion if the individual believes that their life will have a harmful impact (Vallerand et al., 2003).

When harmonious passion is present in an organization, not only are the employees happier with their career choice, but they put more effort into their work (Vallerand et al., 2003). Harmonious passion allows people to transfer their positive energy from one activity to another. For case in point, Khapova and Korotov (2007) research heightens readers' knowledge on career attributes among a Russian workforce. They found that employees experienced career development when displaying harmonious passion (Khapova \& Korotov, 2007). 
Employees are always in search of an organization to contribute to their wellbeing, which supports harmonious passion and can eventually influence organizational commitment (Moss, 2013). Harmonious passion promotes fostering creativity, which can in turn stimulate an unbreakable bond between the employee and the organization (Luh \& $\mathrm{Lu}, 2012$ ). Individuals that convey harmonious passion are more productive than those who are not passionate toward their work (Kaufmann, 2011). In other words, those who possess harmonious passion know how to make work a part of their daily routine. Not only are they flexible and can balance their lives, but they are also prone to be more successful than those who do not possess harmonious passion. Employees that show harmonious passion will remain engaged in the organization if their work continues to be enjoyable (Vallerand et al., 2014). As an example, Wang and Chu (2007) studied individuals that gamble and found that those who possessed harmonious passion had a more positive outlook toward gambling than those who have less harmonious passion. Gamblers that conveyed harmonious passion were less likely to get addicted; given that they focused on the task they needed to accomplish as opposed to letting distractions, such as losing, hinder their train of thought (Wang \& Chu, 2007; Vallerand, 2008).

When work is important, individuals have a higher output of harmonious passion (Seguin-Levesque, Laliberte, Pelletier, Blanchard, \& Vallerand, 2003). Harmonious passion emerges when "individuals have freely accepted the activity as important for themselves without any contingencies attached to it" (Vallerand et al., 2003, p. 757). If an organization wants more autonomy among their employees, researchers recommend harmonious passion (Mageau \& Vallerand, 2007). Harmonious passion employees not only engage in their work, but they are involved in organizational events, which 
exemplifies solid organizational commitment (Burke, Astakhova, \& Hang, 2014). For the same reason, the self-determination theory is the theoretical foundation of harmonious passion. The next section discusses the details of the self-determination theory.

\section{Self-Determination Theory}

The self-determination theory is a traditional framework that examines human motivation and personality (Seguin-Levesque et al., 2003). Deci and Ryan (1985) developed the self-determination theory while they were expanding on research regarding intrinsic and extrinsic motivation. The researchers define intrinsic and extrinsic sources of motivation that influence an individual's well-being and quality of work. The selfdetermination theory supports healthy trends, such as the daily activities of an individual's life, but in efficient ways; and is recognizable around the globe.

Researchers Ryan and Deci (2000) examined and explored the self-determination theory throughout their tenure as psychologists. The purpose of their studies was to expand the knowledge of the self-determination theory in the new era of the 20th century. Ryan and Deci (2000) discuss various findings on self-determination regarding a variety of environments, specifically in an organization. The theory required the individual to have a need and want to flourish in their career through the required need for competence, autonomy, and relatedness (Deci \& Ryan, 2014). Deci and Ryan (2014) found that organizations and other entities lack these three basic needs of their employees. Competence is the need to master the environment; relatedness is the need for having close, affectionate relationships; and autonomy is the need for the individual to have control over their life (Tran, 2014). As an example, employees want prompt feedback about performance to reinforce competence. Employees seek opportunities to 
develop and implement ideas in the organization and to experience autonomy (pertinent in harmonious passion); and they want the organization to listen and respond to experience relatedness (Deci \& Ryan, 2014). Without these three components, individuals are less likely to appear motivated or committed to the organization. The self-determination theory provides the foundation for an individual to experience more autonomy. The employee must grasp the meaning and worth of their job duties in the organization; without the meaning and worth, the individual will lack competence, autonomy, and relatedness (Ryan \& Deci, 2000).

The self-determination theory is dynamic in supporting studies among teams, organizations, and clinics (Tran, 2014). The theory enriches, rather than diminishes, the need for satisfaction, which can possibly benefit with harmonious passion and organizational commitment (Tran, 2014). Self-determination aids with understanding how individuals evolve and integrate their experiences and challenges into their daily lives. The concept of the theory encourages researchers to understand what motivates people, but most importantly gives organizations understanding of what intrinsic motivation factors assist employees to perform their best and produce efficient work (Tran, 2014).

The theory in which harmonious passion most closely associates with is the selfdetermination theory (Seguin-Levesque et al., 2003). Harmonious Passion arose from the self-determination theory of motivation. Individuals that possess harmonious passion have greater self-determination toward their work (Seguin-Levesque et al., 2003). Liu et al. (2011) designed their study around the self-determination theory via two multilevel studies regarding the mediating role of harmonious passion. They had empirical 
evidence that demonstrated harmonious passion as a strong motivational feature in an individual's life.

Vallerand et al. (2003) relies heavily on the self-determination theory when examining harmonious passion since the theory relates to the individual's engagement with their daily activities. Mageau et al. (2009) argues that the constructs of the selfdetermination theory, such as motivation, should generate greater harmonious passion. The overall purpose of their research was to study three phases (the novice, intermediate, and expert) of an engaged activity that will likely lead to the expansion of passion (Mageau et al., 2009). They conducted three studies in the development of their research using correlational and short-term longitudinal designs with a variety of people ranging from experts to beginners, which predicted the development process of passion (Mageau et al., 2009). The researchers convey through their results that individuals whose settings support their autonomy are more likely to have characteristics of harmonious passion (Mageau et al., 2009). A theoretical implication found in the study was that the development of passion follows an active movement, and as a person spends more time on the activity, the harmonious passion begins to increase (Mageau et al., 2009).

The self-determination theory is a useful predictor of retention (Gagné \& Forest, 2008). An employee is less likely to leave the organization when self-determination is prevalent in the individual and the organization (Tremblay Want, Ma, Belec, \& Vigneault, 2009). Tremblay et al. (2009) conducted a twofold research project; first, they looked at the extrinsic and intrinsic motivation scale, and second, they tested the factorial structure of the scale. They hypothesized that self-determination positively correlated 
with organizational commitment, and that organizational commitment related to decreasing voluntary turnover (Tremblay et al., 2009).

Vallerand and team have evidence that shows how the self-determination theory predicts positive and negative consequences of other theories regarding motivation, satisfaction, commitment, and voluntary turnover (Vallerand et al., 2003). Levesque et al., 2013 research studies the underlying behavior of the determined individual, as their work must align with their goals and values. Individuals naturally want to achieve their goals and will commit to the task that is even uninteresting when their personal values and meaning is understood (Stone, Deci, \& Ryan, 2009). To retain committed employees, the organization must have a free work environment and not a controlled environment (Gillet, Gagn, Sauvagre, \& Fouquereau, 2013). A free work environment gives an individual a sense of control, whereas in a controlled environment the individual has less power over their surroundings. Gillet et al. (2013) uses the self-determination theory as a guiding theoretical framework to study 735 workers' perceptions of organizational and supervisor autonomy support, turnover intentions, and other variables. The results of their study showed scholars and practitioners that a definite link between the self-determination theory and predicting turnover is present. Therefore, future research should look more into organizational commitment and harmonious passion as they relate to voluntary turnover (Gillet et al., 2013).

\section{Voluntary Turnover}

Voluntary turnover is defined as, "a process in which an employee makes a decision whether to stay or leave the organization" (Long, Thean, Ismail, \& Jusoh, 2012). Voluntary turnover may be detrimental to organizations as turnover can impact the goals 
and objectives outlined by the organization (Long et al., 2012). Voluntary turnover typically consists of the most talented employees leaving the organization, which is why the effect is negative to the company. When talent leaves voluntarily, so does the knowledge, skills, and abilities that they possess, which affects the efficiency and quality of work that the organization provides to the community (Long et al., 2012). The opposite of voluntary turnover is involuntary turnover, which is when the organization is in control of whether the employee stays or goes (Long et al., 2012). Involuntary turnover does not have as much emphasis on the organization as voluntary turnover.

Retaining employees is important because of the financial influence turnover can have on the business. Gaining commitment from employees early in the employment cycle might decrease voluntary turnover (Sharma et al., 2014). On average, voluntary turnover can cost a state organization at the minimum, $\$ 54,000$ per $\mathrm{SW}$ to replace, which includes but is not limited to separation costs, paperwork, and unemployment (Barrett \& Greene, 2016). According to the Bureau of Labor Statistics (2006), employers were noticing that employees remain approximately 2 years before leaving the organization. Voluntary turnover among organizations has been a concern for organizations, private and public, small and large (Long et al., 2012). The influence of turnover in an organization, both directly and indirectly is regarding cost (Long et al., 2012). Direct cost refers to the selection of the candidate and the training received (Long et al., 2012). Indirect cost applies to overhead cost, for instance, rent and utilities (Long et al., 2012). The cost of employee turnover is roughly $30 \%-150 \%$ of the employees' compensation; affecting a variety of departments in an organization, which is a major effect on the 
quality of service provided by the business (Long et al., 2012; Schlesinger \& Heskett, 1991). Therefore, the chief impact of the cost comes from both direct and indirect cost. Voluntary turnover among employees has been a major concern confronted by organizations regardless of their size, environment, or location of business (Long et al., 2012). High turnover refers to the dissatisfaction employees have with their current employer (Carsten \& Spector, 1987). High voluntary turnover affects the goals and objectives outlined by the organization, which can influence organizational commitment and harmonious passion (Long et al., 2012). On the other hand, low turnover can indicate high organizational commitment and employees aligning themselves with the goals and values of the company. Offering a workplace that fosters a motivated environment, personal and professional growth can increase harmony and lower employee turnover and absentee rates drastically (Graphic Art Monthly, 2005).

Understanding why SWs are voluntarily leaving the profession is of great concern to the human capital field (Weaver, Chang, \& Gil de Gibaja, 2006). Turnover has become a serious issue regarding the human capital aspect of the organization due by virtue of the function of human capital not being at its best, especially the knowledge, skills, and abilities of the SWs (Balfour \& Neff, 1993; Strober, 1990). CPS SWs deal with some of the toughest cases, such as sexual and physical abuse, along with the death of a child (Rafique, 2016). According to Rafique (2016), CPS SWs are turning over during the first couple of months of being hired. Executive Directors recognize that there is a hindrance to the services provided by the organization to such high voluntary turnover; thus, affecting the quality of services provided to the community in which they serve (Tollen, 1960). According to Finnemore (1990), a researcher that focuses on 
unemployment and turnover rates in Eastern Cape, noticed that high turnover could have a key influence on the programs offered by the facility. Therefore, Executive Directors should familiarize themselves with the human capital in their organizations; followed by understanding what is causing voluntary turnover in their organization before they can begin to tackle the problem of reducing turnover (Barak et al., 2001).

Human capital is critical in the workforce in view of how human capital ties into the principal contributing factor of efficiency (Dess \& Shaw, 2001). Efficiency decreases when turnover increases; hence, having a damaging effect on human capital. Not only does voluntary turnover influence human capital, but turnover can also negatively influence the return on investment; bearing in mind the loss of critical employees and the knowledge they take with them (Dess \& Shaw, 2001).

Voluntary turnover is a major concern in social services, but specifically the SW profession (Koeske \& Kirk, 1995). Geurts, Schaufeli, and De Jonge (1998) found that the trigger of poor organizational commitment is an unpleasant emotional state and a necessary antecedent of turnover intention. The higher the turnover rates, the more likely the level of trust with the client will decrease (Geurts et al., 1998). They suggest that future research should differentiate between various kinds of organizational commitment, such as affective, continuance, and normative (Geurts et al., 1998).

If a SW leaves in the middle of an assignment, there is a $60 \%$ chance that the cases they were working on are put on hold until someone can take on additional assignments (Barrett \& Greene, 2016). In January 2016, one of the largest counties in a southern state lost a third of their SWs by November of the same year (Barrett \& Greene, 2016). Losing such a large number of employees placed the county in a horrible place; 
caseloads increased, development of backlogs began, and burnout increased (Barrett \& Greene, 2016). By the end of 2016, state agencies employing SWs noticed that turnover was at an all-time high at $25 \%$, as employees were leaving within 1 year of service (Barrett \& Greene, 2016).

Extreme voluntary turnover can disrupt the functions of the organization and the quality of care provided by the individuals of the business. Studies conducted by StrolinGoltzman, Kollar, and Trinkle (2010) found that childcare workers had positive perceptions of their job and planned to remain with their organization. When a SW leaves the organization, the departure can have an unwanted influence on the life of the families and communities that they serve, which in turn can have a negative effect on other employees that are still with the organization and caseloads increase (StrolinGoltzman et al., 2010).

Retaining SWs is crucial by reason of the personal investment that they have put into their education and the contributions they offer society. Weaver et al. (2006) research examines the influence of offering professional development opportunities to SWs employed by the state government on voluntary turnover. They acknowledge if an employee states they intend to leave the organization, more than likely they will, along with others who said they did not intend to leave taking into account job satisfaction, job burnout, and lack of professional development opportunities (Weaver et al., 2006). Weaver et al. (2006) studies a variety of variables, but concludes the lack of organizational commitment was critical to voluntary turnover; not just organizational commitment, but finding if affective, normative, and continuance commitment is truly lacking. Barret and Green (2016) confirmed that voluntary turnover does not affect 
organizations that support professional development as much as it affects other organizations that do not. Sara Munson, Director of the Institute for Families at Rutgers University School of Social Work, states within Barrett and Green (2016) that "If the workers are well-supported and well-trained, stable and committed, they're able to do that same kind of work with children and families to get them stabilized. When we do well by the workforce, that keeps cost down later" (p. 1).

Callahan (2014), a researcher who focuses on how turnover is problematic, interviewed a few SWs in DHS, states that insufficient training makes the employee feel ill prepared to do their job and eventually decide to leave the organization and possibly the field. The continuation of training develops a workforce that is competent, consistent, effective, and efficient (Graphic Art Monthly, 2005). Employers can increase commitment and decrease voluntary turnover if they keep their employees abreast with plans and policy changes, and provide training related to their skills (Testa, 2008).

Research found that trained workers were less likely to contribute to turnover. Ultimately, employers should strive to have $0 \%$ voluntary turnover and strive even more to be the "employer's choice" in their market which may aid employees to see their job more fulfilling (Thomas, 2009).

Voluntary turnover rates vary throughout time. For instance, during the 20012006 fiscal years, the annual turnover rate for all sectors of industry averaged $39.6 \%$, and the hospitality sector experienced an average annual rate of $74.6 \%$ (Bureau of Labor Statistics, 2006). For the most part, if an employer, such as CPS, has a higher turnover rate than their competitors, which is the private and federal government sector, their average tenure declines compared to those in the same industry. High voluntary turnover 
can have a negative influence on the company resulting from the loss of skilled and knowledgeable workers, especially if the workplace consists of more trainees than those with tenure. To analyze a worker's reason for leaving, organizations typically try to capture and track voluntary turnover by offering employees an exit survey to complete, but few respond honestly (Spain \& Groysberg, 2016).

Voluntary turnover for SWs in 2012 was $56.3 \%$ but rose $3.5 \%$ in 2013 within the United States (Equifax Workforce Solutions, 2014). In 2013, the northern United States turnover rate was 55.5\%, while the southern United States was 52.6\% (Lewis, 2014). As voluntary turnover continues to be a challenge around the United States, turnover among various industries is important to examine, as the effects are different for each sector. Once an employer is aware of what causes voluntary turnover in their company, they can make wise use of their resources to reduce turnover and retain committed employees.

Boyas, Wind, and Kang (2012) study suggest that younger SWs have a higher turnover rate than older SWs. Their study is similar to older research, such as Kermish and Kushin (1969), and focused on the age, in which individuals voluntarily leave the organization. Boyas et al. (2012) found that younger employees reported significantly lower levels of organizational commitment than older employees. They identify a 77\% level of intent to leave among younger SWs (Boyas et al., 2012). Younger SWs are keener to experiencing job burnout and have a higher chance of leaving an organization voluntarily, compared to their older counterparts (Boyas et al., 2012). Interestingly, they also note that older employees encouraged younger employees to pursue other avenues (Boyas et al., 2012). 
Another portion of the research, involving turnover among SWs, has dealt with the sex of the participant. Tollen (1960) proposes that there are no significant dissimilarities between male and female turnover rates. However, Meld (1974) found in his early research that male SWs were less likely to contribute to turnover than women were. The statistics of Meld's study were that $34 \%$ of men and $54 \%$ of women change jobs in the first 2 years upon conferring their degree. Other research rebuts the statistics of the previous studies finding that women have more reasons to change or leave their job that their male counterparts (Loewenberg, 2014). As long as voluntary turnover is steadily increasing among SWs, the assumption is that a workforce that have high turnover does not have efficiency and productivity (Mabengano, 2003).

Executives are looking for hard data and current literature to assist with the ongoing challenges of voluntary turnover (SHRM, 2008). When employees leave voluntarily, organizations can perceive the departure as a curse or an opportunity (Lewis, 2014). What opportunities mean in the context provided is that the employers have a chance to gain talent (Lewis, 2014). The downside would be to lose the valued talent. Equifax Workforce Solutions (2014) acknowledges that employees leaving to explore new opportunities is on the rise, in other words, voluntary turnover is increasing.

Although an agreement exists among the SW community that turnover is not desirable, administrators who want to decrease voluntary turnover have little accurate literature to refer to regarding possible causes and solutions (Loewenberg, 2014). The research available focuses on the quality and quantity of SWs. Documented research highlights that the first and second year of recruitment of an employee is the most critical time to gain commitment in consideration of turnover being more prevalent during the 
first and second year; however, the longer the employee is in service with the organization, the less likely they are to contribute to voluntary turnover (Loewenberg, 2014).

\section{Summary}

The impact of the rising cost of turnover has placed a burden on human resource personnel (Barrett \& Greene, 2016). The role and the feeling of satisfaction among SWs are important to the continuing development of a strong workforce and providing quality services to their community. Vital to the organization and profession is the commitment of SWs. The three-component model assist with understanding the employees thought pattern, as the model relates to their intent to stay committed to the organization. Although previous research examines organizational commitment among a variety of occupations, there remains a need for research among SWs. Validation of appropriate commitment and harmonious passion components could aid in developing human capital and lowering the cost of replacing employees. While employees that possess organizational commitment and harmonious passion find motivation through intrinsic needs more than extrinsic, they want to gain knowledge and contribute to the organization (Tran, 2014; Tremblay et al., 2009). However, researchers have emphasized that future studies should focus on breaking down organizational commitment, and measuring the variable with a large population (Aarons \& Sommerfeld 2011). On the other hand, research has not examined harmonious passion among SWs, but the recommendation for research is to study the variable with different populations (Ho, Wong, \& Lee, 2011). Examining and exploring organizational commitment and harmonious passion influence on voluntary turnover is essential for organizations to be 
aware of in both the field of SW and the organization as a whole (Weaver et al., 2006). The next chapter details the research design and methods that assisted in accomplishing the research objectives of the current study. 


\section{CHAPTER III - RESEARCH DESIGN AND METHODOLOGY}

In Chapter III, a description of the research methodology used to examine and explore the effects of organizational commitment and harmonious passion on voluntary turnover among SWs is presented. This information details the context of the study, the participants, the instruments, and the methods used in gathering the data. The current study sought to garner the participants' perceptions regarding organizational commitment, harmonious passion, voluntary turnover, and their intent to leave.

\section{Research Question and Objectives}

Four research objectives guided the examination and exploration of the influence of organizational commitment and harmonious passion on voluntary turnover among SWs. The central research question the study answered is how does organizational commitment and harmonious passion contribute to the participants' intent to leave? To answer this question, the study addressed the following research objectives:

$R O 1$ - Describe the demographics of the participants in terms of gender, age, educational attainment, and years of employment.

$R O 2$ - Explore the participants' perspectives about how organizational commitment and harmonious passion affects voluntary turnover in the organization.

RO3 - Determine the relationship between organizational commitment and harmonious passion on voluntary turnover.

RO4 - Describe the effects of organizational commitment and harmonious passion on voluntary turnover. 


\section{Research Design}

Mixed-methods integrate both quantitative and qualitative research and is a common approach to conducting research in the social sciences (Creswell, 2014). A concurrent mixed methods design is utilized in this study. Creswell and Plano-Clark (2011) describe a concurrent mixed-methods design as when both quantitative and qualitative data are collected simultaneously; however, several other terms also describe the mixed-methods approach, such as integrating, multimethod, synthesis, etc. (Bryman, 2012; Tashakkori \& Teddlie, 2010). Mixed-methods originated in the late 1980s and early 1990s based on the work of several individuals in a variety of fields (Creswell, 2014). The methodology has become widely accepted from a wide range of users with applications, such as federal funding initiatives, dissertations, and journals across the realm of social and health sciences (Creswell, 2010, 2011). The present study used a pragmatic approach to focus on the problem rather than the method (Creswell, 2003). Using a pragmatic approach allowed the researcher to triangulate their results due to using multiple methods to study the research problem. Figure 2 illustrates a version of Creswell, Plano-Clark, Gutmann, and Hanson's (2003) concurrent mixed-methods design, which outlines the technique used in the present study. Data collected during the quantitative phase provided information on the SWs levels of organizational commitment, harmonious passion, and their intent to leave CPS. The qualitative aspect of the study consisted of one-on-one interviews, which provided a deep explanation of how SWs perceive organizational commitment, harmonious passion, voluntary turnover, and intent to leave. 


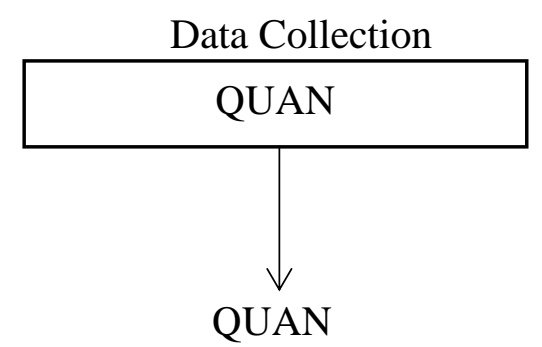

Data Analysis
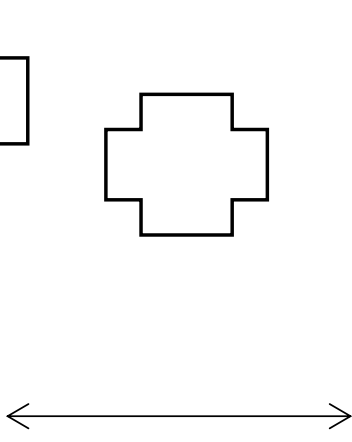

Comparison of Results

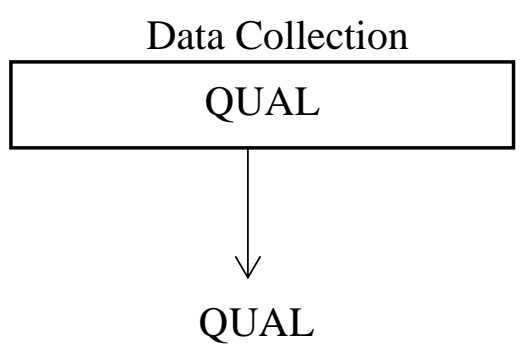

Data Analysis

Figure 2. Concurrent Mixed-Methods Design

The suggested strategy for mixed-methods research includes four domains: implementation, priority, integration, and theoretical perspective (Creswell, 2003). The strategy outlined by Creswell and Plano-Clark (2011) allowed the researcher to gain perspective and see the advantages of both methods (Creswell \& Plano-Clark, 2011). For the concurrent mixed methods design, the timing of the data collection occurs simultaneously for both the quantitative and qualitative processes; according to Creswell (2006), this process strengthens a study. The concurrent design aids in confirming and cross validating the findings of research (Creswell \& Plano-Clark, 2011). Using mixedmethods also assisted in overcoming the limitation of using a single design. For example, only using a quantitative design can misrepresent the target population, which can lead to miscalculating the probability distribution (Sudeshan, 2016). The limitation of using only a qualitative design is the data collected cannot be obtained from a large population, along with the inability to analyze the results and noting if the data were statistically significant or not (Atieno, 2009).

Researchers who apply the mixed methods approach have a greater understanding of both quantitative and qualitative processes, and the outcomes from the results 
regarding SWs (Aarons, Fettes, Sommerfeld, \& Palinkas, 2011). Aarons et al. (2011) note that mixed methods research is vital for research in social science, specifically when examining human service settings. Researchers recommend a mixed method design to study voluntary turnover among child welfare services (Aarons et al., 2011). A mixed method design is well suited for the purpose of the current study. The following section will explain the quantitative design.

\section{Quantitative Design}

The quantitative design allowed the researcher to reach a larger sample of SWs at CPS than the qualitative design to measure the constructs of the study. Quantitative research provides the connection between empirical and numerical expressions (Monette, Sullivan, \& DeJong, 2011). The researcher used a Likert scale questionnaire containing demographic, organizational commitment, harmonious passion, and anticipated turnover questions. However, unlike the qualitative, the quantitative design does not allow the freedom to explore the lived experiences of the participants (Monette et al., 2011).

\section{Qualitative Design}

Berg and Lune (2011) state "when investigators are interested in understanding the perceptions of participants or learning how participants come to attach certain meanings to phenomena or events, interviewing provides a useful means of access" (p. 115). Since qualitative research focuses on a specific phenomenon, there can be generalizability, which is whether the results of the research can be transferred or offered in a broader context (Eriksson \& Kovalainen, 2008; Lincoln \& Cuba, 1985). The one-onone semi-structured interviews aided in collecting qualitative data. The qualitative design allowed the researcher to gain a richer understanding of the effect of organizational 
commitment and harmonious passion on voluntary turnover among SWs. Because the interview questions are exploratory, the questions served as a guide to understanding the participants' perceptions (Aarons \& Sommerfeld, 2011; Tran, 2014; Tremblay et al., 2009). The purpose of the in-depth interviews was to identify themes within the data; however, according to Charmaz (1990), the significance of a qualitative instrument is to "categorize the data and then to analyze relationships between categories while attending to how the lived experience of research participants can be understood" (p. 1162). Interviews are an appropriate source for collecting data that is difficult to obtain via a written response, such as personal experiences (Ocak, 2011; Phillips et al., 2013).

\section{Institutional Review Board Approval}

The current study involved interacting with human participants; therefore, the researcher followed specific guidelines outlined by the University of Southern Mississippi Institutional Review Board (IRB) for participant anonymity, informed consent, and minimizing risk to participants during data collection. The researcher explained in detail within the IRB application the purpose of the study, the population of interest, and all forms of communication used between the researcher and the participants. The researcher completed the following steps to obtain approval: (a) completed a Human Subjects Research Application Form; (b) emailed completed and signed forms to their dissertation chair for review and signature; (c) the dissertation chair submitted the IRB application to the Head of the Department and the University of Southern Mississippi IRB. The researcher received approval from the IRB to conduct the study (Appendix A). After obtaining approval from the IRB, data collection began. 


\section{Population}

Agarwal and Mishra (2016) recommend researchers examine organizational commitment from a broader and more representative sample across a selected state. The target population for the present study are SWs within CPS located in the southern United States. At the time of data collection, CPS employed 370 SWs across 14 regions (Deputy Commissioner of Human Resources \& Administration, personal communication, January 1, 2018). CPS was chosen considering the agency employs a high number of SWs compared to other agencies across the United Sates and SWs play a critical role within the organization. The population included male and female participants, 21 years of age or older, with an average age of 42.4 (Bureau of Labor Statistics, 2014). Most job positions represented in the population for the current study require at least a Bachelor's degree. Researching among this population is important because it examines the effectiveness of how SWs engage within their organization along with programs they implement to increase recruitment and retention (Smith, 2014). In addition, SWs play a critical role within the communities they serve. If turnover continues to rise among the SW population, it potentially hinders the services rendered by the agency. The Executive Director of DHS granted permission for this research (Appendix B).

Sampling Procedures

The present study utilizes a concurrent mixed-methods design; therefore, the collection of data consists of both quantitative and qualitative data. Two methods were used to sample the selected population, census for the quantitative design and purposive sampling for the qualitative design. To select participants for the quantitative aspect of the study, CPS provided the researcher with a census of the current SW population. The 
survey was distributed to 370 employees. Raosoft, a sample size calculator, that estimates the number of responses needed to reach a $95 \%$ confidence level, indicating the researcher needed 189 responses (http://www.raosoft.com/samplesize.html).

For the qualitative aspect, the researcher selected participants using purposive sampling, which is the technique of choosing an appropriate sample of a population for determining features of a specific population (Patton, 2001). A more specific form of purposive sampling is homogeneous sampling, which supports the recruitment of SWs for the current study (Patton, 2001). Homogeneous sampling allows the researcher conducting the study to be selective of the participants they choose to interview, and ensure the participants will add in-depth knowledge to the study (Patton, 2001). The population consisted of a certain group, CPS SWs, which added the possibility of the participants adding meaning to the data collected. The sampling method selected is an important technique many studies use (Teddlie \& Tashakkori, 2009). Teddlie and Tashakkori (2009) suggest researchers use homogeneous sampling if the study utilizes a mixed methods design and the research objectives outlined in the study address issues related to a single population of interest. Furthermore, Creswell (2013) recommends researchers reach out to individuals who share like experiences with the phenomena. According to Dworkin (2012), the sample size for qualitative research is smaller than the sample used for quantitative research. Some researchers suggest 12-30 participants are needed to reach saturation and redundancy in qualitative research for homogeneous sampling (Charmaz, 2006; Dworkin, 2012; Guest, Bunce, \& Johnson, 2006; Morse, 1994, 1995). Fusch and Ness (2015) state, "Data saturation is reached when there is enough information to replicate the study, when the ability to obtain 
additional new information has been attained, and when further coding is no longer feasible" (p. 1408). Saturation is important in qualitative research for that failure to reach saturation will influence the quality of the findings (Fusch \& Ness, 2015). Burmeister and Aitken (2012) acknowledge that data saturation is not about the quantity, but the depth of the data. Each study should comprise a sample size that presents an opportunity to reach saturation (Fusch \& Ness, 2015). Once no new themes or data are received, saturation has been reached (Fusch \& Ness, 2015).

Sampling SWs provided informative data to address the research objectives of the present study. Fourteen regions fall within the state selected for the current study and at least one SW was interviewed from each region. The purpose of selecting individuals from different regions helped capture a representative sample of SWs that expanded across the state. According to Austin Research (2014), a non-representative sample could be subject to bias. Interviewing at least one social worker from each region reduces the possibility of one region being over-represented. The researcher asked the participant at the end of the interview to identify their region, which allowed the researcher to track the regions represented within the data, and ensured a representative sample across the selected agency.

\section{Instruments}

Two types of instruments were used to collect data: a survey and a semistructured interview protocol. The discussion of the quantitative instrument occurs first, followed by the discussion of the qualitative instrument. Survey research is a wellorganized way of collecting data to aid in addressing central research questions and objectives. One of the key challenges of developing a survey is developing a reliable and 
valid measure that captures the data the researcher is interested in (Phillips, Phillips, \& Aaron, 2013). Previous literature validates the questionnaires used in the current research. The survey embodied a mixture of questions regarding organizational commitment, harmonious passion, and anticipated turnover to measure the participants' level of each construct; participants received the survey electronically.

There is a possibility that participants took both the survey and interview; though, there was no requirement for completing both. The researcher gained consent to use each instrument outlined in the current study (Appendix C). The next four sections will discuss the instruments the researcher used to collect data.

\section{Three Component Model Employee Commitment Survey}

To study organizational commitment, the three-component model (TCM) employee commitment survey, developed by Meyer and Allen in 2004 was used. The instrument measured the current level of organizational commitment among SWs at CPS. The survey consists of three validated scales; affective commitment, normative commitment, and continuance commitment (Meyer \& Allen, 2004). There are two versions of the survey; the original version and the academic version (Meyer \& Allen, 2004). The original version of the commitment scale includes eight items per scale, totaling 24 questions. The academic version of the scale includes six items per scale, totaling 18 questions designed to determine the commitment level of the employee. Meyer and Allen (2004) acknowledge that the two versions are similar, and the only major difference between the two versions is in the normative commitment portion. The original version of the normative scale focuses more on the basis for obligation, whereas the academic version focuses on the feeling of obligation (Meyer \& Allen, 2004). The 
researcher measured organizational commitment using the academic version because it aligned with the purpose and research objectives of the study.

Modifications are allowed for the number of items on each of the scales to reduce the length of the survey (Meyer \& Allen, 2004). However, no more than two to three items can be removed to retain the reliability of the instrument (Meyer \& Allen, 2004). Another common modification to the scale is reducing the Likert scale from 7 to 5 points (Meyer \& Allen, 2004). Reducing the scale below 5 points disrupts the reliability and validity of the scale. The reliability and validity of the instrument accrued over years of research determined using unaltered scales (Allen \& Meyers, 1996, 2000). Davis (2014) study, using the three-component model employee commitment survey, concluded the Cronbach's alpha totals .87 for affective commitment, .75 for continuance commitment, and .79 for normative commitment. No modification to the scale were made for the present study. Therefore, the researcher used the 7-point Likert scale ranging from 1 (strongly disagree) to 7 (strongly agree). The next section of the instrument will be the passion scale.

Passion Scale

Marsh et al. (2013) states development of the passion scale was created to meet the need of measuring passion; specifically, harmonious and obsessive passion (negative affect on passion, by way of the individual not being in control of their life). Vallerand and colleagues created the passion scale in 2003. Over 20 studies were used to validate the instrument in the past two decades (Vallerand, 2015). The studies were used to validate the passion scale, which involved researchers translating the scale in different languages, such as French and Chinese. For example, Zhao, St-Louis, and Vallerand's 
(2015) validated the passion scale, and their study yielded a Cronbach alpha of 0.86 for the instrument. Amiot, Vallerand, and Blanchard (2006) conclude that the passion scale is adequate, reliable, and valid to use when measuring harmonious passion. Empirical findings and exploratory factor analysis support the two-factor passion scale (Vallerand, 2010). The passion scale consists of internal consistency and has external evidence of reliability and validity in diverse undertakings (Vallerand, 2010).

The passion scale consists of 17 items measuring harmonious passion, obsessive passion, and general passion. The 7-point scale ranged from 1 (not agree at all) to 7 (very strongly agree). The harmonious passion questions emphasized an active perception where the employee has control over their activity. The obsessive passion questions emphasized a passive perception where the employee is forced to engage in the activity. The general passion questions emphasized the desire an employee has toward an activity, in which they invest time and energy. Vallerand recommends using the full scale, because the results will enlighten the reader on what type of passion the participant embodies.

The passion scale provides a brief, psychometric measure to study and understand the participants' engagement in a specific task (Marsh et al., 2013). Studies, such as the research conducted by Marsh et al. (2013), found that the passion scale's internal consistency, factor structure, and construct reliability and validity is strong. The passion scale has high levels of reliability and validity (Vallerand et al., 2003). The researchers acknowledge the scale is an appropriate instrument for measuring harmonious passion in diverse fields (Marsh et al., 2013). No modifications were made to the passion scale for this study. The last section of the survey is the Anticipated Turnover Scale. 


\section{Anticipated Turnover Scales}

To measure voluntary turnover, the researcher used the Anticipated Turnover Scale (ATS). Hinshaw and Atwood (1978) developed ATS to study turnover among nurses. The instrument consists of a 12-item questionnaire on a 7-point Likert scale, ranging from 1 (disagree strongly) to 7 (agree strongly). ATS fits with the purpose of the study considering the items on the survey relate to the anticipated length of time before the participant will voluntarily leave (Almalki, FitzGerald, \& Clark, 2012). Hinshaw and Atwood (1982) estimated the construct validity of ATS using factor analysis; and reported a Cronbach's alpha of .84. Over time, the Cronbach's alpha has increased, indicating reliability of the ATS, which is contributed to variations in sample sizes and variability of the sample (Almalki et al., 2012).

A meta-analysis performed by Barlow and Zangaro (2010) provided evidence of reliability and construct validity of the ATS among populations, such as nursing across the United States. The ATS assisted the researcher with explaining anticipated turnover and suggest ways to improve retention and prevent unnecessary turnover based on the data collected from the study (Barlow \& Zangaro, 2010). Many researchers use the scale to measure the intent of turnover among nursing in a variety of healthcare settings (Almalki et al., 2012). The ATS was not modified for the current study. The researcher

conducted one-on-one semi-structured interviews simultaneously with the distribution of the survey, which is discussed next.

\section{Qualitative Interviews}

The researcher used an interview protocol to gain insight on the SWs perception of organizational commitment, harmonious passion, voluntary turnover, and intent to 
leave. In addition, the data contained demographic information, which included gender, age, years of employment at CPS, educational accomplishment, and years as a licensed SW. The researcher designed the interview questions, based on the research objectives outlined for the current study, to gain deeper insight on how SWs view organizational commitment, harmonious passion, and their intent to leave. Jacob and Furgerson (2012) state, "Researchers may use many different techniques, but at the heart of qualitative research is the desire to expose the human part of a story" (p. 1). Researchers also note first time qualitative interviewers should use an interview protocol as a procedural guide (Jacob \& Furgerson, 2012). The researcher used an interview protocol to ensure the same information was collected from each participant (Appendix D). The researcher practiced the interview protocol with three colleagues before beginning the interview process. The practice interviews assisted the researcher with making sure questions were adequate and clear to the participant. Each interview was conducted one-on-one via telephone and lasted between 15-30 minutes; the organization did not want employees away from their duties for an extended period. Once each individual semi-structured interview was completed, a transcription service transcribed the recorded interviews.

\section{Role of the Researcher}

The role of the researcher is unique in a mixed-methods study. For quantitative studies, the researcher does not exist in theory, which eliminates researcher bias from the study (Simon, 2011). Ideally, the study should be replicable to others; however, in qualitative studies, the researcher is the instrument (Denzin \& Lincoln, 2003). Sutton and Austin (2015) acknowledged that the biasness of a qualitative researcher is an advantage when the researcher recognizes, embraces, and comprehends their personal bias. The 
researcher had to describe themselves in the context of the study, including personal biases and assumptions, and the experiences that qualify them to conduct the study (Greenbank, 2003). Hence, the researcher represented both methods equally.

The researcher of the current study was new to qualitative research; therefore, they made sure they had a firm understanding of how to properly conduct qualitative research to ensure the participant felt safe. The researcher used ideas and theories in the literature review to further examine and explore the research objectives outlined for the current study. The role of the researcher in the qualitative aspect of the study was to assess the feelings and views of the SWs. It was the responsibility of the researcher to make the participants feel safe and ensure them that the information they shared would remain anonymous. The researcher used probing questions to gain a deeper understanding of how SWs perceive organizational commitment, harmonious passion, voluntary turnover, and intent to leave. Understanding the participant's view while conducting the interview was important to the current study by reason of having a clear understanding aided in decreasing bias. By combining quantitative and qualitative methodologies, the researcher bias was lessened, as the combination of both methodologies is identified as triangulation (Gunnell, 2016).

\section{Data Collection Procedures}

To uphold internal validity for the collection of data, a documentation log was maintained on each aspect of the collecting process, which consisted of (a) raw data, (b) notes on data analysis regarding coding decisions, and (c) following interview protocol and adhering to the administration of the instruments used to conduct surveys (Creswell, 2009). Participants agreed to participate in the study electronically before completing the 
survey and verbally before participating in the interview. Participants were reassured that the survey was confidential and there would not be a way for the researcher to trace where the survey came from.

\section{Quantitative Method}

To collect quantitative data, the survey consisted of the instruments discussed earlier (Three Component Model Employee Commitment Survey, Passion Scale, and ATS). The survey was comprised of 52 questions focusing on the participants' experiences, perceptions, and attitudes toward organizational commitment, harmonious passion, and intent to leave (Appendix F). Since the population consisted of 370 CPS SWs located in vast geographical areas, an electronic survey was used as it allowed the researcher to target a variety of markets and the electronic version was a cost-effective measure for the study (Dillman, 2000; Fink, 2003).

Administration of the survey occurred via Qualtrics, a computer based research software, the survey was emailed by the researcher to participants (Appendix G). Qualtrics offers the option for the responses to the questionnaire to be anonymous; therefore, utilization of the anonymous option provided anonymity to the participants. Only the researcher has access to the username and password to Qualtrics, which ensured the security of keeping the participants information confidential. The following steps were taken to collect responses for the questionnaire, which are outlined by QuestionPro (2018). The first step was reviewing the basic objectives of the study. The second step was obtaining a list of names from the agency of licensed SWs, which was the target audience of the study. The third step was personalizing the email invitations; each participant received an email addressing them personally. The fourth step was keeping 
the email short and making sure all possible questions were addressed. The fifth step was making the first survey page simple, which consisted of providing background about the study, IRB information, and gaining consent. Participants were able to review the current study requirements, risks, and content on the first page of the survey. The sixth step was making sure the participant understood that their identity was protected, which was outlined in the email and reiterated on the first page of the survey. The seventh step was sending out reminder emails; the researcher sent two follow-up emails to the participants (Appendix H, Appendix I). The survey was open for a total of four weeks. The researcher was not allowed to offer an incentive for survey participation per strict state government policies. Qualtrics survey software estimated that the survey would take approximately 10 minutes to complete.

\section{Qualitative Method}

Creswell (2007) recommends the researcher follow the following steps outlined for qualitative research, (a) identify participants to interview based on the criteria set by the researcher; (b) determine the best type of interview; (c) record interviews for transcribing; (d) design and use an interview protocol; (e) refine interview questions; (f) determine how the interviews will be conducted; and (g) obtain consent from each participant (Creswell, 2007). The qualitative instrument explored the SWs perception of the influence of organizational commitment, harmonious passion, voluntary turnover, and intent to leave. The format of one-on-one semi-structured interviews referenced the establishment of a protocol. The researcher used probing questions to assist with providing the participant a positive experience. Doing so enabled the researcher to recognize the participant perspective significance and prevented the researcher from 
injecting personal opinions. Thus, the researcher established trust with the participant

(Fontana \& Frey, 2005). Table 1 provides an overview of the data collection procedures.

Table 1

Data Collection Timeline

\begin{tabular}{ll}
\hline \multicolumn{1}{c}{ Week } & \multicolumn{1}{c}{ Task } \\
\hline Week 0 & $\begin{array}{l}\text { Received approval from the Institutional Review Board at The } \\
\text { University of Southern Mississippi. }\end{array}$ \\
Week 0 & Practiced interview protocol with three colleagues. \\
Week 1 & $\begin{array}{l}\text { Child Protective Services reached out to Social Worker } \\
\text { Supervisors from each region to inform them that all Social } \\
\text { Workers under their supervision would receive an email from } \\
\text { the researcher containing survey and interview instructions. }\end{array}$ \\
Week 1 & $\begin{array}{l}\text { Sent out recruitment email to participants containing survey } \\
\text { and interview instructions. }\end{array}$ \\
Week 1 & $\begin{array}{l}\text { Began sending qualitative interview transcripts to the } \\
\text { transcription service }\end{array}$ \\
Week 2 & Started conducting member checking of interviews \\
Week 2 & Sent first follow-up email. \\
Week 2 & Started analyzing qualitative data. \\
Week 3 & Sent second follow-up email. \\
Week 4 & Closed surveys and completed interviews. \\
Week 4 & Started analyzing quantitative data \\
Week 6 & Completed data analysis
\end{tabular}

\section{Data Analysis}

The current mixed-methods study utilized frequency distribution, content analysis, and multiple regression to analyze the research objectives. The data collected is 
part of three categories: nominal, interval, and narrative. Data analysis occurred simultaneously. The researcher outlined the data analysis plan and its relation to each research objective, along with the statistical tests used to evaluate the data in Table 2.

Table 2

Data Analysis Plan

\begin{tabular}{|c|c|c|}
\hline Research Objective & Data Category & Statistical Test \\
\hline $\begin{array}{l}R O 1 \text { - Describe the } \\
\text { demographics of the participants } \\
\text { in terms of gender, age, } \\
\text { educational attainment, and } \\
\text { years of employment at CPS. }\end{array}$ & $\begin{array}{l}\text { Nominal } \\
\text { - Survey Q1-Q5 } \\
\text { - Interview Q1-Q5 }\end{array}$ & $\begin{array}{l}\text { Frequency Distribution } \\
\text { - Percent } \\
\text { - Cumulative Percent }\end{array}$ \\
\hline $\begin{array}{l}R O 2 \text { - Explore CPS SWs } \\
\text { perspectives about } \\
\text { organizational commitment and } \\
\text { harmonious passion. }\end{array}$ & $\begin{array}{l}\text { Narrative } \\
\text { - Interview Q6-Q23 }\end{array}$ & $\begin{array}{l}\text { Content Analysis } \\
\text { - Description of verbal } \\
\text { communication via } \\
\text { information provided } \\
\text { during the interview. }\end{array}$ \\
\hline $\begin{array}{l}R O 3 \text { - Determine the } \\
\text { relationship between } \\
\text { organizational commitment and } \\
\text { harmonious passion on } \\
\text { voluntary turnover. }\end{array}$ & $\begin{array}{l}\text { Interval } \\
\text { - Survey Q6-Q52 }\end{array}$ & $\begin{array}{l}\text { Multiple Regression } \\
\text { - Independent Variables } \\
\text { - Affective } \\
\text { Commitment } \\
\text { - Normative } \\
\text { Commitment } \\
\text { - Continuance } \\
\text { Commitment } \\
\text { - Harmonious } \\
\text { Passion } \\
\text { - Dependent Variable } \\
\text { - Anticipated Turnover }\end{array}$ \\
\hline $\begin{array}{l}\text { RO4 - Describe the effects of } \\
\text { organizational commitment and } \\
\text { harmonious passion on } \\
\text { voluntary turnover among CPS } \\
\text { SWs. }\end{array}$ & $\begin{array}{l}\text { Interval and } \\
\text { Narrative } \\
\text { - Survey Q6-Q52 } \\
\text { - Interview Q6-Q28 }\end{array}$ & $\begin{array}{l}\text { Content Analysis and } \\
\text { Multiple Regression }\end{array}$ \\
\hline
\end{tabular}


The analysis plan for RO1 involved describing the demographics of the participants using frequency distribution, which reports a detailed analysis of the number of instances each value occurred (gender, age, educational attainment, years at CPS, and years as a SW). The demographic questions are Q1-Q5 on both the survey and interview. For RO2, the researcher used content analysis to describe the participant's perspectives regarding organizational commitment and harmonious passion. Content analysis allowed the researcher to gather categories and themes from the communication with each participant. The categories and themes derived from patterns found throughout the text during the reading of each interview transcript. The use of content analysis assisted the researcher in estimating the number of times each theme occurred. The advantage of using content analysis for the current study is the ability to analyze the phenomena in a non-invasive way.

The analysis plan for RO3 required conducting a multiple regression analysis. This statistical test, multiple regression analysis, permitted the researcher to determine the relationship between the independent variables (affective commitment, normative commitment, continuance commitment, and harmonious passion) and the dependent variable (anticipated turnover). For RO4, the researcher examined the content and multiple regression analysis to describe the effects of organizational commitment and harmonious passion on voluntary turnover. Examining analysis from both methods enabled the researcher to compare the quantitative and qualitative data to see if there were similarities within the results. 


\section{Summary}

The current research used a mixed-methods approach to determine SWs perception of organizational commitment, harmonious passion, and intent to leave due to the influence the variables have on voluntary turnover. The population included SWs from CPS in the southern United States. The study embodied a concurrent mixed method design; the quantitative phase used a survey and the qualitative phase used in-depth interviews. The survey consisted of 52 questions, five demographic questions and 47 questions from three reliable and validated scales which are the three-component model employee commitment survey, passion scale, and anticipated turnover scale. The interview script consisted of 28 questions, five demographic questions and 23 probing questions regarding organizational commitment, harmonious passion, voluntary turnover, and intent to leave. The researcher used frequency distribution, content analysis, and multiple regression to analyze the data. The next chapter will outline the results from the quantitative and qualitative data. 


\section{CHAPTER IV - RESULTS}

This chapter provides an overview of the results of the current study. The study explored and examined the influence of organizational commitment and harmonious passion on voluntary turnover among CPS SWs. The data collected answered the research objectives of the current study. This chapter provides insight into the perceptions of CPS SWs that participated in the current study by presenting the analysis and results of the survey and interview.

\section{Quantitative Analysis}

The population for the study consisted of Licensed CPS SWs located in the southern United States. CPS provided the researcher with a comprehensive list of 370 Licensed CPS SWs names, position, and emails. The survey, along with instructions regarding the interview, was sent to all CPS SW email address. The researcher asked participants demographic questions at the beginning of the survey, to capture gender, age, educational background, length of time with CPS, and time as a licensed SW. The data obtained provided demographic information about the sample.

The data analysis consisted of interval data. Even though individual Likert scale items are considered ordinal, the combination of the Likert items may be treated as interval data (Boone \& Boone, 2012). To determine if a linear relationship exists between two or more variables, the researcher used the statistical technique, multiple regression. Using multiple regression assisted with describing the relationship between the organizational commitment and harmonious passion influence on voluntary turnover.

All quantitative data was derived from Likert Scale responses on a 7-point scale. A Likert Scale is a rating scale that measures the individual's attitudes and opinions 
(Boone \& Boone, 2012). The researcher used SPSS version 25 to analyze the quantitative data. The analysis provided by SPSS allowed the researcher to gain greater understanding of the data collected. Table 3 categorizes the coding of the variables used in SPSS for the demographic items.

Table 3

Variable Coding in SPSS

\begin{tabular}{|c|c|}
\hline Variable & SPSS Coding \\
\hline \multicolumn{2}{|l|}{ Length of time with agency } \\
\hline$<1$ year & 1 \\
\hline $1-5$ years & 2 \\
\hline $5-10$ years & 3 \\
\hline $10-15$ years & 4 \\
\hline$>15$ years & 5 \\
\hline \multicolumn{2}{|l|}{ Gender } \\
\hline Female & 1 \\
\hline Male & 2 \\
\hline Prefer not to answer & 3 \\
\hline \multicolumn{2}{|l|}{ Age } \\
\hline 20-30 & 1 \\
\hline $31-40$ & 2 \\
\hline $41-50$ & 3 \\
\hline$>50$ & 4 \\
\hline \multicolumn{2}{|c|}{ Length of time as Licensed Social Worker } \\
\hline$<1$ year & 1 \\
\hline $1-5$ years & 2 \\
\hline $5-10$ years & 3 \\
\hline $10-15$ years & 4 \\
\hline$>15$ years & 5 \\
\hline \multicolumn{2}{|c|}{ Degree (Educational Accomplishment) } \\
\hline Bachelors & 1 \\
\hline Masters & 2 \\
\hline Specialist & 3 \\
\hline Doctorate & 4 \\
\hline
\end{tabular}


Once data was transferred from Qualtrics to SPSS, the researcher performed a quality check to confirm each variable and identified the coding outlined in Table 3. Four of the questions within the Three-Component Employee Commitment Survey were reverse-keyed items, where a strongly agree reflected a lower level of commitment (Meyer \& Allen, 2004). Three questions were reverse-coded for affective commitment (Q14, Q20, and Q22) and one for normative commitment (Q8). The reversed keyed items were properly coded before averaging the score. Next, the researcher converted the harmonious and obsessive passion responses to z-scores. To obtain the z-scores, the researcher conducted a descriptive statistics analysis of harmonious and obsessive passion to covert the interval data to z-scores. Once these changes were made to the data, the researcher examined the descriptive statistics and frequency distributions via SPSS.

SPSS data was exported into Microsoft Excel to further review the data for accuracy. Per research recommendations, each participant response was reviewed to determine if four or more questions per scale were answered (Meyer \& Allen, 2004). If less than four responses were captured per scale, the average would create false data and would impact the analysis (Meyer \& Allen, 2004). For example, if a participant did not answer four questions within a scale, the researcher could not use the response. Further, the researcher calculated the score of each question per scale using the average equation function within Microsoft Excel. Once the researcher confirmed the data was properly coded, data was exported from the Microsoft Excel spreadsheet into SPSS to run a multiple regression analysis. The discussion of the quantitative results is discussed next. 


\section{Quantitative Results}

A total of 226 of the 370 CPS SWs completed the electronic survey, a response rate of $61 \%$. The sample of 208 females and 11 males represents CPS SWs. Most participants were in the $31-40$ age bracket $(n=77,34.1 \%)$. Roughly $50 \%$ of participants possessed a Bachelor's Degree and 50\% held a Master's Degree. The participants' time with the agency ranged from $<1$ year to $>15$ years, and length of time as a licensed SW ranged from 1 year to $>15$ years. Table 4 outlines the frequency distribution of the quantitative demographic data.

Table 4

Quantitative Frequency Distribution

\begin{tabular}{lccc}
\hline $\begin{array}{c}\text { Demographic } \\
\text { Variable }\end{array}$ & Frequency & Percent & $\begin{array}{c}\text { Cumulative } \\
\text { Percent }\end{array}$ \\
\hline $\begin{array}{l}\text { Gender } \\
\text { Female }\end{array}$ & 208 & $92.0 \%$ & $97.3 \%$ \\
Male & 11 & $4.9 \%$ & $4.9 \%$ \\
Prefer not to & 6 & $2.7 \%$ & $100 \%$ \\
answer & & & \\
Age & & & \\
$21-30$ & 29 & $12.8 \%$ & $12.9 \%$ \\
$31-40$ & 77 & $34.1 \%$ & $47.1 \%$ \\
$41-50$ & 55 & $24.3 \%$ & $71.6 \%$ \\
$>50$ & 64 & $28.3 \%$ & $100 \%$ \\
& & & \\
Degree (Educational & & & \\
Accomplishment) & 114 & $50.4 \%$ & \\
Bachelors & 108 & $47.8 \%$ & $90.9 \%$ \\
Masters & 1 & $.4 \%$ & $99.6 \%$ \\
Specialist & 1 & $.4 \%$ & $100 \%$ \\
Doctorate & & & \\
\hline
\end{tabular}


Table 4 (Continued)

Demographic

Variable

Length of time as

Licensed Social

Worker

$<1$ year

1-5 years

5-10 years

10-15 years

$>15$ years
28

57

49

23

65
Cumulative

Percent

The data collected from the questionnaire was used to determine the relationship between organizational commitment and harmonious passion on voluntary turnover. Participants were asked to respond to questions relative to organizational commitment. The commitment levels were measured using the Three Component Model Employee Commitment Questionnaire. Affective, normative, and continuance questions based on a Likert scale ranging from 1 (strongly disagree) to 7 (strongly agree) addressed organizational commitment. Eighteen questions represented six statements for each of the three organizational commitment scales. Participants indicated their level of agreement or disagreement with each statement pertaining to their perceived relationship with the organization and their reasons for staying with the organization. The questions for this portion of the survey captured the SWs desire to remain with the organization, the need to remain with the organization, and their perceived obligation to remain with the agency. For example, a statement for normative commitment is, 'I owe a great deal to my organization.' To identify the participant's commitment to the organization, the 
scoring of each scale was separate, and responses were averaged to determine the level of organizational commitment. Consistent with Meyer and Allen (2004) protocol, when a participant failed to respond to three or more items per scale (affective, normative, and continuance), their responses are not calculated due to missing data.

To determine the level of organizational commitment among the participants, the researcher used the average scores from the individual scales. A high score of five or more from each scale indicates a strong affective, normative, or continuance commitment to the organization (Meyer \& Allen, 2004). The mean scores of the organizational commitment scales ranged from 3.919 to 4.142 . The participants of this study had the highest mean score on normative commitment $(M=4.142, S D=1.035)$, and the lowest score on affective commitment $(M=3.919, S D=.767)$. According to Moldogaziev and Silvia (2015), employees who express a low level of affective commitment means the individual does not pay attention to details regarding their task, and do not identify with leadership. Furthermore, low affective commitment can result in an increase of voluntary turnover (Meyer et al., 2002). Normative commitment was the highest score, which indicates the employee remains with the organization because they feel obligated, versus staying for the strong relationship they have with the organization (Grimsley, 2003). The continuance commitment score is moderate, and signifies the employee is only staying with the organization since they feel they must. According to Grimsley (2003), employees may stay because financial or other means of support, such as healthcare insurance. The next section discusses the results of harmonious passion.

Harmonious passion was measured using the Passion Scale Questionnaire. Participants were asked to answer questions based on thinking about being a SW and 
indicating their level of agreement to each question. The 7-point scale ranged from 1 (not agree at all) to 7 (very strongly agree). The questions for this portion of the survey captured SWs passion for their SW role, consisting of general passion statements (I like my job), harmonious passion statements (My job is in harmony with other activities in my life), and obsessive passion statements (If I could, I would only do my job). Mageau et al. (2009) recommended the z-score (standard score) be used to score the passion scale. According to Field (2013), the z-score will allow the researcher to compare two items (harmonious and obsessive passion) derived from calculating the probability of a score occurring within a normal distribution. Furthermore, Mageau et al. (2009) supports the use of z-scores to obtain the most accurate results to indicate harmoniously or obsessively passionate employees. The resulting mean z-score for harmonious passion is $z=-.00065$, and the $\mathrm{z}$-score for obsessive passion is $z=.000000284$.

The last section of the survey measured intent to leave using the Anticipated Turnover Scale. The anticipated turnover score was obtained by calculating the sum of all scale items divided by the number of scale items (Almalki et al., 2012). The anticipated turnover scores ranged from 1 (disagree strongly) to 7 (agree strongly); a higher score reflects a greater chance of the employee leaving their position or organization (Almalki et al., 2012). The questions for this portion of the survey captured participants' intent to leave their organization, which consisted of intent to leave statements. For instance, a statement from the anticipated turnover scale is "I plan to stay in my position awhile". The average score for anticipated turnover is $M=3.821(S D=$ .567). A low average anticipated turnover score represents a lesser chance an employee will leave the organization, or in other words, a higher chance the individual will remain 
with the organization (Almalki et al., 2012). The next section discusses the relationship between the independent variables (affective commitment, normative commitment, continuance commitment, and harmonious passion) and the dependent variable (anticipated turnover).

To analyze the quantitative data, multiple regression analysis using SPSS version 25 was conducted. According to Field (2013), the four assumptions for multiple regression analysis are (a) linearity between the outcome variable and the predictors, (b) normality, (c) homoscedasticity, and (d) independence. Field's (2013) suggest using a scatter plot to spot check for linearity and homoscedasticity. The assumption was met, since there was no systematic relationship between the errors in the scatter plot. Field's (2013) recommends the use of Q-Q plots to check for normality. The researcher conducted a Kolmogorov-Smirnov and Shapiro-Wilk test to produce the Q-Q plots. The assumption was met, since there was no deviation of the points from the diagonal line. Lastly, Field (2013) notes if participants are not influenced by other participants' participation, independence is met. The assumption was satisfied, since each participant completed the survey once, and there were no influences made on the participants. All four assumptions were satisfied; therefore, a multiple regression analysis was conducted (Appendix K).

Multiple regression analysis was used to test if organizational commitment (affective, normative, continuance) and harmonious passion predicted participants' anticipated turnover. The results of the Analysis of Variance (ANOVA) indicated affective commitment, normative commitment, continuance commitment, and harmonious passion explained $3.1 \%$ of the variance $\left(R^{2}=.031, F(4,208)=1.679, p>\right.$ 
.156). Frost (2013) suggests that $R^{2}$ is typically low when examining human behavior, as humans are difficult to predict, but further explains that a low $R^{2}$ is not necessarily bad. The ANOVA for the multiple regression is not significant; none of the regression coefficients are significantly different from zero. The Durbin-Watson is 1.969 , which indicates that the values are independent. For this study, the low F-value indicates the means of the population are close together and relative to the variability with each group. The F-value was used to determine the overall significance of the data. It was found that organizational commitment and harmonious do not predict intent to leave. The researcher cannot conclude that there is a statistically significant association between the dependent variable (anticipated turnover) and the independent variables (affective commitment, normative commitment, continuance commitment, and harmonious passion), as a combined model $(p=.156)$. In other words, there is no relationship between the intent to leave dependent variable and independent variables (affective commitment $(p=.091)$, normative commitment $(p=.471)$, continuance commitment $(p=$ $.104)$, and harmonious passion $(p=.709))$. For the coefficients table, the $B$ informs the researcher of what degree each predictor affected intent to leave. The relationship between intent to leave and two of the predictors (normative commitment and harmonious passion) is positive. In addition, the relationship between intent to leave and the other two predictors (affective commitment and continuance commitment) is negative. The ANOVA table (Table 5) and coefficient table (Table 6) display the results of the multiple regression analysis. 
Table 5

Results of ANOVA from the Multiple Regression

\begin{tabular}{rccccc}
\hline Source & Sum of Squares & $d f$ & Mean Square & $F$ & Sig. \\
\hline Regression & 6.653 & 4 & 1.663 & 1.679 & .156 \\
Residual & 206.025 & 208 & .991 & & \\
Total & 212.678 & 212 & & & \\
Note. df, degrees freedom; F, F-Statistic, Sig., significance. F $(4,208)=1.679$, Sig. $=.156, \mathrm{R} 2=.031$. &
\end{tabular}

Table 6

Results from Multiple Regression Analysis Illustrating the Relationship between the independent variables (affective commitment, normative commitment, continuance commitment, and voluntary turnover) and the dependent variable (anticipated turnover).

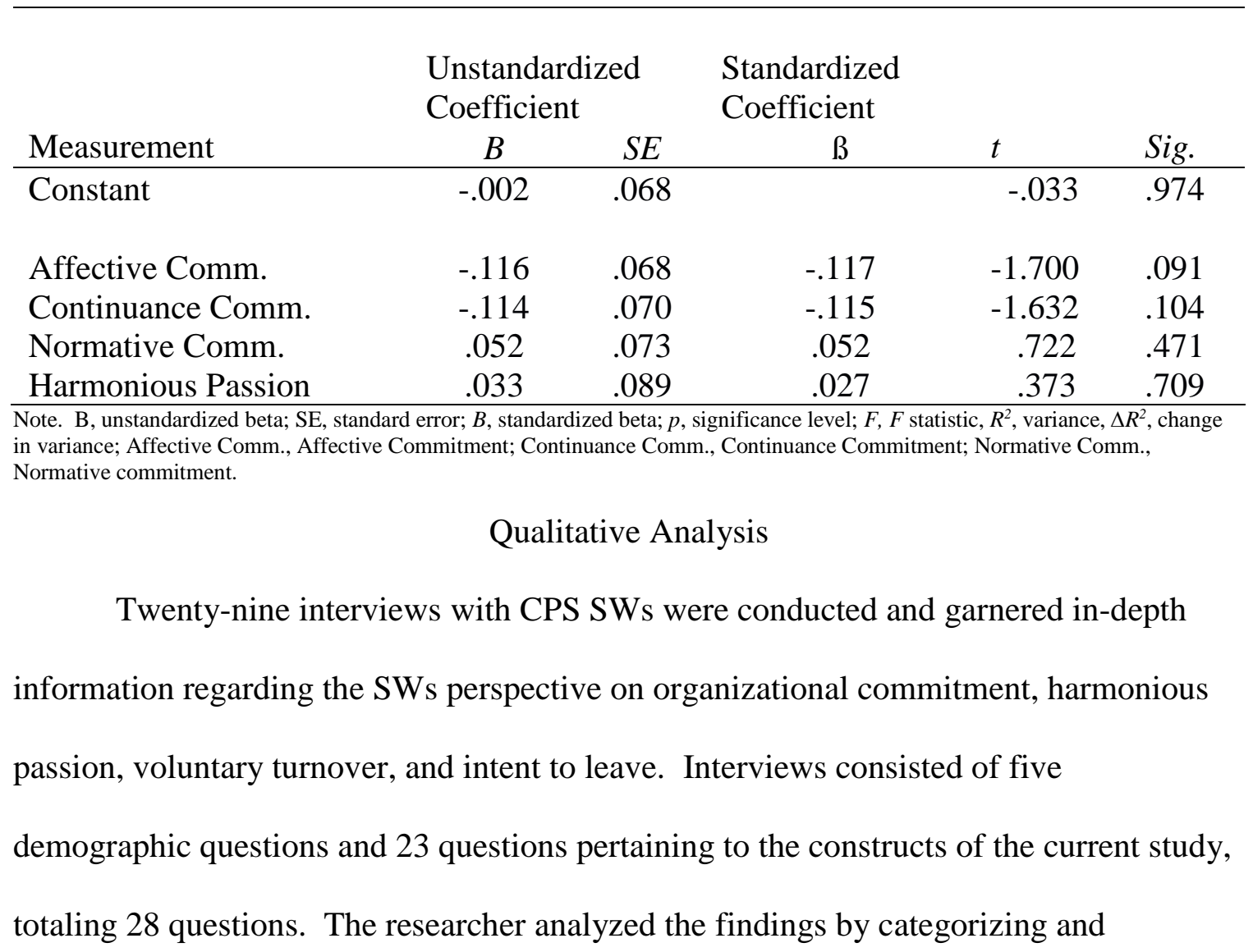


identifying themes. Each recorded phone interview took approximately 15-30 minutes. The interview was confidential and did not elicit any personal or sensitive information. According to Creswell (2009), analysis of qualitative data includes several steps. The first step consisted of reading the transcripts several times to ensure that the data collected was accurately transcribed. The researcher listened to the recordings and read along with the transcript to ensure that the participant's information was properly captured. The second step involved transcribing the interviews to categorize the data. As reported by Creswell and Plano-Clark (2007), "[categorizing] is the process of grouping evidence and labeling ideas so that they reflect increasingly broader perspectives" ( $\mathrm{p}$. 132). The researcher developed the interview script in sections to assist with the categorization of the data. In addition, the researcher used a transcription service to assist in transcribing the interviews. The transcription service quickly transcribed the interview recordings allowing the participants the opportunity to review the transcript, member checking validation was accomplished. Once the participant approved the transcript via email, the researcher began coding for themes. If the participant had changes to their transcript, the researcher made the suggested changes and used the updated transcription for analysis. Only two of the 29 participants had minor changes. The third step consisted of using the categories to develop themes from the interviews. The researcher read through each transcript several times to find themes among the responses. The researcher connected the themes and added supporting quotes to each category. The researcher compared replies and patterns to categories of the participant responses. Identification of the themes aided in analyzing the data, and ranking the themes by noting how many times the participants discussed each theme. The last step consisted of interpreting the data 
collected. The researcher interpreted the data by examining the categories and labeling the themes from the data.

\section{Qualitative Results}

All 29 respondents answered each demographic question. Though saturation was met at interview 14, the researcher conducted 15 additional interviews to ensure a representative sample from each region and to offset interviews that were less than ten minutes. The sample of 27 females and two males all over than 21 years of age represents CPS SWs located across the Southern United States in this study. Fifty percent of the participants possessed a Bachelor's Degree and 50\% possessed a Master's Degree. The participant's time with the agency ranged from $<1$ year to $>15$ years. Length of time as a licensed SW ranged from 1 year to $>15$ years. Most participants stated they do not intend to leave the agency. The sample represented at least one SW from each region. The frequency data and participant demographics are outlined in Table 7.

Table 7

Qualitative Frequency Distribution

\begin{tabular}{lccc}
\hline $\begin{array}{c}\text { Demographic } \\
\text { Variable }\end{array}$ & Frequency & Percent & $\begin{array}{c}\text { Cumulative } \\
\text { Percent }\end{array}$ \\
\hline $\begin{array}{l}\text { Gender } \\
\text { Female } \\
\text { Male }\end{array}$ & 27 & $93.1 \%$ & $93.1 \%$ \\
& 2 & $6.9 \%$ & $100 \%$ \\
Age & & & \\
$21-30$ & & & \\
$31-40$ & 3 & $10.3 \%$ & $10.3 \%$ \\
$41-50$ & 11 & $37.9 \%$ & $48.3 \%$ \\
$>50$ & 6 & $20.7 \%$ & $69.0 \%$ \\
& 9 & $31.0 \%$ & $100 \%$ \\
\hline
\end{tabular}


Table 7 (Continued)

\begin{tabular}{|c|c|c|c|}
\hline $\begin{array}{c}\text { Demographic } \\
\text { Variable }\end{array}$ & Frequency & Percent & $\begin{array}{c}\text { Cumulative } \\
\text { Percent }\end{array}$ \\
\hline \multicolumn{4}{|c|}{ Degree (Educational } \\
\hline Bachelors & 12 & $41.4 \%$ & $41.4 \%$ \\
\hline Masters & 17 & $58.6 \%$ & $100 \%$ \\
\hline \multicolumn{4}{|c|}{ Length of time with } \\
\hline \multicolumn{4}{|c|}{ Child Protective } \\
\hline \multicolumn{4}{|l|}{ Services } \\
\hline$<1$ year & 3 & $10.3 \%$ & $10.3 \%$ \\
\hline $1-5$ years & 7 & $24.1 \%$ & $34.5 \%$ \\
\hline $5-10$ years & 8 & $27.6 \%$ & $62.1 \%$ \\
\hline $11-15$ years & 4 & $13.8 \%$ & $75.9 \%$ \\
\hline$>15$ years & 7 & $24.1 \%$ & $100 \%$ \\
\hline \multicolumn{4}{|l|}{ Length of time as } \\
\hline \multicolumn{4}{|l|}{ Licensed Social } \\
\hline \multicolumn{4}{|l|}{ Worker } \\
\hline 1-5 years & 7 & $24.1 \%$ & $24.1 \%$ \\
\hline $5-10$ years & 10 & $34.5 \%$ & $58.6 \%$ \\
\hline $10-15$ years & 1 & $3.4 \%$ & $62.1 \%$ \\
\hline$>15$ years & 11 & $37.9 \%$ & $100 \%$ \\
\hline \multicolumn{4}{|l|}{ Intent to leave } \\
\hline Yes & 9 & $31.0 \%$ & $31.0 \%$ \\
\hline No & 15 & $51.7 \%$ & $82.8 \%$ \\
\hline Maybe & 5 & $17.2 \%$ & $100 \%$ \\
\hline
\end{tabular}

To explore the participants' perspectives about how organizational commitment and harmonious passion effects voluntary turnover in the organization, the researcher used an outlined interview protocol. The interview protocol aided the researcher in defining the participants' perceptions. The interview focused on understanding the lived 
experiences of the participant. The one-on-one interviews allowed the researcher to explore the phenomenon around how SWs perceive organizational commitment, harmonious passion, voluntary turnover, and intent to leave. The criteria outlined by the researcher, ensured that the individuals who participated in the interview were CPS SWs located in the southern United States. The researcher identified five categories, eight themes, and two sub-themes as significant to the study. The five categories are value and experience, organizational commitment, harmonious passion, voluntary turnover, and organizational support. The description of the categories and themes from the data collected are discussed next.

\section{Category: Value and Experience}

The category value and experience arose from participants discussing their values toward the field of SW and their experience thus far as a SW and with CPS. Two themes were obtained from this category: helping and encouraging people and rewarding experience. The first theme is helping and encouraging people, which encompasses the emphasis SWs, who participated in the study, place on making a difference with each client and family they encounter. The theme relates to what they value within their work. Visibly seeing how they have made a difference in an individual's life assists with seeing the bigger picture of why they are a valued asset to the organization. SWs suggest that making a positive change in their clients and family's lives motivates them to continue helping and encouraging people daily. Twenty-three of the participants mentioned helping and encouraging people under the value and experience category.

- "It was just my passion to help others to make a family lifestyle better."

- "I enjoy being able to help, educate, empower, and give hope to people." 
- "I just like helping people. That's what it boils down to."

- "I truly enjoy helping others with their strengths. They can overcome anything, they don't know that they have those things, some people don't know they have strengths. But you can use those strengths to better them and never aspect it off. Pour them their strengths to show them that you know, the quality of life that they do have and they can have."

- "I love helping me."

- "It was just my passion to help others to make a family lifestyle better."

- "I enjoy the fact that I can go in and evaluate a home and share wisdom, resources of the area, and discuss their goals and their tasks and in helping them accomplish their goals and tasks."

- "I enjoy the benefits of being there just for people to kind of be able to respond to if they need be. Not necessarily, you're not going to help everybody. But just basically being there as a support and being available for people. To be able to talk about their problems or to be able to help them if we can with their problems."

- "Just wanting to be helpful and I saw my mom in the community take in strangers and just being helpful. So that inspired me, I knew I wasn't going to take in anybody. So just wanting to be helpful and to offer my support in other ways to be able to help people that might be going through something."

- "I enjoy the benefits of being there just for people to kind of be able to respond to if they need to. You're not going to help everybody necessarily. But just being 
there as a support. And being available for people. To be able to talk about their problems or to be able to help them if we can with their problems."

- "When I first started it was to help children. I just wanted to help children."

- "The need to help others."

- "Help people gain what they need."

- "The ability to change situations. To encourage people, to assist in the change of their situation."

- "I’ve, like most social workers I was always interested in helping people."

- "You know, I think I enjoy the end results of me helping children and families."

- "The aspect of helping those that are in crisis or underprivileged. Just being able to help them."

- "I like helping people and I like stepping in during people's time of distress. And, just being able to encourage people. It's a lot of people that are hurting in the world. To be able to work with families, and meet with families, and sometimes when we are finished working with them and see them pull themselves up by their bootstraps. I just like working with people and encouraging them and being there to provide the support and give them that guidance that perhaps that they didn't know that they had."

- "And I always knew, you know, that I wanted to help people and I think that was just the big-the big part of it."

- "I just love to say that I'm helping someone else." 
- "I'm able to kind of give them some insight and kind of give them some encouragement to not to give up on what you're doing because there's a reason why you chose social work."

- 'I mean we're making changes in children's lives and trying to help them for the better."

- "I enjoy encouraging people daily."

The second theme under this category is rewarding experience, which demonstrates the participants experience as a SW thus far and their experience with CPS. Participants mentioned each day is a learning experience, as no day is the same. They have positive and negative stories, but note that regardless of the outcome, there is always some form of success which makes their experience rewarding. If they can help one person, it's seen as a reward. Fifteen of the participants mentioned having a rewarding experience under the value and experience category.

- "Oh, it is seen as a rewarding. I have had some negative but the positive outweighs the negative."

- 'It's demanding and you got to really know if it's for you, because it's the least rewarded, when I say rewarded, it's rewarded in the sense that you help your client, but it's the appreciation part, and not necessarily that you're looking for a pattern there, but yeah, it's good but I think the expectation of a social worker is demanding."

- "It's been a rewarding experience." 
- "The reward it gives me for helping and making sure the children and families are safe and are getting what they need from, life basically."

- 'It's very rewarding and I just enjoy the job of being a social worker with this agency."

- "I get a great reward from helping families in crisis or underprivileged families."

- "I enjoy the personal reward from being able to help people."

- "It's been rewarding, as far as working with the agency I work with, but it's also been challenging and hard."

- "The job is challenging, but it's not without its rewards."

- "Being in the Social Work career field has been very rewarding."

- "I have had a very rewarding and rich experience."

- "My experience has been very rewarding, personally."

- "My career in Social Work has led to a rewarding career."

- "Being a Social Work has been interesting, challenging, frustrating, but overall it has been rewarding."

- "The most rewarding experience of being a Social Worker is being able to make a difference in other people's lives."

\section{Category: Organizational Commitment}

The category organizational commitment arose from participants discussing the importance of organizational commitment and what organizational commitment means to them as a SW. One theme was derived from this category. The theme that came from this category is the SWs perception of organizational commitment, which is commitment 
to the agency and vision. All participants stated organizational commitment is important. SWs that have been with the agency for more than 15 years expressed a higher level of commitment than those that have been with the agency for 10 years or less. The participants who have been with the agency less than 10 years are not as committed to the agency as they are to the vision of the agency. Eighteen out of 29 participants noted they are committed to serving the clients and families of the community, but are not necessarily committed to the agency. Eleven of the participants mentioned commitment to the agency and vision under the organizational commitment category.

- "I'm committed to the families, but not as committed to the agency."

- "Moderate commitment to the agency overall, but less commitment toward the agency."

- "Employees who are committed to the agency have been with the agency for 15 or more years are committed to the agency, but the millennials are not as committed. They are committed to the vision, but they do not care about remaining with the organization."

- "As Social Workers we are committed to the vision and mission of serving children, more than we are to the organization."

- "I'm committed to the profession of Social Work, but my commitment to the agency is low."

- "My commitment to my organization, of course, I have been here $15+$ years. And I'm committed to the organization because the organization has changed its focus to be committed to the community, and that was very positive to me. So, I view 
as long as my agency is positive and working for family, which is what I always support, then I feel like my commitment would continue to them."

- "Need commitment from the agency to increase organizational commitment to the agency. Social Workers are very committed to the vision, but commitment to the agency fluctuates.”

- ' 'I'm very committed to CPS. I mean my mother has worked for CPS for years. And it is not something that I'm going to stop being committed to. I have a commitment to children and families in my area."

- "I think the current statement of commitment is 50-50. Mainly because the older Social Workers are a lot more committed than the younger Social Workers. The older Social Workers are commitment the agency and the vision, whereas, the younger Social Workers are committed to more of the vision than the agency."

- "You really got to love your job at CPS to be committed and be successful."

- "Right now, I will say I am about 50\% commitment to the agency, and 95\% committed to the vision.

\section{Category: Harmonious Passion}

The category harmonious passion arose from participants discussing the importance and current state of harmonious passion at CPS. One theme and one supporting element was gained from this category: motivation and boosting morale. The theme for this category is motivation, which describes the importance of harmonious passion. Harmonious passion is what keeps SWs, who participated in this study, motivated to care for the families they serve, which contributes to harmonious passion. 
However, to increase passion, CPS leaders should build trust and show appreciation to their SWs. Employees become more productive and are ready to engage with the community as harmonious passion increases. Without motivation, the SW will not be able to successfully do their job or make a positive impact on the families they are serving. Harmonious passion assists with the employee having a balanced home and work life. It is important for SWs to be able to separate from their job when they go home, as it can influence their home life negatively. If there is no separation between home and work, there could be a decrease in harmonious passion. Twenty-six of the participants mentioned motivation under the harmonious passion category.

- "Passion keeps you motivated to work. We all know that SW is not a very lucrative profession. So, the fact that you're dedicated to wanting to help people, despite not getting the amount of pay, it keeps you going."

- "If you're going to be a social worker, you have to have a passion for it, because if not you're going to fail, you going to dread coming to work."

- 'Oh, I think that if you don't have a passion about this job then first of you're going to be unhappy with your day-to-day job duties. But also, it's going to be detrimental with the populations that you work with just because you're not going to be doing level of practice and service that I think needs to be done and the service to your clients."

- "If you don't have motivation or passion, it has to do with the service you run, the quality of service. It impacts that service. If I don't care that much about it, what type of service am I offering to my clients?" 
- "Well, I think that way if you have passion about your job, then I think first off, you're going to enjoy it. And you're going to work hard at it and do the very best that you can. Also, if you have passion for your job, you probably go above and beyond what's expected of you. But it's sometimes needed. I think that you care more so you're going to do more for the clients then if you have more passion."

- "It makes helping others bond, be more of a quick response when you are passionate, and totally motivated to the cause of helping those children that's in custody so yes, I feel that social workers should be motivated, and that it will help you do your job even better."

- "Harmonious passion is important because it's what's going to drive you. So, if you're not motivated about it, then of course you're not going to be very considerate of the people's lives that you are impacting every day. So, it drives you."

- "You have to be motivated to do your job because if you don't want to be here and you don't feel that you are able to do your job, then you're not going to produce good work. So, if you're not feeling good about your job then you're not going to do good work."

- "If people don't have passion or are not motivated about their job, they're not going to do a good job. It's not going to work because you just see it as a job. Then you're not going, you're just going to do enough to get by."

- "Because it can be a very stressful job, you have to be motivated to come to work every day." 
- 'If I don't have passion then I'll feel like that it's just a job to me. So, if you don't care about what you do, then you're just there for a paycheck."

- "You have to have motivation, in order to do the job effectively."

- "If you don't have harmonious passion, it reflects in your practice."

- "Without motivation, social workers will not be able to properly serve the families."

- "To do the job that we do daily, you have to have some form of motivation. And we should be motivated by the agency, but right now that is not happening because commitment and passion is low."

- "Passion is what's going to help you to provide that extra level of care and sensitivity, without pay, without reward or without like ignition from someone else. It is also the motivation, that is so important, because motivation is what's going to drive you to see change, to see change. It helps you build that extra mile to feed that extra resource so that families could get that extra hour to that family when there's no real reward. So, passion and motivation is really important. It's like the gas that's going to keep you going."

- "Passion keeps you motivated to work. I mean we all know that social work is not a very lucrative profession. So, the fact that you're dedicated to the field, you want to help people, despite not getting that amount of pay, it keeps you going."

- "If you are committed, you have to have passion. Passion drives you, it drives me. When you have a passion for something it drives you. You don't stop, you continue to go, and you continue to know that me doing this will help a family. Maybe if I can get this child back with her family, then the next step might be to 
keep her adoption or whatever, but it's motivation that drives you, and it makes you want to be a better worker, a better person, you know you live in society with everybody."

- "Without passion they will not be able to successfully reunite children with their families or find permanent homes for children. They won't want to come, they will not want to come to work every day with that desire to make a child's life better or to make the family's lives better. So, I think they have to...everybody has to be motivated that drives them to do this job."

- "I think having motivation is important to have passion about their job because if they don't have passion, it just be another job. You're going to work with that family a little bit more, you're not going to give up on their parents which are half gone, and banished for a couple of months. You are going to continue to reach out to them you are going to continue to work with fathers even if the father has been in the pinch to try and engage others. They have to keep coming or trying. If you don't have that motivation to do that, then it's just another day on the job."

- 'Well, if they don't have passion they're not going to last. That is just the way it is. If you don't have motivation for what you're doing, you're just not going to last and you're not going to do the work to the best of your ability and your other world will start colliding into your job.”

- "If you don't have motivation, you can't actively, effectively care for your family. You can't help a child. You got to have some motivation when it comes to dealing with individuals, population of drug addiction, and sexual abuse. You got to have that passion to be able to give the right kind of service." 
- "We're dealing with people. And if you don't have that motivation, then how are you going to serve people?"

- "It's important to have motivation because...I mean, what we do on daily basis is impacting the lives of others. I mean we're making changes in children's lives and trying to help them for the better. If you don't have that motivation to push you, then what kind of a difference are you really making?

- 'This isn't a field that you should go into if you don't have passion for it. I've had interns that I have told they need to find a different method of work. We've had students come in and do the 20-hour service work and, according to them, they need to go back to school and find a different area to go into. This is not something you do to get a paycheck every two week. You must have the motivation to do this. Because you're not...you're holding people's literal lives in your hands, with what we do. Sometimes it even ends up in there. It ends up ripping families apart, it ends up in some horrifying situation with very, very ill children, whether it be medically or mentally."

- 'If you don't have that motivation, then you start to wonder what you're doing and why you're there. It's important to put passion to what you do, especially when you're working with people. Not just children, but people in general. Because people that come to our agency specifically, you know, they're probably at the worst point in their lives. They're always with the children when they're fostering children, that's really, really tough. And you need to have people who are motivated working on the cases to be making these decisions that are right." 
A sub-theme of motivation is boosting morale, which derived from further discussion on how CPS can increase harmonious passion. Participants asserted they need support from leadership. Leadership should support and embody harmonious passion. Subordinates model what they see; therefore, it is important CPS leaders support SWs, value SWs, and provide the necessary tools to increase harmonious passion. Participants commented that harmonious passion can be increased by recognizing staff for hard work. For example, providing a quarterly newsletter highlighting positive stories from different regions would help to recognize SWs hard work. Recognizing SWs not only during SW week, but throughout the year could help to create a culture of recognition. Furthermore, SWs stated leadership should visit face-to-face with them to gain a more meaningful understanding of what they do for the agency. Twelve participants mentioned boosting morale as a supporting element for the harmonious passion category.

- "Building trust, showing appreciation, maybe creating I guess this circle of safety for people. So, they could be more productive and be able to be productive in their own place and be able to really productively engage with children and families.”

- "In order to increase harmonious passion, CPS needs to boost morale."

- "It's all about leadership because if people lack passion, it brings morale down."

- "If they want to increase, they need to bring people in, they need to figure out how to boost morale and like I said, we need positive leadership to do that."

- "Boosting morale is needed to have stability for the children and the client that we serve. Stability within court systems. It creates more of a functional office. It increases morale." 
- "CPS leaders should come talk with us, that will help boost morale for us."

- "Social work morale is a major issue which needs to be addressed by CPS leaders."

- "Boosting morale among social workers will help with employees no feeling alienated and frustrated at work."

- "CPS leaders affect social work morale. Like I said before we feel unvalued and nobody is listening to us, which in turns lowers morale."

- "I look at things from a micro and macro level, and morale of social works is dependent on these levels which I am interested in analyzing and understanding to boost morale among my peers."

- "Poor working conditions and the high caseloads are impacting morale currently, but CPS leaders can assist in boosting morale by hiring the proper qualified people."

- "Low morale impacts the social workers motivations, which then leads to a decrease in the quality of services that we provide to the families."

\section{Category: Voluntary Turnover}

The category voluntary turnover emerged from participants discussing voluntary turnover among CPS SWs. Two themes (hiring practices and negative impact on agency) and one sub-theme (major voluntary turnover problem) were extracted from this category. Hiring practices was a theme derived from voluntary turnover, which describes one of the many ongoing issues regarding voluntary turnover. SWs stated a need to have qualified, skilled, trained supervisors who receive training on a regular basis 
and are active in the agency and community. Participants communicated hiring practices need to be revamped to hire more qualified licensed SWs. SWs are aware of the high voluntary turnover issue and understand the need for hiring unlicensed SWs; however, unlicensed SWs should be held to the same standards as licensed SWs upon entering into a SW role. Nineteen participants mentioned hiring practice for the voluntary turnover category.

- "I thought I would never say this, but CPS needs to hire more qualified license Social Workers. It is important to be licensed, because it comes with more responsibility and understanding of what the job encompasses."

- "The people being hired right now are not committed to the agency, and they are not here to remain or learn. Voluntary turnover will continue to be a problem if they don't change the way they select people to hire."

- "Voluntary turnover is critical right now at CPS, and they are just hiring people who don't qualify and give them large caseloads that they will not be able to handle. If they want to be able to put a dent in turnover, they are going to have to change the way they hire people."

- "CPS keeps hiring the same people over and over again. If a bad employee left of their own term, but decides to come back they rehire them. Because they keep rehiring the same employees who didn't contribute anything, it is leading to an increase in turnover."

- "I would say hiring the right social workers will help with voluntary turnover, the interview process needs to be consistent. So, they can't just ask random questions 
but I mean it takes a different kind of person to work here. Not just anybody or any profession can do this job."

- "To retain social workers, CPS needs to hire qualified social work supervisors."

- "The hiring process needs to be revamped. They need to weave out people that might not be the best fit or best fit for the agency."

- "CPS should investigate the social workers they are bringing on. Do a detail background check like we do for families that want to adopt. If we keep just hiring people who don't fit with the agency, we will continue to see turnover increase."

- "To retain social workers, CPS should change their hiring practices."

- "We need to hire more qualified people to serve the families we see on a daily basis."

- 'I think I really feel like, just from what I've seen in the field and different areas that I serve, is that we need to do a better job of hiring qualified and effective workers rather than just hiring somebody to fill the position."

- “We hire so many workers and they don't even last six months. I don't have the figures on it but I would guess that it's a high number as far as how many workers we have within a month or six months after receiving training. So yes, I think it's really bad right now."

- "I think a lot of people that we hire just want to be able to put it on their resume and just kind of use CPS as a stepping stone, when it's really a great job for social workers. So yes, the voluntary turnover is pretty bad right now." 
- "Because CPS hires unqualified social workers, peers have to spend more time with them to get them up to speed which takes a lot of time from the caseloads we have. If they hire more qualified people, it would help a lot with the caseloads and decreasing turnover."

- "You can hire somebody who has good grades, good personality but they don't have some values. I can't teach people certain things. Certain things have to come with them, integrity... has been one of those things. And values. And whether it's to yourself or to the agency, or just the value of knowing that I have committed myself to a job. So, we have to hire the most qualified people."

- "So, they need to hire qualified people. We have such a great need that we couldn't...there weren't enough social workers to help or we couldn't get enough social workers interested. And, there's a lovely hiring process that has to go through so many steps and hands that people can find a job in the interim from the time you interview them to the time the state office does hire them."

- "I feel that the majority of the people that come here, come and they're just not the right caliber of what we need and, I mean to be honest I feel like we'll hire anybody off the street to fill the position. And so, I feel like there are people here that are completely committed but the lack of commitment from the majority just makes it harder for those who are committed."

- "I believe that we need new management, to be honest. I believe that we need to hire licensed social workers. People who want to come to the field. It's a very difficult field to work in. So basically, I think for CPS to change, they need to start from the top and change it all." 
- 'Ideally in a perfect world this agency would be fulfilling what's expected of us and helping these children. But unfortunately, a lot of times I feel that we fail them because we're not hiring, professionals, if that makes sense. We're not hiring people who really, really see the mission and emphasize the importance of really working with that passion."

The second theme for voluntary turnover is the negative impact on the agency. When a SW leaves, the entire agency is impacted. First and foremost, the clients are impacted because they must relive and discuss their trauma to different SWs, which can be as many as six different SWs. Second, SW peers are impacted because they take on additional cases when someone leaves the agency. Last, the quality of work is reduced tremendously, as SWs are overwhelmed and are forced to do the bare minimum to complete assignments. These negative impacts influence organizational commitment and harmonious passion negatively for participants in this study. Twenty-four participants mentioned voluntary turnover negatively impacts the agency.

- "When a SW leaves, a case can turnover 3-6 times to a new worker who you have to sit down with and try to explain your (the client) whole life over again. And that's kind of disheartening and affects the agency negatively."

- "Well, the supervisor is impacted, but more than anything, I mean those professionals they can make their shift up, but the children, the families are the biggest impacted because it affects their trust level. You know, if you have a different case worker in 5 months you don't trust anybody. You don't trust the agency." 
- "The clients are impacted because we have clients that I have several clients since I've been here that since I've had multiple social workers, join them, the niche of my case. So, there's an inconsistency with that, cases are staying out longer because of the turnover and workers taking up a case and not really understanding it, so you're starting over and there's a lot of that going. Again, staff are being pulled out of their normal offices to go help a different office, so then you impact another office. It's just a lot of levels that you know, is being impacted."

- "Everyone is impacted. The client, the children. The community. The agency, your coworkers."

- "Everyone is impacted, the client, the children, the other staff members, and the supervisors."

- "The whole agency is impacted our clients, especially. I mean, I have to say they're probably more affected if you're working on them one-on-one. I mean, we do work one-on-one but say if you've been working with them for quite some time when you leave then that's a major impact."

- “The people impacted are, our clients, our customers, our families, and our children. Even our community is impacted by the fact that our turnover is so great and our providers. Because one minute you have this person that you are helping with a child and when you know the thing, and somebody else and so the dots are not connecting quickly to assist the child properly. Or their families."

- "The families and the community are impacted. Social workers are also impacted because of course, their colleagues, because if you're operating with three workers where you're supposed to have six in a single county, then of course it 
affects your colleagues, increases their chances of burn out and oversight on the work."

- "The children are impacted. Because they got to start over."

- "The rest of the social workers are impacted in the office because their caseload is just distributed to all the other workers. So, their caseload goes up."

- "Our clients are impacted. And then the stakeholders, the agency itself."

- "The clients are impacted."

- "The community and the clients are impacted."

- "Clients are impacted, because they got use to a certain worker and when that worker leaves they are not sure enough, I already established rapport with this worker, I feel confident with her, I feel like, you know, I know her, and I can trust her now, somebody else is coming out to see me. I don't know you, so I'm don't necessarily want to work with somebody else, or feel comfortable working with somebody else. So, the clients are affected as well. And maybe even some of our services because of workers having to pick up the slack from somebody voluntarily leaving the agency."

- "Our children are impacted, that's the most aggravating thing, our children. And our families. They're affected the most. Our family and our foster family. But our children who are in care, our children who are in crisis are affected the most. They're setting here, they're building relationship with someone who has a critical role in their lives and in all of the sudden that person is gone. That's another loss, that's another disruption for them. That's another getting away in their chain." 
- "Well, I mean from-from the bottom of the frontline, you have your clients. But then the clients are probably more used to turnover than anybody. If a case averages three-four year, they probably had 3-4 social workers per year, because the frontline may have moved up into the supervisor position or they found something better altogether. Just so the supervisor has to deal with spreading out the caseload amongst the other workers that are remaining. And then the regional director has to find somebody to fill in those slots. So, I mean, it's just always going to be something. It's always a domino effect when somebody leaves. You feel that pressure when somebody leaves."

- "The other workers are impacted. Their peers that are in the office with them are impacted. The supervision's, the supervisor is impacted and most importantly, the children and the families and the community that that worker was serving is impacted. Because every time we lose a worker, that family has to go through another worker."

- "The workers are impacted for the most part, the families are impacted. Because when a worker leaves and they've been used to dealing with a certain person, then you know, they're like oh yeah, here we go again. I've had my case open for six months and I've had three different social workers in six months. It impacts other social workers being that that worker leaves and I have to take the cases and divide them among other social workers and their workload has now become a workload of two people instead of the one workload of one person. It affects the children that are in care. So, they're used to this social worker and they got all these kids switching in and out of their lives. So, teach them not to form 
affectionate, you know, with people in which I leave here if I get close to you and you're going to leave, I'm just going to stay over here in my corner. Same thing for resource and all. If you switching children from home to home, they don't form attachment. I'm going to act out because I know you just going to get tired of me and want me to leave. So, it's just a lot of impact there when a social worker quits."

- "The children and the families are probably impacted the most. It's surprising you know, whenever you're talking to these families, how many different social workers they've had over the life of their case. They've met and have been involved with CPS for six months, a year, a year and half, two years, and they may have had 4, 5, 6 new workers during the entire case. I think it impacts the children and the families the most because they've established that or in some cases they've established that trust and relationship with that worker and when you're constantly having that turnover, I feel like it's just doing disservice to the family that we're trying to serve."

- "The families and children we serve are impacted."

- "Your community, your children, your schools, and your courts. Other workers and families. Because you leave them short notice and they're not prepared. Let's say you may have a family you just started working with. You up and leave and in that case, they turnover $3,4,5$ times to a new worker who you have to sit down with and try to explain your whole life over again. And that's kind of disheartening." 
- "The families that they were helping. For example, I have a family on my caseload now that they had a case for about a year now and I'm their sixth caseworker."

- "The kids, our caseloads, for one. And then all of us. The supervisors, the clerks. The direct line social workers, for sure they would be the second to the kids."

- "The whole agency. From top to bottom, as well as people in the community. Because you know when someone leaves-it's a lot invested to training a worker from everybody's behalf, from the workers to finances, tax payers, you know, things of that nature, the community. So, when someone you know, quits, especially when people say we not getting our money's worth. It's hard. So, everyone is impacted."

A sub-theme of voluntary turnover is the major voluntary turnover problem at $C P S$, which describes the SWs, who participated in this study, experience with voluntary turnover. Participants revealed that voluntary turnover is a major constant problem at CPS, and has been for many years. Interestingly, participants reported that smaller counties are not impacted by turnover as much as larger counties. This is partially due to smaller counties having more of an intimate setting, versus larger counties, where SWs may feel lost in a large setting. Furthermore, some employees are leaving within the first six weeks to six months of hire due to unrealistic training and feeling overwhelmed once on the job. Eight-teen participants mentioned voluntary turnover as a major problem.

- "It's awful. The workers, they come in and try to tie in the training they have received from the textbook. They don't get the reality training. When you come 
in, you go to training for eight weeks, you're told this from a book. But, you're not being told what's actually going on in your community."

- 'I think turnover is continuous, ongoing, and excessive. There's a high turnover rate. I do contribute to a lot of that on caseloads and just the burn out is what causes it."

- "In some counties voluntary turnover may not be as critical but I think overall, it's critical because you're not having worker retention, and you're bringing people in, hiring them and then give them these caseloads and they're already maybe in a county that's behind. So, you're handed this caseload and you're expected to perform $100 \%$, and you may have practice model coaches and your supervisor but sometimes the supervisors won't. So, it's overwhelming. The expectations are overwhelming."

- "I believe turnover at CPS is a revolving door. It's like going into a department store that has a revolving door, people going in and out, in and out, in and out. And to me that's what is going on now. So, somebody has to evaluate their look at that, investigate like we do when we get reports on children who are abused and neglected. Somebody needs to investigate that, there needs to be an internal investigation regarding that. So that we can see why is it that our workers are going in and out, in and out so quickly."

- "The current state of voluntary turnover is not good at CPS."

- "Turnover is a problem. Voluntary turnovers are one of those things that it's going to happen. I don't feel that it's any, because some of those things voluntary 
turnover comes right back and be rehires. It is a higher turnover rate at the moment."

- "Voluntary turnover is very negative because sometimes you don't even know that the person is gone until you go looking for them."

- "Right now, we have them, they stay no more than about like six months. So, it's very high at this point."

- "Current state is terrible right now, turnover is a major problem."

- "Voluntary turnover is problematic. High. They lay them on a special assignment right now when they're, another area, because I guess turnover or lack of staff. And you don't get told. You know, you kind of get told you have to do that."

- "I think turnover continues to be a problem, especially on the frontline investigation, foster care area. I think it continues to be a problem. I don't know if this is as bad as it was, five or six years ago, but it continues to be a problem, especially in high demand areas, which I have had to work in a high demand area or region, county. Turnover is still a major issue."

- "Turnover is especially a problem for frontline social worker staff. On our unit not so much, in licensing unit not so much. But frontline workers like in Washington County, we only have two supervisors left, for frontline that's left. And Washington County is one of the largest counties, so county C, and they are struggling with keeping, the people come out of the training, seeing the training for new workers and they may stay six months a year and then they gone. So, then a judge has something to do with Washington county, so the judge is very 
strict and a judge will often give the worker a fine. You know, if-you don't pay your fine she'll put you in jail if you don't do this so I think the judge does has something to do with that in Washington County, but most of it is they are not staying in that county and I think it's because Washington County it's a large county so and they have an influx of foster children. And the workers are very, very extreme and difficult cause they are changing policies now."

- "Voluntary turnover is high across the state. I don't know how to keep them here, I don't know how to keep workers here. But I do know that, one of the main keys is the supervision but it's very, very high voluntary turnover."

- "I would say turnover is not so good. I think we have a lot of voluntary turnover with workers who just leave the agency and they don't necessarily have another job and they are just fed up with a lot of the demands that are being put on them and then it's impossible to do with the number of workers that we turn out."

- "We hire so many workers and they don't even last six months. I don't have the figures on it but I would guess that it's a high number as far as how many workers we have within a month or six months after receiving training. So yes, I think it's bad right now. I think a lot of people that we hire just want to be able to put it on their resume and just kind of use CPS as a stepping stone, when it's really a great job for social workers. So yes, the voluntary turnover is pretty bad right now."

- "Voluntary turnover is awful at CPS. Like I said, the workers, they come in, they don't they're trying tie in the training that they get, they get the textbook training. They don't get the reality training. When you come in, when you go to training 
eight weeks, you're told this from a book. But, you're not being told what's actually going on in your community."

- "The turnover right now is constant. But like I said, this has been a problem for so many years it's, like I said, there's never going to be any change. That's just CPS."

- "Turnover varies from location to location. For example, the Southern county and coastal county have a higher turnover than some of the rural areas where you have workers that have been there for 20 plus years. A lot of it also, it's not just a matter of CPS, it also has to do with the agencies that we work with, like our court systems and law enforcement and middle health, and being able to have that support from those other agencies as well."

\section{Category: Organizational Support}

The category organizational support emerged from participants discussing why voluntary turnover is high, and organizational commitment and harmonious passion levels are low. Two themes were attained from this category: valuing SWs and support from leadership. SWs expressed that Valuing SWs is important. Participants expressed they do not feel that CPS administrators value the SW profession, and individuals marginalize their career choice as a SW. Not valuing SWs could decrease organizational commitment and harmonious passion, which leads to an increase in voluntary turnover, as cited by participants in this study. Eight-teen participants mentioned valuing SWs is important. 
- "SW is a real profession and should not be watered down; encourage staff to continue their education. Encourage them to be licensed. Offer incentives to support them to get extra training in areas that's going to benefit them."

- "I think they should value us and provide more recognition to frontline staff. I know it feels a lot of times that the higher-ups are removed from what's going on out in the field and I think that's important for the field workers to know that these people that are seeing what we do. And those making big decisions are aware of what they're seeing on a day-to-day basis, and I think that's very important for them."

- "Once you get your good social workers, pin them and appreciate them. Because you burn them out, and it's almost like the bad is more appreciated. So, you sort of left in the wing and in other words, it's your passion, you give it your all but that seems to not be appreciated. I just feel what I'm seeing now coming in, it's really disheartening to see because of what I see happening.”

- "Accountability across board, from every level, and make that accountability be fair and applied to all in the same manner, not just because in other words, it is wrong when someone, Sue did it, it should be wrong when Sally do it. And then just those incentives, again, pay raise. You're not getting paid enough to do what you do and deal with what you're dealing with daily. And the support system from leadership. So, the benefit of all that you're saying you're doing to improve that agency. You don't see the benefit of it."

- "I want to say it's going to go back to being supportive of the workers. Because a lot of times we get a lot of flak from certain judges and not having that support 
in front of the judge or wherever. You know, I think I hear a lot of workers complaining about that. Also, not being appreciated. I hear a lot of workers upset about that as well."

- "Value SWs by promoting more success stories. They're not all happy endings, I get that. But promote the good news. Because we're all here about the bad stuff that happens. Or I'd say more about the good stuff that happens and I think that will be really nice."

- "I believe that more training is needed for your supervisors in charge, so that they will know how to show appreciation to their employees, those social workers and a little praise. We know that is what we tell the parents. That's what we try to give the children, it will go a long way even when you are underpaid and overworked. It's just saying okay job well. And I think that they were doing that quite frequently, they even had Social Work Day but they kind of lagged off of that, but sometimes we have to encourage ourselves and that's what we tell our clients."

- 'I do feel that the job kind of, you know you shouldn't get a pat on your back every time you do something. I've heard it's left to the individual social workers,' supervisors to handle that. But you know, praise from higher-ups and just to say, we do recognize the county offices and things of that nature because it's almost as that we go work in the field and then you have a state office that's looking down on you but they're not communicating with the county offices so it's almost as a foreign agent there." 
- "We would like to be rewarded and appreciated, not every day, but let us know that we are a valued asset to the agency."

- 'The support, the respect. The individual workers' knowledge and skills that they bring to the table. The pay you got for your work, the whole work you do. Just really for management. Just more treating your employees like we social workers treat our client. With your basic bounty, social work county that shows your social workers are valued."

- "I think the back end, it plays a part of it, feeling appreciated, and this is within any organization, feeling appreciated that what they think matters that they value their employees."

- "I think it goes both ways. I think the organization needs to value that social worker and have the line of communication open both ways. So, I think it's a mutual respect type of thing. If that agency values the employee, then that employee should value and recognize that company's investment in them as well as that information. So, it's just that relationship."

- "The company needs to value that employee and then have the employee and the company have a mutual respect."

- "But I think that if the organization's value its social workers. Like we do, I'm glad that they had a raise in pay. Which is great. However, they should provide CEUs. Everybody is not encouraging anybody to go higher than your Master's, which is I think is crazy because in CPS it's a clinical thing. So, I would think that they would have somebody who has a licensed clinical social worker, you know, on the upper-upper administration. And they will have a program 
designed to take those workers and groom them to be clinical social workers. I think that was a kind of, you know... served as a good reason to stay with the organization a long time."

- "But I think they need to invest in the welfare of your workers is so important because the workers invest in the welfare of society and the welfare of our children. So, we must invest in our workers wellbeing. Because if you don't invest in their wellbeing they are going to burn out, and they are going to make mistakes and then they going to start-because they are going to-come to point where they are going to seek other jobs."

- "I believe that they need to still be valued, specifically with CPS, you know, there's a lot of different, avenues or areas that you know, go into work now. I think we have the court system, then we have you know, our side contracted agencies that come in and help. Just the work that we do a lot of times it's not valued. People don't take us seriously. I know I believe that has a lot to do with the specific person."

- "If you feel like your agency values you and appreciates you and respects you, that, of course is a win."

The second theme is support from leadership, participants reported, to increase organizational commitment and harmonious passion among SWs, support from leadership is critical. Within this theme, pay increase was also mentioned; however, SWs voiced that pay was not important as they knew SW was not a lucrative field upon entrance. Yet, to offset low salaries, having support from leadership with regards to 
providing additional up-to-date realistic trainings and valuing their career would be beneficial. Twenty-three participants mentioned support from leadership is important.

- "It's all about support and unity, and mutual respect. And everybody understanding that not one person can do this job completely by themselves."

- "I think that first they need the support of the organization. I think that they need to feel that they are worth something to that employer, or to an agency, but I also feel like they need to be able to have access with the training and salary to make them feel like what they're doing is worth something. I know as frontline worker when I was working the first time, you felt like you were the one out there that weren't getting the compensation that you needed. For that one it's not about the money. You also have to have a way to live off of it and whatnot. I think social workers are overworked and underpaid."

- "The higher-ups need to be supporting as well. I get that they have tons of stuff to do in the state office and I would not want to be doing that. But to send down an email every now and then, to be acknowledged. Just randomly to frontline worker, which probably pays really nice, I think."

- "Without support, voluntary turnover increase."

- "Increase pay and just more support from those in higher up positions. Support is everything. You can have a great team but without the correct support, it doesn't even matter."

- "Well it begins with the support. And so that means engaging and listening to the employees and what they're saying and interacting with them on a level that they understand. I mean, everyone would not have the opportunity to engage 
with the workers who are in the field, but as much as possible. That will help a lot. And children, that you are interested and concerned about the things that they are interested in and concerned with. And I think it would work. I think if it's much as organized as possible with less people as possible and it is a lot of chefs in the kitchen and not enough cooks. Something like that because you can't have too many people giving so many directions and nothing is exactly heard. Sometimes we encounter that."

- "We need extra support from CPS leaders, specifically immediate supervisors." - 'I feel that they need to listen to us more that sometimes something can't do, be done at our time schedule, that sometimes it happens to go over. So, they need to listen to us more and realize okay, we do know that this can't be done in this time, and if we can give you a little more. You know, be flexible sometimes."

- "Ongoing training and support. Mostly ongoing support and training."

- "We need ongoing support and flexibility."

- "In order to increase organizational commitment, we need managerial support."

- "You definitely need good supervision, and you need to be able to have support. And that's just not from your immediate supervisor, but I think it needs to come from the state office, all the way down to the county."

- "It is important to have a supportive supervisor to increase organizational commitment and harmonious passion."

- "Well I think they should take our suggestions seriously because we are the people doing frontline work and we know what we're talking about. I know that it might be hard to advocate but it just seems like the more we talk about these 
things, the less it gets accomplished and then we feel like we're not being supported. So, if you don't feel that support from your administration then of course if you see something that's going to strike the issues, whether that be lower pay, not full time, you better jump on in. Just because you don't want to have to deal with all of the stress of having somebody not support you in your career."

- "The thing that would make it easier is a lot of support, support from other management in general, in dealing with child protection services. It is easier for upper management to fit in their office and dictate what needs to happen in the field, and without extra coming into the field and getting suggestions or talking to the social workers and talk to the supervisors. That, I just feel that would help, you know, guide the agency in terms of basically getting out of this low point that we have been in."

- "I think the current state of commitment, yes, it's their ground. I would say that at least about $40 \%$ of the workers I supervise, they're not happy in their position. They're always talking about leaving and because of the lack of support and there are so many demands being put on the field staff. Some things are just impossible when we don't have enough workers. And the quality is to achieve the goals and task that they have for the workers in the field."

- "I think the biggest thing is salary and the support from upper management. And them willing to come out into the field and have those hard conversations that sometimes people don't want to have. I mean you must listen, be willing to listen 
to the staff. You don't necessarily have to always agree with what they're saying but at least you can listen."

- "Honestly, I would probably have to say the support of your higher ups. I think some of us would like we work and work and work and still something else, you know, it's not done and it's not good enough and you know, some us have children. You know, we sacrifice our home and family life. You know, they try to make the other things better and I think just sometimes just acknowledging that you know, would make us want to do our job and not that we don't. You know, I just think some acknowledgment would help.”

- "I think really just sticking, you know, behind your employees and just making sure they know that they've got somebody to support them in the work that they're doing."

- "Social workers do not feel like they have that kind of support so I guess you can, you can do this."

- "A lot of it also, it's not just a matter of CPS, it also has to do with the agencies that we work with, like our court systems and law enforcement and middle health, and being able to have that support from those other agencies as well."

- 'It's all about support and unity, and mutual respect. And everybody understanding that not one person can do this job completely by themselves."

- "When situations are hard, you got to sure be supportive, you know, to social workers." 
To summarize the results of the qualitative data, low organizational commitment and harmonious passion has an influence on voluntary turnover and the retention of qualified licensed SWs. Voluntary turnover does not affect smaller counties as much as larger counties; however, there is still a great deal of voluntary turnover within the agency. Valuing employees, boosting morale, support by leaders, among other items are needed to increase organizational commitment and harmonious passion. Categories and themes derived from the data is outlined in Table 8 .

Table 8

\section{Qualitative Matrix}

\begin{tabular}{ll}
\hline \multicolumn{1}{c}{ Category } & \multicolumn{1}{c}{ Themes } \\
\hline Values and Experience & $\begin{array}{l}\text { Theme 1: Helping and encouraging people } \\
\text { Theme 2: Rewarding }\end{array}$ \\
Organizational Commitment & Theme 1: Commitment to the agency and vision \\
Harmonious Passion & $\begin{array}{l}\text { Theme 1: Motivation } \\
\text { Sub-theme 1: Boosting Morale }\end{array}$ \\
Voluntary Turnover & $\begin{array}{l}\text { Theme 1: Negative impact } \\
\text { Theme 2: Hiring practices } \\
\text { Sub-theme 1: Major voluntary turnover problem }\end{array}$ \\
Organizational Support & $\begin{array}{l}\text { Theme 1: Valuing SWs } \\
\text { Theme 2: Support from leadership }\end{array}$ \\
\hline
\end{tabular}

Mixed Methods Analysis and Results

To describe the effects of organizational commitment and harmonious passion on voluntary turnover. The researcher integrated the quantitative and qualitative data by examining the level of each construct and comparing the responses from the quantitative and qualitative data. The data was analyzed concurrently for triangulation purposes. The 
researcher prepared the data for coding and transcription of text, reviewed and explored data, analyzed data, and represented data in tables to analyze and synthesize the data that was collected quantitatively and qualitatively. Both designs were given equal priority. Even though the multiple regression showed organizational commitment and harmonious passion do not significantly influence intent to leave. The low scores of organizational commitment and harmonious passion were explained in greater detail via the one-on-one semi-structured interviews.

The scores from each commitment scale (affective, continuance, and normative) were relatively low. The qualitative data supported the low scores with an explanation of why the scores were low through the lived experience of the participants. The participants of this study expressed organizational commitment is important; however, commitment is low amongst the SW population because of the high voluntary turnover and not feeling valued as an employee. The z-scores for both harmonious and obsessive passion were close to zero; therefore, there was no major difference between the two. However, the participants articulated they are passionate about the field of SW, and without passion one could not properly do the job. They also discussed the difficultly of separating work from home and not letting work incidences influence their daily lives. Many of the participants struggle to find a balance between home and work. Furthermore, the anticipated turnover score and the intent to leave questions expressed similar results. The score was low for anticipated turnover, and 15 of the 29 participants stated in their interview they do not intend to leave the agency. It is important to mention seven of the 15 participants were nearing retirement. Though they near retirement, they are trying to pass on wisdom and knowledge to SWs who will remain with the 
organization. If the knowledge is passed down successfully, this may have a positive impact on stakeholders.

\section{Validation of Findings}

The researcher used two components of internal validity to validate the findings of the study; triangulation and member checking (Zohrabi, 2013). Triangulating data is essential to mixed-methods research because it allows researchers to validate findings using multiple methods, such as numerous sources, methods, investigators, and theories (Creswell, 2013). Denzin (1978) suggests that researchers collecting data use multiple methods to validate the findings of their research. To ensure credible research, an individual must have adequate evidence to support an argument (Eisner, 1991). Therefore, the researcher used data source triangulation, also known as member checking, by conducting individual interviews with different SWs from various regions across the southern United States. In addition, member checking helped triangulate the qualitative data. The researcher asked participants to note whether they successfully described experiences by allowing participants to review individual transcripts for accuracy.

In addition, the researcher used content validity to validate the instruments used for the study. Content validity is the use of different behaviors, elements, and skills to best measure the instruments used in the study (Zohrabi, 2013). Numerous research studies validated the instruments used for the quantitative data portion of the study. Three colleagues assisted with validating the qualitative instrument. By using three SW colleagues to validate the interview script, the researcher was able to make changes to the questions, to make certain the questions were clear and understandable to the participants. 
Lastly, the use of the concurrent mixed methods design validates findings from the quantitative and qualitative data (Wisdom \& Creswell, 2013). According to Wisdom and Creswell (2013), the concurrent mixed methods design allowed the researcher to collect data simultaneously, separately analyze both types of data, and compare results side by side. The two types of data provided validation for each design and the researcher was able to draw findings and conclusions from the data.

\section{Summary}

The purpose of this concurrent mixed methods study is to explore and examine the effect organizational commitment and harmonious passion have on voluntary turnover among CPS SWs. The instruments used to measure the perception of organizational commitment, harmonious passion, and intent to leave among CPS SWs was a survey. In addition, interviews were used to capture the lived experiences of CPS SWs. Interviews were practiced with SW colleagues to ensure questions were appropriately probing and understandable. The quantitative instrument was distributed electronically to 370 CPS SWs, which resulted in 226 completed surveys, with a response rate of $61 \%$. The qualitative instrument was administered via telephone to 29 CPS SWs. Based on the data, CPS SWs that participated in this study express relatively low levels of organizational commitment and harmonious passion; however, there is a high chance of the participants remaining with the organization. Additionally, the multiple regression analysis did not show a significant relationship between intent to leave and organizational commitment and harmonious passion. The qualitative data revealed that organizational commitment and harmonious passion is low, and voluntary turnover among SWs negatively impacts the clients, SWs, and the agency, which results in increased 
workloads and voluntary turnover. The final summary and conclusions of this study are discussed in Chapter V. Implications and recommendations for future studies will also be discussed and presented. 


\section{CHAPTER V - DISCUSSION}

Chapters I through IV discussed the influence of organizational commitment and harmonious passion on voluntary turnover among CPS SWs. Chapter V presents a summary of the study, along with the findings, conclusions, and recommendations. This chapter also discusses the implications of the study and future research recommendations.

Summary of the Study

The purpose of this concurrent mixed methods study is to explore and examine the effect organizational commitment and harmonious passion have on voluntary turnover among CPS SWs. Two types of instruments were used to collect data, a survey and semi-structured interviews. The survey measured the levels of organizational commitment, harmonious passion, and the SWs intent to leave. The interviews explored CPS SWs perception of organizational commitment, harmonious passion, voluntary turnover, and intent to leave. The researcher used two methods to sample the selected population, a census for the quantitative design and purposive sampling for the qualitative design. The target population for the present study were SWs within CPS located in the southern United States. At the time of data collection, CPS employed 370 SWs across 14 regions (Deputy Commissioner of Human Resources \& Administration, personal communication, January 1, 2018). The researcher collected 226 surveys and conducted 29 interviews. The participant's levels of organizational commitment, harmonious passion, and intent to leave were low. Furthermore, the SWs provided an explanation of why the levels of organizational commitment and harmonious passion were low, and expressed voluntary turnover is a result of unmanageable caseloads, low 
commitment, unbalanced home and work life, not feeling valued, experiencing high voluntary turnover on a regular basis, which was discussed in Chapter IV.

\section{Summary of Results}

The predictors affective commitment, normative commitment, continuance commitment, and harmonious passion account for $3.1 \%$ of the variance in anticipated turnover. Therefore, no relationship was found between the independent variables (affective commitment, normative commitment, continuance commitment, and harmonious passion) and the dependent variable (anticipated turnover). There were five categories, eight themes, and two sub-themes discovered during the qualitative data analysis. The themes are supported by rich data collected from the participants via oneon-one interviews. The identified categories and associated themes incorporated for this study are listed in Table 9.

Table 9

\section{Qualitative Matrix}

\begin{tabular}{ll}
\hline \multicolumn{1}{c}{ Category } & \\
\hline Values and Experience & $\begin{array}{l}\text { Theme 1: Helping and encouraging people } \\
\text { Theme 2: Rewarding }\end{array}$ \\
Organizational Commitment & Theme 1: Commitment to the agency and vision \\
Harmonious Passion & $\begin{array}{l}\text { Theme 1: Motivation } \\
\text { Sub-theme 1: Boosting Morale }\end{array}$ \\
Voluntary Turnover & $\begin{array}{l}\text { Theme 1: Negative impact } \\
\text { Theme 2: Hiring practices } \\
\text { Sub-theme 1: Major voluntary turnover problem }\end{array}$ \\
Organizational Support & $\begin{array}{l}\text { Theme 1: Valuing SWs } \\
\text { Theme 2: Support from leadership }\end{array}$ \\
\hline
\end{tabular}




\section{Findings and Conclusions}

The following section includes findings based on the results presented in Chapter IV. The findings and conclusions are based on the researcher's interpretation of participant responses from the survey and interview. This section links the findings to the problem of what is influencing SWs to voluntarily leave, through the examination and exploration of CPS SWs perception of organizational commitment and harmonious passion. Also, the limitations, implications of the study, recommendations for future research, and discussion are presented.

\section{Organizational Commitment Perceptions}

Low organizational commitment reduces the quality of work produced by SWs, influences absenteeism, and voluntary turnover intentions (Barak et al., 2001). In addition, low organizational commitment negatively impacts the children, families, and communities they serve. CPS SWs are the face of the agency, understanding their perception is vital not only to increase organizational commitment and decrease voluntary turnover, but also improve the quality of services provided by the organization.

Finding. Valuing employees and support from leadership is vital to increasing organizational commitment among CPS SWs.

The majority of interview participants expressed the importance of valuing SWs within the organization. SWs do not feel their profession is valued, compared to other professions, such as lawyers and doctors, which SWs often encounter via the court system. Feeling undervalued lowers the self-esteem of the employee, and increases chances of voluntary turnover. Almost all participants expressed the importance of having support from leadership. Without support and respect, the employee may feel 
undervalued, levels of commitment may decrease, and chances of voluntary turnover may increase.

Conclusion. The results of this study indicate that when employees are not valued, they express low levels of organizational commitment. The SWs who participated in the current study want to feel their contribution to the organization is important. Valuing employees and their contribution to the organization is essential to increase organizational commitment. In addition, support from leadership is critical to increase organizational commitment. This study supports the findings from Testa (2008) in that commitment increases when individuals are valued. The study also supports the findings from Lapointe and Vandenberghe (2017), which suggests good leadership increases organizational commitment and employee retention.

Recommendations. To ensure SWs are valued and have adequate support from leadership, CPS leaders should boost morale amongst the agency and show they value employees by recognizing personal milestones. For example, celebrating employees' tenure with the agency for as little as six months. Additionally, leaders should make themselves available to listen and engage with employees by asking probing questions and soliciting ideas that may enhance the agency. CPS leaders should communicate success stories to let SWs know that their work is appreciated. Communicating success stories, not only conveys to SWs that their work is valued, but organizational commitment may increase due to the employee feeling valued by the organization. Lastly, leaders should be transparent. Employees' organizational commitment decreases when they feel they are not a part of the agency. For instance, when employees receive 
bad news via media coverage instead of through agency leaders, the news may discourage and make SWs feel undervalued and unsupported.

\section{Harmonious Passion Perceptions}

An individual who possesses harmonious passion is motivated by their work harmonizing with outside activities (Deci \& Ryan, 1985). Harmonious passion exists when an employee's activity becomes a part of their identity. Harmonious passion fuels and enhances peoples' everyday life (Vallerand et al., 2003). For example, an employee strives for a balanced home and work life. However, if home and work are not in harmony, it can affect the employees' life negatively. Additionally, when someone embodies harmonious passion they are in control of what occupies their life.

Finding. Boosting morale is critical for increasing harmonious passion among CPS SWs.

Most of the interview participants expressed the importance of boosting morale to increase harmonious passion. SWs noted morale is extremely low, as a result of lack of recognition for hard work. Overall morale among SWs has declined over the past few years. The SWs mentioned that morale was low because of dissatisfaction with CPS leaders.

Conclusion. Morale among CPS SWs has been declining over the past three years, and continues to decline. Furthermore, the lack of growth opportunities for employees who have continued their education to enhance the quality of services of the agency lowers morale. The lack of upward mobility hinders the overall morale within CPS. Lastly, work and life balance is a critical factor for increasing morale. Having a balanced home and work life increases harmonious passion. This study aligns with 
previous research exploring the general public. Phillipee et al. (2010) states that individuals must view what they do as a part of their identity to increase employee morale or motivation.

Recommendations. To increase morale among CPS SWs, CPS leaders should invest in providing additional counseling services for employees. Counseling services could allow the SW to talk in a safe environment about daily experiences at work. Without adequate counseling sessions, the employee may take their work home, which decreases harmonious passion. It is important for SWs to understand how to balance work and home life. Also, training would provide tools for how to separate work stressors from home. The proper tools provided by the agency can assist with increasing harmonious passion among CPS SWs. Moreover, CPS leaders can boost morale by listening and incorporating feedback they receive from employees. By incorporating feedback received from employees, leaders can help employees feel valued. Furthermore, CPS leaders should invest in employees; specifically, encouraging employees to continue their education. Encouraging employees to continue their education enhances the quality of services provided by the agency, and could be a major morale booster among employees.

\section{Voluntary Turnover Perceptions}

CPS loses hundreds of SWs annually (Liederman, 2003). As voluntary turnover increases, SWs who remain experience an increase in caseloads. Voluntary turnover may be detrimental to organizations as turnover can impact the goals and objectives outlined by the organization (Long et al., 2012). Voluntary turnover typically consists of the most 
talented employees leaving the organization, which is why the effect can be negative to the company (Long et al., 2012).

Finding. Voluntary turnover among CPS SWs negatively impacts the agency and the clients they serve.

All interview participants expressed voluntary turnover negatively impacts the agency and the clients they serve. Participants reported that voluntary turnover is a major and constant problem at CPS. Because of the high voluntary turnover, clients can encounter as many as six or more SWs for their case. Without retaining qualified licensed SWs, organizational commitment and harmonious passion will continue to be low; and voluntary turnover will continue to increase for CPS SWs.

Conclusion. All levels of the agency are impacted, specifically when a qualified licensed SW leaves. First and foremost, the clients are impacted because they must relive their tragedy with each new SW assigned to their case. Second, SWs are affected, as the caseload of SW who leaves must be divided among remaining employees. Lastly, the quality of services provided by the agency is impacted due to an employee's increase in caseload. The constant voluntary turnover among CPS SWs has a negative impact on the agency, which aligns with existing literature. This study supports the findings of Tollen (1960), which concluded high voluntary turnover affects the quality of services provided to the community. Furthermore, the study supports Spain \& Groysberg's (2016) study, which indicates voluntary turnover can have a negative influence on the organization, which can result in the loss of skilled and knowledgeable employees.

Recommendations. To improve the retention of qualified licensed SWs, the agency should value SWs, as they are the individuals the community encounters most 
often. CPS should revamp hiring practices to assist with selecting the most qualified candidates to serve as SWs. CPS hiring authorities should use behavioral questions, and a consistent format for all candidates to assess the best fit for the agency. Furthermore, CPS should offer an incentive for unlicensed individuals to become licensed SWs. For example, the agency could offer scholarships to cover fees for study materials and licensing exam. As a result of hiring more licensed SWs, the quality of services provided by the agency could increase and provide stability for not only the agency but the clients as well. Additionally, CPS should update SW training materials. The current training SWs receive are outdated and unrealistic. The researcher recommends training offered to CPS SWs by re-examining the material bi-annually to ensure curriculum is up-to-date and applicable. Lastly, CPS leaders and immediate SW supervisors should provide support for SWs. Increasing support may decrease voluntary turnover.

\section{Implications of the Study}

CPS is perceived by the community and prospective employees as a difficult place to work. Research acknowledges, CPS has a reputation for continuous voluntary turnover, low salary, poor leadership, an unqualified workforce, and stressful working conditions (Aarons et al., 2011; Newman et al., 2014). Compatible with literature, Coomber and Barriball's (2007) study examined intent to leave and voluntary turnover, the participants of this study perceived similar issues. The results of this study could increase the quality of services provided by the agency for stakeholders, including clients and the community.

The results of the study also convey that seasoned employees, individuals that have been with the agency more than 15 years have passion for what they do, and are 
committed to the organization. Having more passionate SWs, could create a stable qualified workforce, which can potentially provide an improvement in the quality of services clients and the community receive. Lastly, it is important to look at the financial impact voluntary turnover has on the agency. From the results of the qualitative data, the participants expressed new SWs are continuously hired; however, within the first two to six months, many SWs leave the agency. As mentioned in the literature, replacing an employee can cost 50-200\% of the employee's salary (Newman et al., 2014). The high cost of continuing to replace employees impacts the budget, and could cause less qualified individuals to be hired.

Furthermore, voluntary turnover places a burden on the employees remaining, as they must bear additional cases from those leaving the agency. The remaining employees' levels of organizational commitment and harmonious passion decrease as workload increases, which can cause low quality of work and impact the clients negatively. Administrators could focus on increasing organizational commitment and harmonious passion, to retain qualified licensed SWs. This study found that if CPS invests in appropriate training and values and supports SWs, they may be able to increase organizational commitment, harmonious passion, and capture and retain qualified licensed SWs who will commit not only to the agency, but to the mission, vision, and goals outlined by the organization.

\section{Limitations}

Limitations of the current study are items that impact the study, but cannot be controlled by the researcher. Interpretation of the results can be impacted as a result of the limitations of the study. This study is limited to the response of participating CPS 
SWs located in the Southern United States. The decision to focus on this population was made because the researcher assumed they were knowledgeable about voluntary turnover among CPS SWs, and were the most appropriate population to measure organizational commitment and harmonious passion. An agency that does not employ as many SWs are less likely to provide valuable information to the research objectives outlined by the study.

\section{Recommendations for Future Research}

To garner a more meaningful understanding of what influences voluntary turnover among CPS SWs, future research should explore the lived experience of SWs who resigned from CPS within three years. While the three-component organizational commitment questionnaire, passion scale, anticipated turnover scale, and scripted interviews were used to measure CPS SWs perception of organizational commitment and harmonious passion, future research could integrate other scales such as job satisfaction to measure influences of voluntary turnover. Because affective commitment is the most critical component of the three-component model, future research could further examine affective commitment and explore strategies to increase affective commitment within an organization.

\section{Discussion}

Using a mixed method design allowed the researcher to garner an understanding of CPS SWs located in the Southern United States. Organizational commitment and harmonious passion is important; previous research notes that organizational commitment can influence voluntary turnover. However, the quantitative results from this study showed no relationship between organizational commitment and harmonious passion on 
voluntary turnover. For the qualitative aspect, participants acknowledged organizational commitment influences voluntary turnover. Organizational commitment and harmonious passion can impact the quality of work and care provided by SWs. By offering training, and increasing organizational commitment and harmonious passion, CPS SWs may have a positive experience with the organization.

By conducting this research, the researcher hopes that CPS leaders understand how SWs, who participated in the current study, perceive organizational commitment, harmonious passion, and voluntary turnover and how these constructs can impact CPS. Acknowledging the importance of organizational commitment and harmonious passion, along with the importance of reducing turnover and retaining qualified licensed SWs, administrators should incorporate the recommendations outlined in the study for increasing organizational commitment and harmonious passion.

The findings of this study reveal no relationship between affective commitment, normative commitment, continuance commitment, and harmonious passion and anticipated turnover. However, the interview participants suggest a relationship exists between the organizational commitment and harmonious passion on voluntary turnover. Even though the analysis showed organizational commitment and harmonious passion were not statistically significant on voluntary turnover, the data collected showed a low score for organizational commitment and harmonious passion, and the qualitative data provided an explanation of why the scores were low. Organizational commitment and harmonious passion are vital to the organization and can impact the quality of work, and contribute to voluntary turnover among individuals with less tenure. An overwhelming number of SWs expressed that organizational commitment, harmonious passion, and 
retaining qualified SWs is essential for a successful agency and providing quality services to the clients and communities they serve.

The results of this study indicate SWs, who participated in this study, believe organizational commitment is important, but low organizational commitment is the result of feeling undervalued, receiving unrealistic job expectations through training, and receiving little support from agency leaders. Because organizational commitment is low among SWs, the quality of work suffers. Increasing organizational commitment can potentially lead to decreasing voluntary turnover. Additionally, the results of this study indicate harmonious passion is important, but low harmonious passion is the result of low morale. Because harmonious passion is low among SWs, the difficulty of having a balanced home and work life increases. Increasing harmonious passion can potentially lead to higher morale because the SW will feel supported and valued. Lastly, voluntary turnover remains high and a major problem for CPS. All levels of CPS are impacted when SWs leaves the agency. On the contrary, the results of this study indicate a small chance SWs will leave.

Decreasing voluntary turnover starts at the top with leadership, as leaders are the individuals who influence organizational commitment and harmonious passion. Because voluntary turnover is high among SWs, the agency lacks a stable and qualified workforce, which potentially negatively impacts clients and the communities they serve. Decreasing voluntary turnover and hiring and retaining qualified licensed SWs can potentially increase organizational commitment and harmonious passion. 


\section{Summary}

This chapter provided a summary of the study and the interpretation of the results. Findings, conclusions, and recommendations were presented and aligned to the literature of organizational commitment, harmonious passion, and voluntary turnover. The threecomponent model of commitment (Meyer \& Allen, 2004) and the self-determination theory (Deci \& Ryan 195) formed the theoretical framework of the study; which explained the importance of having commitment, specifically affective commitment, and harmonious passion to decrease voluntary turnover and increase the quality of services provided by the agency.

The purpose of the current study is to explore and examine the effect organizational commitment and harmonious passion have on voluntary turnover among CPS SWs. This study utilized multiple regression to determine if there was a relationship between the independent variables (affective, normative, and continuance commitment and harmonious passion) and the dependent variable (anticipated turnover). In addition, the study also utilized content analysis to reveal the participants perception of organizational commitment, harmonious passion, voluntary turnover, and intent to leave. The content analysis allowed the researcher to identify categories, themes, and strategies to improve the retention of qualified licensed SWs. The quantitative and qualitative results support the researcher's findings, conclusions, and recommendations. By valuing SWs, boosting morale, and retaining qualified SWs, CPS may increase organizational commitment, harmonious passion, and decrease voluntary turnover. With the adequate tools and resources, more qualified SWs may decide to stay; further, unlicensed 
individuals may become licensed to improve the quality of services provided by the agency. 


\title{
APPENDIX A - IRB Approval
}

\author{
f \\ (1) THE UNIVERSITY OF \\ IIIIII SOUTHERN MISSISSIPPI
}

INSTITUTIONAL REVIEW BOARD

118 College Drive \#5147 | Hattiesburg, MS 39406-0001

Phone: 601.266 .5997 | Fax: 601.266 .4377 | www.usm edu/research/institutional.review.board

\section{NOTICE OF COMMITTEE ACTION}

The project has been reviewed by The University of Southern Mississippi Institutional Review Board in accordance with Federal Drug Administration regulations (21 CFR 26, 111), Department of Health and Human Services (45 CFR Part 46), and university guidelines to ensure adherence to the following criteria:

- The risks to subjects are minimized.

- The risks to subjects are reasonable in relation to the anticipated benefits.

- The selection of subjects is equitable.

- Informed consent is adequate and appropriately documented.

- Where appropriate, the research plan makes adequate provisions for monitoring the data collected to ensure the safety of the subjects.

- Where appropriate, there are adequate provisions to protect the privacy of subjects and to maintain the confidentiality of all data.

- Appropriate additional safeguards have been included to protect vulnerable subjects.

- Any unanticipated, serious, or continuing problems encountered regarding risks to subjects must be reported immediately, but not later than 10 days following the event. This should be reported to the IRB Office via the "Adverse Effect Report Form".

- If approved, the maximum period of approval is limited to twelve months.

Projects that exceed this period must submit an application for renewal or continuation.

PROTOCOL NUMBER: 17120705

PROJECT TITLE: The Affects of Organizational Commitment and Harmonious Passion on Voluntary Tumover among Social Workers: A Mixed Methods Study

PROJECT TYPE: Doctoral Dissertation

RESEARCHER(S): Ashley Scales

COLLEGE/DIVISION: College of Science and Technology

DEPARTMENT: Human Capital Development

FUNDING AGENCYISPONSOR: N/A

IRB COMMITTEE ACTION: Expedited Review Approval

PERIOD OF APPROVAL: 01/03/2018 to 01/02/2019

Lawrence A. Hosman, Ph.D.

Institutional Review Board 


\section{APPENDIX B - Permission to Access Population}

February 01,2016

Ms. Ashley Scales

730 East Beach Boulevard

Long Beach, MS 39560

\section{Dear. Ms. Scales:}

Congratulations on reaching this point in your course of study. I completed my undergraduate degree at the University of Southern Mississippi, many years ago, and consider myself fortunate to have attended such a great institution. I appreciate your consideration of the Department of Human Services as you prepare for your dissertation proposal. Please accept this letter as confirmation of my full support of your request. There are many changes occurring within the Department which should provide you with an opportunity to gather great information.

I consider staff to be our most valuable resource. The executive management team recently worked with a professor from Brandeis University to assist us with identifying methods to improve employee satisfaction and retention rates. The Department also has a leadership development unit which has worked closely with our national partners at the American Public Human Services Association to embed leadership development within the organization at every level. My staff and 1 will eagerly assist you in any way you deem appropriate.

Deputy Administrator for Administration, supervises the Department's support services divisions including the Division of Human Resources and will act as a liaison to facilitate your research project. Jacob may be contacted via email at or telephone

you would like to share, I would like very much to see a copy of the paper you are presenting in Jacksonville, Florida. Should you need my assistance, do not hesitate to contact me via email at or telephone

Sincerely,

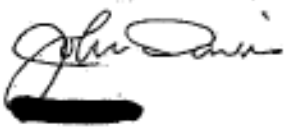

JD:sk

cc:

Dr. H. Quincy Brown, Department of Human Capital Development 
APPENDIX C - Authors' Permission to Use Instrument

M Gmail

Ashley Scales <scalean@gmail.com>

TCM Employee Commitment Survey | Academic Download

1 message

info@employeecommitment.com <info@employeecommitment.com>

Thu, Apr 28, 2016 at 10:07

Reply-To: info@employeecommitment.com

To: scalean@gmail.com

TCM Employee Commitment Survey | Academic Download

Name: Ashley Scales

Email: scalean@gmail.com

To download a copy of the TCM Employee Commitment Survey - Academic Package, please click the

following link: http://employeecommitment.com/TCM-Employee-Commitment-Survey-Academic-Package-
2004. pdf 


\section{Re: Permission to Use Passion scale \\ 3 messages}

Bob Vallerand <vallerand,bob@gmail.com>

To: Ashley Scales <scalean@gmail.com>

Thu, Jan 5, 2017 at 3:26 PM

Hi Ashley,

Of course you can. You can find it on our website.

Good luck with your research and all the best for the New Year!

$\mathrm{Bob}$

Robert J. Vallerand, Ph.D., FRSC

Chaire de Recherche du Canada/Canada Research Chair-1

in Motivational Processes and Optimal Functioning

Professeur de Psychologie Sociale

Professor of Social Psychology and Director

Laboratoire de Recherche sur le Comportement Social

Département de Psychologie

Université du Québec à Montréal

Local SU-4325

(514) $987-4836$

http://www.Ircs.uqam.ca

Fellow

Institute of Positive Psychology and Education

Australian Catholic University

For more on passion: see my recent book on the Psychology of Passion with Oxford University Press.

On Thu, Jan 5, 2017 at 6:21 PM, Ashley Scales <scalean@gmail.com> wrote: Good Afternoon Dr. Vallerand,

I am Ashley Scales, a Doctoral Candidate at The University of Southern Mississippi in Human Capital Development. I am studying harmonious passion among Social Workers, and wanted to ask if I could use your Passion Scale to collect quantitative data from the participants.

Thanks,

Ashley Scales, MPH, CTDP

Health Science Specialist

Geriatric Research, Education and Clinical Center 
Ashley Scales <scalean@gmail.com>

\section{Anticipated Turnover Scale}

2 messages

Ada Hinshaw <ahinshaw@umich.edu>

To: scalean@gmail.com

Thu, Jan 12,2017 at 8:35 AM

Cc: Ada Hinshaw <ahinshaw@umich.edu>, "J. Atwood" <atwoodj@comcast.net>

Dr. Atwood and I would be pleased to have you use the ATS instrument in your study of social workers.

The most recent reliability and validity estimates are available in turnover studies in the nursing literature.

Best of success with your research!

Ashley Scales <scalean@gmail.com>

To: Ada Hinshaw <ahinshaw@umich.edu>

Thu, Jan 12, 2017 at 9:16 AM

Cc: "J. Atwood" <atwoodj@comcast.net>

Thank you for permitting me to use the passion scale in my upcoming study.

Best,

Ashley

[Quoted text hidden] 


\section{APPENDIX D - Interview Protocol}

The interview will begin with informing the participant about the length of the interview, what the interview will contribute to, the definition of organizational commitment and harmonious passion, and the stages of the research process. The researcher will inform the participant that they can end the interview at any time. The researcher will also gain verbal consent from the participant and answer any questions they may have regarding the study and their confidentiality.

The researcher will ask the participants basic demographic questions, followed by questions related to their experiences in their job setting. Each question is open-ended to gather information regarding their lived experiences. The researcher will ask the participants to describe how they perceive being a SW, organizational commitment and harmonious passion at CPS, and their intent to leave. Questions will aim to discover themes that the literature on voluntary turnover in SW research did not explore. Specifically, the interview will address the following items: how the SW perceives organizational commitment, harmonious passion, and voluntary turnover at CPS; how the SW perceives organizational commitment and harmonious passion influence on voluntary turnover at CPS; additional comments that the SW deems relevant to voluntary turnover at CPS; suggestions on how CPS can increase organizational commitment and harmonious for SWs; and their intent to leave CPS. 


\section{Interview Script}

Study ID:

Interviewer:

Date of interview:

Start time:

End time:

Introduction

Before we start with the interview process, I would like to thank you for taking the time out of your busy schedule to participate in my study. I am a PhD Candidate at The University of Southern Mississippi, and I am currently in the data collection phase of my dissertation. My study focuses on voluntary turnover among Social Workers. This interview will take about 15 minutes. Please feel free to take a break at any time during the interview.

\section{Consent}

1. Purpose - The goal of this study is to examine if organizational commitment and passion influence voluntary turnover among Social Workers (SWs). Your answers to the questions will assist with describing the current state of Social Workers at CPS regarding the affects organizational commitment and harmonious passion has on voluntary turnover. Your answers may also provide suggestions to CPS regarding the current state of organizational commitment, harmonious passion; and voluntary turnover.

2. Description of Study - Participation in the study will entail completing the oneon-one interview via telephone. The interview will be recorded for transcription 
purposes, but I would like to reiterate that your identity will remain confidential. No personal information, such as name, email, date of birth, etc. will be recorded. The researcher will interview at the minimum 12-14 Social Workers' for the current study.

3. Benefits - There are no direct benefits to you as a research participant. Eventually, this research may help improve the quality of services clients receive. The researcher may learn more about the influences of voluntary turnover among Social Workers' and what may be causing the increase in voluntary turnover at CPS. The information you provide will be grouped with other participants to determine Social Worker perception regarding retention, organizational commitment, and passion.

4. Risks - The only risks associated with this project would be a disclosure of your responses that might complicate your relationship with your supervisor(s). To protect against this, we made sure no identifying information will be collected, so no disclosure can be made.

5. Confidentiality - No identifying information will be recorded or reported. All reported data will be anonymous and will be in an aggregated format.

6. Participant's Assurance - This project has been reviewed by the Institutional Review Board, which ensures that research projects involving human subjects follow federal regulations. Any questions or concerns about rights as a research participant should be directed to the Chair of the IRB at 601.266.5997, irb@usm.edu. Participation in this project is completely voluntary, and 
participants in this project is completely voluntary, and participants may withdraw from this study at any time without penalty, prejudice, or loss of benefits.

7. By agreeing to participate, you understand the purpose and nature of this study and your participation is voluntary. You also understand that you can withdraw from the study at any time, without any penalty or consequence.

Do you consent to participate in the research study?
a. Yes
b. No

If yes, proceed. If no, thank you for your consideration and have a nice day.

8. Do you have any questions?

a. If not, let us begin the interview.

\section{Background}

To begin, I would like to ask you a few questions about your background.

1) Are you a SW employed by CPS?
a. Yes
b. No

2) Of the following categories, what is your age bracket?
a. 21-30
b. $31-40$
c. 41-50
d. $>50$

3) Of the following choices, what is your highest level of education?
a. Bachelors
b. Masters 

c. Specialist
d. Doctorate

4) Of the following categories, how long have you been a Licensed Social Worker?
a. $<1$ year
b. 1-4 years
c. 5-10 years
d. 11-15 years
e. > 15 years

5) Of the following categories, how long have you worked for CPS?
a. $<1$ year
b. 1-4 years
c. 5-10 years
d. 11-15 years
e. > 15 years

II. Values towards being a Social Worker

a. What inspired you to pursue a career in Social Work?

i. What do you specifically enjoy about being a Social Worker?

b. What has been your experience as a Social Worker thus far?

i. How has CPS impacted your experience? (For example, has CPS or turnover impacted how you view the field of SW?)

III. Perception of organizational commitment - Organizational commitment is your commitment to your current organization and desires to continue to be a part of it.

a. Is being committed to an organization important to you?

i. What do you feel is needed for SWs to become more committed to an organization? (For example, more incentives, flexibility in work schedule, pay, etc.) 
ii. How would you describe your commitment to the organizations?

b. How would you describe the current state of commitment at CPS? (For instance, SWs are very committed to CPS; SWs are not very committed to CPS; etc.)

i. How can CPS assist with increasing commitment to the agency among SWs?

IV. Perception of harmonious passion - Harmonious passion is when you feel in control of your work, feel good about yourself while working, and find that your work is in harmony with your other activities.

a. Why is it important for SWs to have passion about their job?

i. How would you describe your passion toward SW at CPS? (For example, due to your environment at CPS, has your passion remained positive toward the field of SW and CPS?)

b. How can CPS assist with increasing passion toward the field of SW?

i. Who do you think has the greatest influence in helping increase passion toward the field of SW within CPS? (Is it your supervisor, commissioner, peers, etc.?)

V. Perception of voluntary turnover - Voluntary turnover is when someone leaves the organization at their own will. In other words, the employee quits.

a. Do you think voluntary turnover is a problem at CPS?

i. How would you describe the current state of voluntary turnover at CPS?

b. How does voluntary turnover among your peers affect your daily responsibilities? 
i. Who else is impacted when a Social Worker voluntarily leaves?

c. Do you think it is important to retain Social Workers?

i. Why do you think it is important to retain Social Workers?

ii. What can CPS do to retain Social Workers?

VI. Intent to leave - Intent to leave is when the employee is contemplating on leaving the organization. For example, I intend to leave my current job within the next 6 months to a year.

a. Do you intend to leave CPS in the near future?

i. If so, do you have a projected time frame of when you may leave?

ii. What would be your reason for leaving CPS?

Thank you for spending the time to share your experiences as a Social Worker. I appreciate your involvement and assistance with my study. You will be able to review your final transcript within the next week to ensure that I captured your responses in the manner you wanted.

Do you have any questions?

i. If no, thank you and have a nice day.

\section{End of Interview}




\section{APPENDIX E - Consent}

Title of Research Study: The effects of organizational commitment and harmonious passion on voluntary turnover among social workers: A mixed methods study

Researcher's Contact Information:

Ashley Scales, (601) 559-3529, ashley.n.scales@usm.edu or Dr. H. Quincy Brown (Advisor), (228) 214-5414, hamett.brown@usm.edu

Introduction

You are invited to take part in a research study conducted by Ashley Scales, a Doctoral Candidate at The University of Southern Mississippi. Before you decide to participate in this study, you should read the information below. Your involvement as a participant in this study is completely voluntary. You are free to refuse to participate. No one at your job will know whether or not your participated. Your job will not be affected.

Description of Project

The goal of this study is to examine if organizational commitment and passion influence voluntary turnover among Social Workers (SWs). The researcher will collect data from SWs located in the Southern United States to understand the influence of organizational commitment and passion on their intent to leave Child Protective Services. The data can inform future organizations of how SWs perceive the organization, specifically regarding organizational commitment, passion, and voluntary turnover.

\section{Explanation of Procedures}

Participation in the study will entail completion and submission of an online survey

Time Required

The survey is expected to take approximately 10 minutes to complete.

Risks or Discomforts

The only risks associated with this project would be a disclosure of your responses that might complicate your relationship with your supervisors. To protect against this, we made sure no identifying information will be collected, so no disclosure can be made.

Benefits to the participant

There are no direct benefits to you as a research participant. Eventually this research may help improve the quality of services clients receive. The researcher may learn more about the influences of voluntary turnover among Social Workers and what may be causing the increase in voluntary turnover at CPS. The information you provide will be aggregated (grouped) with other social workers' responses to determine SW perception regarding organizational commitment, passion, and intent to leave.

\section{Confidentiality}

No identifying information will be recorded or reported. All reported data will be anonymous and will be in an aggregated (grouped) format.

This project has been reviewed by the Institutional Review Board, which ensures that research projects involving human subjects follow federal regulations.

Any questions or concerns about rights as a research participant should be directed to the Chair of the IRB at 601.266.5997, irb@usm.edu. Participation in this project is completely voluntary, and participants in this project is completely voluntary, and participants may withdraw from this study at any time without penalty, prejudice, or loss of benefits.

If you have any questions, or would like a copy of this consent letter, please contact me at 601.559 .3529 or ashley.n.scales@usm.edu.

Thank you in advance for your participation!

Ashley Scales

By clicking yes below, you concur with following statement "I agree to participate in the research study. I understand the purpose and nature of this study and I am participating voluntarily. I understand that I can withdraw from the study at any time, without any penalty or consequences."
Yes
No 
APPENDIX F - Survey
Of the follow
$0<1$ year
1-4 years
5-10 years
11-15 years
$>15$ years

Select the gender you most identify with?

Male

Female

Prefer not to answer

Of the following categories, what is your age bracket?

$21-30$

$31-40$

$41-50$

$>50$

Select the highest degree you have obtained:

Bachelors

Masters

Specialist

Doctorate

Of the following categories, how long you have been a Licensed Social Worker?
$0<1$ year
$1-5$ years
5-10 years
10-15 years
$>15$ years 
With respect to your own feelings about the organization by which you are employed, please indicate the degree of your agreement or disagreement with each statement by selecting an agreement from Strongly Disagree to Strongly Agree using the scale below.

\begin{tabular}{|c|c|c|c|c|c|c|c|}
\hline & $\begin{array}{l}\text { Strongly } \\
\text { Disagree }\end{array}$ & Disagree & $\begin{array}{l}\text { Slightly } \\
\text { Disagree }\end{array}$ & Undecided & $\begin{array}{l}\text { Slightly } \\
\text { Agree }\end{array}$ & Agree & $\begin{array}{r}\text { Strong } \\
\text { Agree }\end{array}$ \\
\hline $\begin{array}{l}\text { I would be very happy to spend } \\
\text { the rest of my career with this } \\
\text { organization }\end{array}$ & 0 & $\bigcirc$ & $\bigcirc$ & $\bigcirc$ & 0 & 0 & $\bigcirc$ \\
\hline $\begin{array}{l}\text { Right now, staying with my } \\
\text { organization is a matter of } \\
\text { necessity as much as desire. }\end{array}$ & 0 & 0 & 0 & 0 & 0 & 0 & 0 \\
\hline $\begin{array}{l}\text { I do not feel any obligation to } \\
\text { remain with my current employer. }\end{array}$ & 0 & 0 & 0 & 0 & 0 & 0 & 0 \\
\hline $\begin{array}{l}\text { One of the few negative } \\
\text { consequences of leaving this } \\
\text { organization would be the scarcity } \\
\text { of available alternatives. }\end{array}$ & 0 & 0 & 0 & 0 & 0 & 0 & 0 \\
\hline $\begin{array}{l}\text { This organization has a great deal } \\
\text { of personal meaning for me. }\end{array}$ & 0 & 0 & 0 & $\bigcirc$ & 0 & $\bigcirc$ & 0 \\
\hline $\begin{array}{l}\text { It would be very hard for me to } \\
\text { leave my organization right now, } \\
\text { even if I wanted to. }\end{array}$ & 0 & 0 & 0 & 0 & 0 & 0 & 0 \\
\hline $\begin{array}{l}\text { Even if it were to my advantage, I } \\
\text { do not feel it would be right to } \\
\text { leave my organization now. }\end{array}$ & 0 & 0 & 0 & $\bigcirc$ & $\bigcirc$ & $\bigcirc$ & $\bigcirc$ \\
\hline $\begin{array}{l}\text { If I had not already put so much } \\
\text { of myself into this organization, I } \\
\text { might consider working } \\
\text { elsewhere. }\end{array}$ & 0 & 0 & 0 & 0 & 0 & 0 & 0 \\
\hline $\begin{array}{l}\text { I do not feel like "part of the } \\
\text { family" at my organization. }\end{array}$ & 0 & 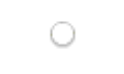 & 0 & 0 & $\bigcirc$ & 0 & 0 \\
\hline $\begin{array}{l}\text { Too much of my life would be } \\
\text { disrupted if I decided I wanted to } \\
\text { leave my organization now. }\end{array}$ & 0 & 0 & 0 & 0 & 0 & 0 & 0 \\
\hline $\begin{array}{l}\text { I would feel guilty if I left my } \\
\text { organization now. }\end{array}$ & 0 & 0 & 0 & 0 & $\bigcirc$ & $\bigcirc$ & $\bigcirc$ \\
\hline $\begin{array}{l}\text { I feel that I have too few options } \\
\text { to consider leaving this } \\
\text { organization. }\end{array}$ & 0 & 0 & 0 & 0 & 0 & 0 & 0 \\
\hline $\begin{array}{l}\text { I really feel as if this } \\
\text { organization's problems are my } \\
\text { own. }\end{array}$ & 0 & $\bigcirc$ & 0 & 0 & $\bigcirc$ & $\bigcirc$ & $\bigcirc$ \\
\hline $\begin{array}{l}\text { I owe a great deal to my } \\
\text { organization. }\end{array}$ & 0 & 0 & 0 & 0 & 0 & 0 & 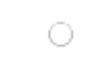 \\
\hline $\begin{array}{l}\text { I do not feel a strong sense of } \\
\text { "belonging" to my organization. }\end{array}$ & 0 & 0 & 0 & $\bigcirc$ & 0 & $\bigcirc$ & $\bigcirc$ \\
\hline $\begin{array}{l}\text { I would not leave my organization } \\
\text { right now because I have a sense } \\
\text { of obligation to the people in it. }\end{array}$ & 0 & 0 & 0 & 0 & 0 & 0 & \\
\hline $\begin{array}{l}\text { I do not feel "emotionally } \\
\text { attached" to this organization. }\end{array}$ & 0 & 0 & $\bigcirc$ & 0 & 0 & $\bigcirc$ & \\
\hline $\begin{array}{l}\text { This organization deserves my } \\
\text { loyalty. }\end{array}$ & 0 & 0 & 0 & 0 & 0 & 0 & \\
\hline
\end{tabular}


While thinking of being a Social Worker and using the scale below, please indicate your level of agreement with each item. Please note that being a Social Worker is the 'activity' in each statement.

\begin{tabular}{|c|c|c|c|c|c|c|c|}
\hline & $\begin{array}{l}\text { Not Agree at } \\
\text { All }\end{array}$ & $\begin{array}{l}\text { Very Slightly } \\
\text { Agree }\end{array}$ & $\begin{array}{l}\text { Slightly } \\
\text { Agree }\end{array}$ & $\begin{array}{l}\text { Moderately } \\
\text { Agree }\end{array}$ & Mostly Agree & $\begin{array}{l}\text { Strongly } \\
\text { Agree }\end{array}$ & $\begin{array}{l}\text { Very Strongly } \\
\text { Agree }\end{array}$ \\
\hline $\begin{array}{l}\text { This activity is in harmony with } \\
\text { the other activities in my life. }\end{array}$ & 0 & 0 & 0 & 0 & 0 & 0 & 0 \\
\hline $\begin{array}{l}\text { I have difficulties controlling my } \\
\text { urge to do my activity. }\end{array}$ & 0 & 0 & 0 & 0 & 0 & 0 & 0 \\
\hline $\begin{array}{l}\text { The new things that I discover } \\
\text { with this activity allow me to } \\
\text { appreciate it even more. }\end{array}$ & $\bigcirc$ & ○ & $\bigcirc$ & $\bigcirc$ & 0 & 0 & ○ \\
\hline $\begin{array}{l}\text { I have almost an obsessive } \\
\text { feeling for this activity. }\end{array}$ & 0 & 0 & 0 & 0 & 0 & 0 & 0 \\
\hline $\begin{array}{l}\text { This activity reflects the qualities I } \\
\text { like about myself. }\end{array}$ & $\bigcirc$ & 0 & 0 & $\bigcirc$ & 0 & 0 & 0 \\
\hline $\begin{array}{l}\text { This activity allows me to live a } \\
\text { variety of experiences. }\end{array}$ & 0 & 0 & 0 & 0 & 0 & 0 & 0 \\
\hline $\begin{array}{l}\text { This activity is the only thing that } \\
\text { really turns me on. }\end{array}$ & $\bigcirc$ & 0 & 0 & 0 & 0 & $\bigcirc$ & 0 \\
\hline $\begin{array}{l}\text { My activity is well integrated in my } \\
\text { life. }\end{array}$ & 0 & 0 & 0 & 0 & 0 & 0 & 0 \\
\hline $\begin{array}{l}\text { If I could, I would only do my } \\
\text { activity. }\end{array}$ & $\bigcirc$ & $\bigcirc$ & $\bigcirc$ & 0 & $\bigcirc$ & $\bigcirc$ & 0 \\
\hline $\begin{array}{l}\text { My activity is in harmony with } \\
\text { other things that are part of me. }\end{array}$ & 0 & 0 & 0 & 0 & 0 & 0 & 0 \\
\hline $\begin{array}{l}\text { This activity is so exciting that I } \\
\text { sometimes lose control over it. }\end{array}$ & $\bigcirc$ & $\bigcirc$ & $\bigcirc$ & $\bigcirc$ & $\bigcirc$ & 0 & 0 \\
\hline $\begin{array}{l}\text { I have the impression that my } \\
\text { activity controls me. }\end{array}$ & 0 & 0 & 0 & 0 & 0 & 0 & 0 \\
\hline $\begin{array}{l}\text { I spend a lot of time doing this } \\
\text { activity. }\end{array}$ & $\bigcirc$ & 0 & 0 & 0 & 0 & 0 & 0 \\
\hline I like this activity. & 0 & 0 & 0 & 0 & 0 & 0 & 0 \\
\hline This activity is important for me. & $\bigcirc$ & $\bigcirc$ & 0 & $\bigcirc$ & $\bigcirc$ & 0 & 0 \\
\hline This activity is a passion for me. & 0 & 0 & 0 & 0 & 0 & 0 & 0 \\
\hline This activity is part of who I am. & $\bigcirc$ & $\bigcirc$ & $\bigcirc$ & $\bigcirc$ & $\bigcirc$ & $\bigcirc$ & $\bigcirc$ \\
\hline
\end{tabular}


For each item below, select the appropriate response.

\begin{tabular}{|c|c|c|c|c|c|c|c|}
\hline & $\begin{array}{l}\text { Disagree } \\
\text { Strongly }\end{array}$ & $\begin{array}{l}\text { Moderately } \\
\text { Disagree }\end{array}$ & $\begin{array}{l}\text { Slightly } \\
\text { Disagree }\end{array}$ & Uncertain & $\begin{array}{l}\text { Slightly } \\
\text { Agree }\end{array}$ & $\begin{array}{l}\text { Moderately } \\
\text { Agree }\end{array}$ & $\begin{array}{l}\text { Agree } \\
\text { Strongly }\end{array}$ \\
\hline $\begin{array}{l}\text { I plan to stay in my position } \\
\text { awhile. }\end{array}$ & 0 & 0 & 0 & 0 & $\bigcirc$ & 0 & 0 \\
\hline $\begin{array}{l}\text { I am quite sure I will leave my } \\
\text { position in the foreseeable future. }\end{array}$ & 0 & 0 & 0 & 0 & 0 & 0 & 0 \\
\hline $\begin{array}{l}\text { Deciding to stay or leave my } \\
\text { position is not a critical issue for } \\
\text { me at this point in time. }\end{array}$ & $\bigcirc$ & 0 & $\bigcirc$ & $\bigcirc$ & 0 & $\bigcirc$ & $\bigcirc$ \\
\hline $\begin{array}{l}\text { I know whether or not I'll be } \\
\text { leaving this agency within a short } \\
\text { time. }\end{array}$ & 0 & 0 & 0 & 0 & 0 & 0 & 0 \\
\hline $\begin{array}{l}\text { If I got another job offer tomorrow, } \\
\text { I would give it serious } \\
\text { consideration. }\end{array}$ & $\bigcirc$ & 0 & 0 & 0 & 0 & 0 & 0 \\
\hline $\begin{array}{l}\text { I have no intentions of leaving my } \\
\text { present position. }\end{array}$ & 0 & 0 & 0 & 0 & 0 & 0 & 0 \\
\hline $\begin{array}{l}\text { I've been in my position about as } \\
\text { long as I want to. }\end{array}$ & 0 & 0 & 0 & 0 & 0 & $\bigcirc$ & 0 \\
\hline $\begin{array}{l}\text { I am certain I will be staying here } \\
\text { awhile. }\end{array}$ & 0 & 0 & 0 & 0 & 0 & 0 & 0 \\
\hline $\begin{array}{l}\text { I don't have any specific idea how } \\
\text { much longer I will stay. }\end{array}$ & 0 & 0 & 0 & 0 & 0 & 0 & 0 \\
\hline $\begin{array}{l}\text { I plan to hang on to this job } \\
\text { awhile. }\end{array}$ & 0 & 0 & 0 & 0 & 0 & 0 & 0 \\
\hline $\begin{array}{l}\text { There are big doubts in my mind } \\
\text { as to whether or not I will really } \\
\text { stay in this agency. }\end{array}$ & 0 & 0 & 0 & 0 & 0 & 0 & 0 \\
\hline I plan to leave this position shortly & 0 & 0 & 0 & 0 & 0 & 0 & 0 \\
\hline
\end{tabular}

We thank you for your time spent taking this survey. Your response has been recorded. 


\section{APPENDIX G - Recruitment Email}

Subject line: Social Workers expertise needed!

I am writing to request your participation in a brief survey about Social Workers. Your expertise is extremely valuable to learning more about the perception of Social Worker retention, commitment, and passion. The survey is very brief, needing about 10 minutes to complete. In addition, I am also conducting short interviews and would enjoy hearing your expertise, as it is extremely valuable in learning more about your perception of Social Worker retention, commitment, and passion. The interview will be by telephone. The time commitment involved is very short; if you are interested in participating in the interview, please let me know a date and time that works best for you to conduct the interview. The Deputy Commissioner of Child Protective Services approved this study.

Please note that participation is voluntary, and there is no penalty for refusing to answer the questions in the survey and/or the interview. Additionally, we will not collect any information that can be used to identify you; all your responses will remain anonymous. If you are willing to participate in the study, please click the link below to go to the survey website.

Survey link: https://usmuw.co1.qualtrics.com/jfe/form/SV_1G3jj5s22o2b6u1 \

The processes and procedures of this study were approved by the University of Southern Mississippi’s Institutional Review Board (IRB).

Thank you very much for your time and cooperation. Your feedback is very important. Sincerely, 
Ashley Scales

601.559.3529

Ashley.n.scales@usm.edu 


\section{APPENDIX H - Follow-Up Email to Participants}

Subject line: Social Workers: There is still time to share your expertise!

Two weeks ago, you received an email requesting your participation in a brief survey about Social Workers. Your expertise is extremely valuable to learning more about the perception of Social Worker retention, commitment, and passion. The survey is very brief, needing about 10 minutes to complete. If you have already completed and submitted the survey, thank you for your valuable input. In addition, I am also conducting short interviews and would enjoy hearing your expertise, as it is extremely valuable in learning more about social worker retention, commitment, and passion. The interview will be by telephone. The time commitment involved is very short; if you are interested in participating in the interview, please let me know a date and time that works best for you to conduct the interview

Please note that participation is voluntary, and there is no penalty for refusing to answer the questions in the survey and/or the interview. Additionally, we will not collect any information that can be used to identify you; all your responses will remain anonymous. If you are willing to participate in the study, please click the link below to go to the survey website.

Survey link: https://usmuw.co1.qualtrics.com/jfe/form/SV_1G3jj5s22o2b6u1

The processes and procedures of this study were approved by the University of Southern Mississippi’s Institutional Review Board (IRB).

Thank you very much for your time and cooperation. Your feedback is very important. Sincerely, Ashley Scales 


\section{APPENDIX I - Second Follow-Up Email to Participants}

Subject line: Last chance to share your expertise as a Social Worker

Last chance to participate in a brief survey about Social Workers. Your expertise is extremely valuable to learning more about the perception of Social Worker retention, commitment, and passion. The survey is very brief, needing about 10 minutes to complete. If you have already completed and submitted the survey, thank you for your valuable input.

Please note that participation is voluntary, and there is no penalty for refusing to answer the questions in the survey and/or the interview. Additionally, I will not collect any information that can be used to identify you; all your responses will remain anonymous. If you are willing to participate in the study, please click the link below to go to the survey website.

Survey link: https://usmuw.co1.qualtrics.com/jfe/form/SV_1G3jj5s22o2b6u1

The processes and procedures of this study were approved by the University of Southern Mississippi’s Institutional Review Board (IRB).

Thank you very much for your time and cooperation. Your feedback is very important. Sincerely, Ashley Scales 


\section{APPENDIX J - Interview Transcript Email}

Subject line: Final Interview Transcript

Dear XXX,

Thank you for taking the time to speak with me on [date] to voice your thoughts and concerns regarding your perception of social worker retention, commitment, and passion. At the end of the interview, I stated that you would be able to review your final transcript for quality assurance, and to ensure that your voice is heard in the manner that you wanted. I would like to reiterate that no personal information, such as name, email, date of birth, etc. was recorded or transcribed. Attached is your final interview transcript, if you have any edits, please let me know no later than [date]. If I do not hear from you by the requested date, I will assume you are satisfied with the transcript.

Again, thank you for being a part of my study.

Cordially, Ashley Scales

601.559 .3529

Ashley.n.scales@usm.edu 


\section{APPENDIX K - Assumptions}

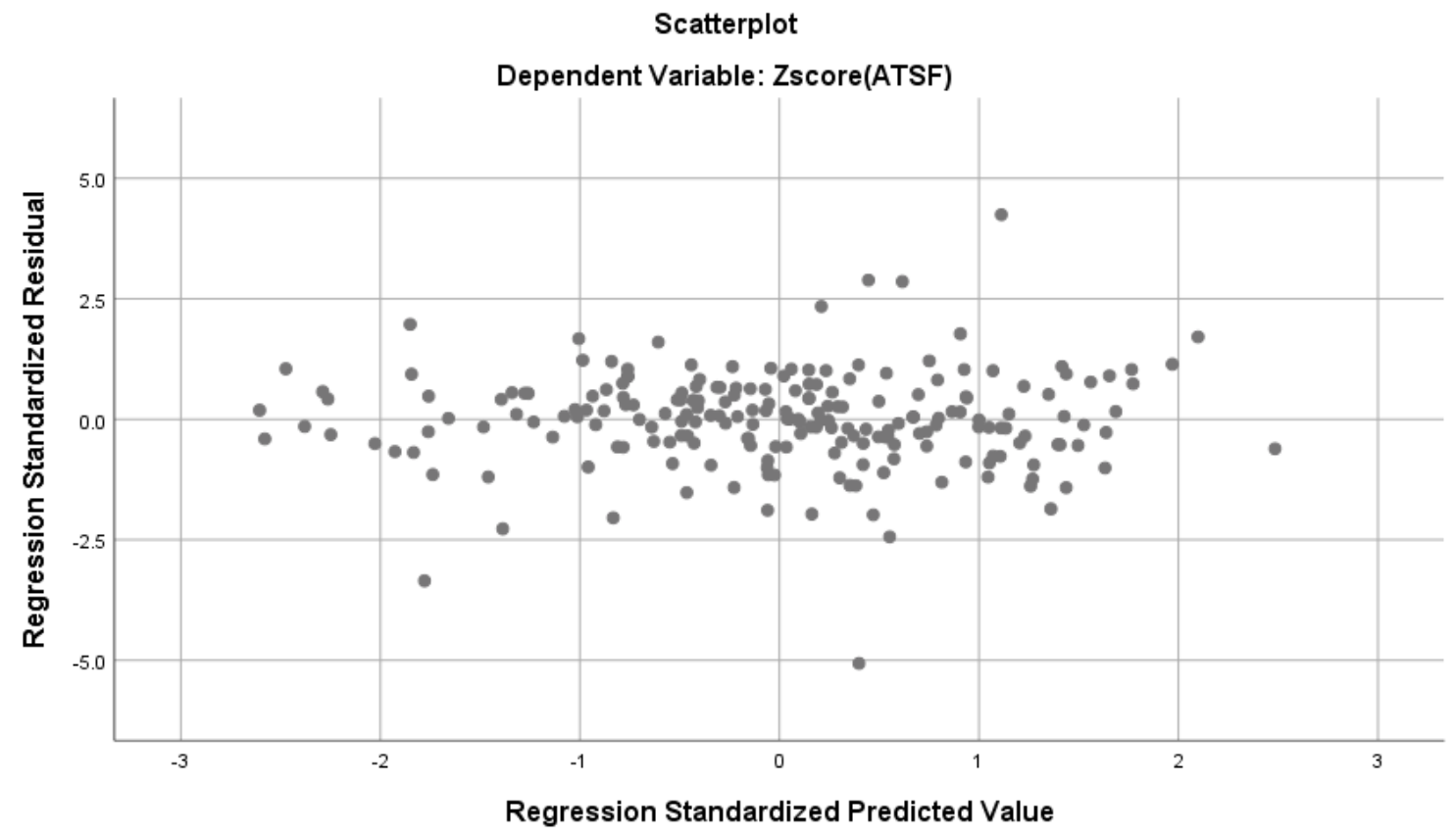

Figure 3. Linearity and Homoscedasticity Plot

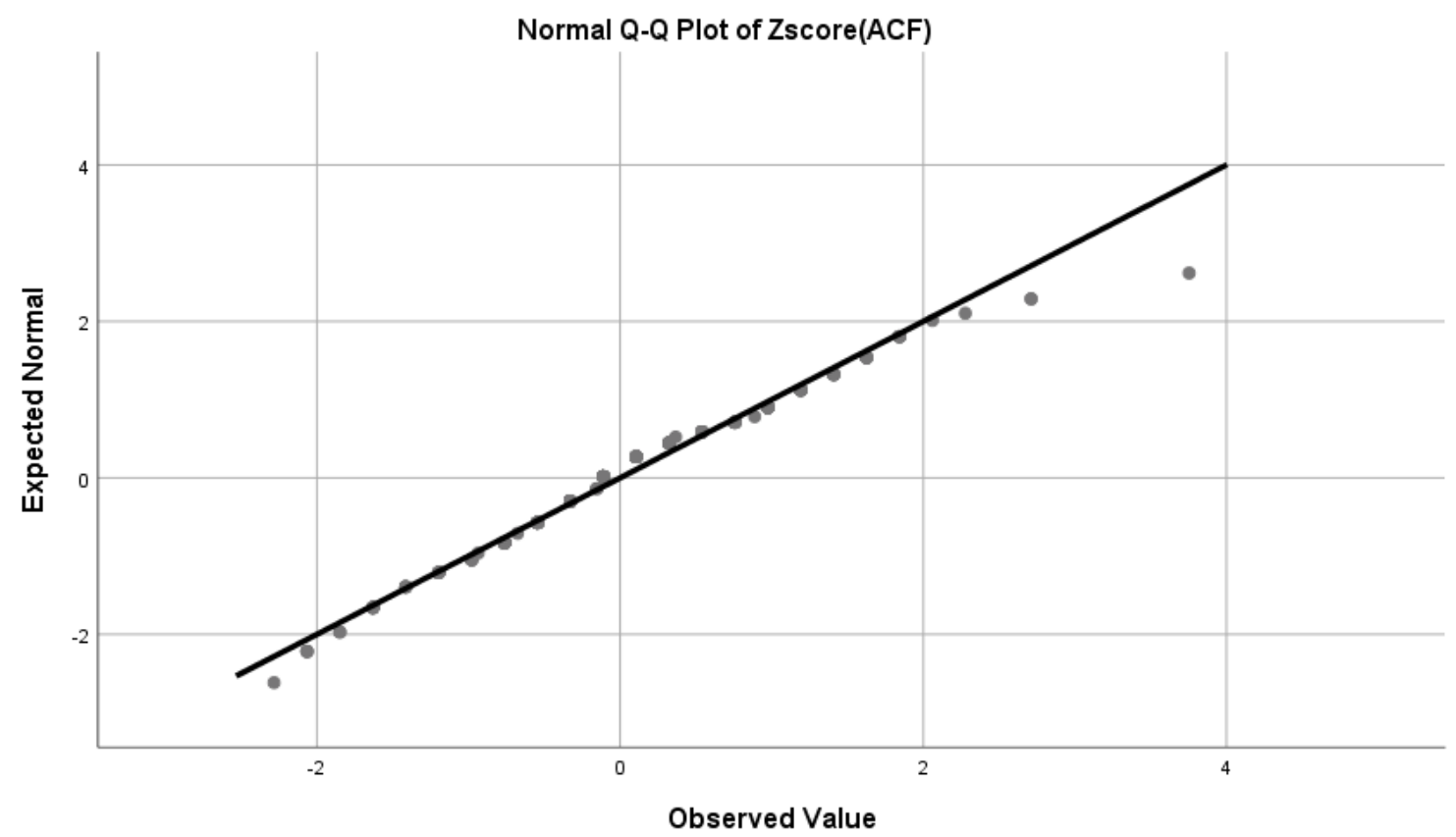

Figure 4. Affective Commitment Normality Plot 


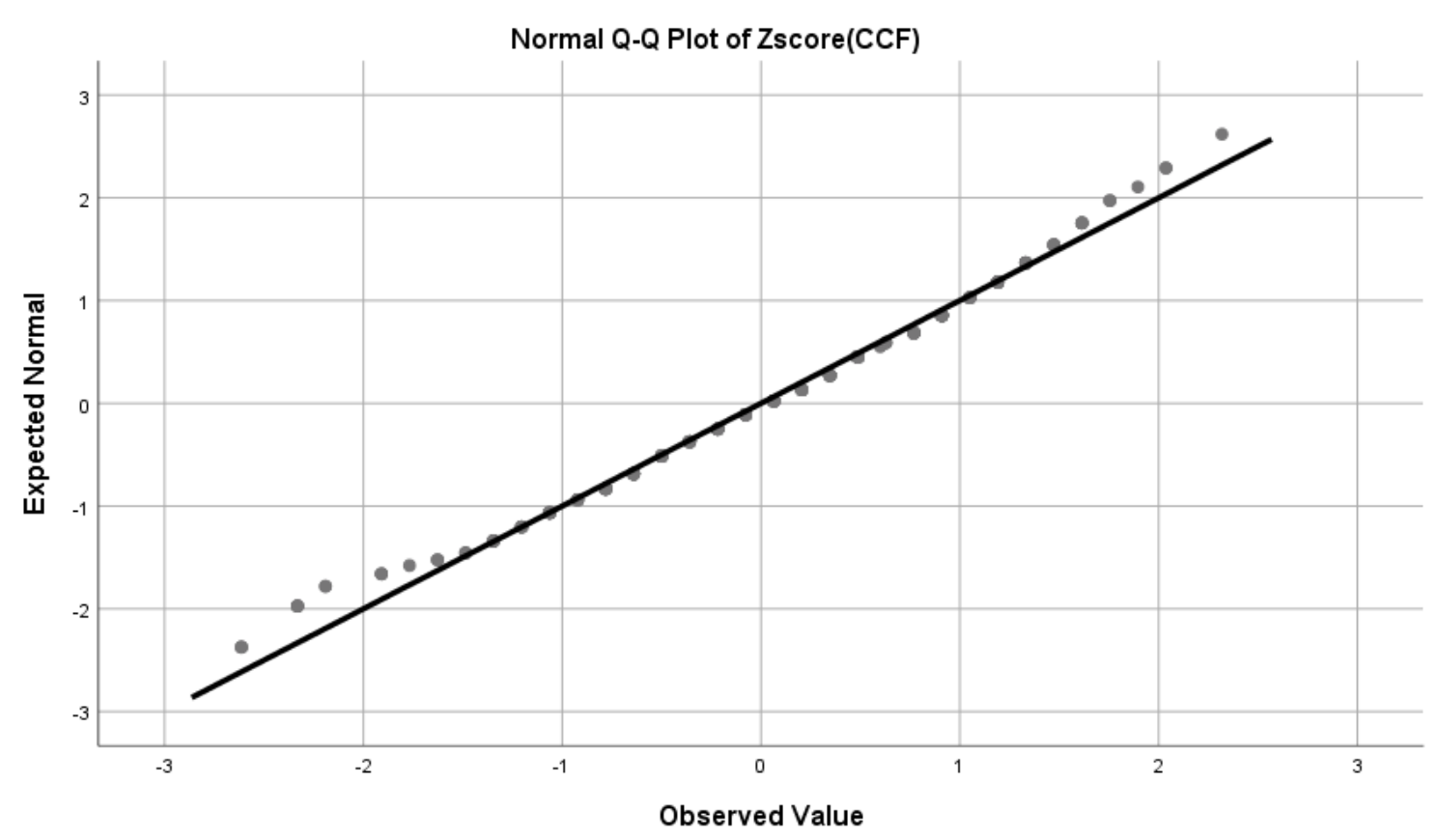

Figure 5. Continuance Commitment Normality Plot

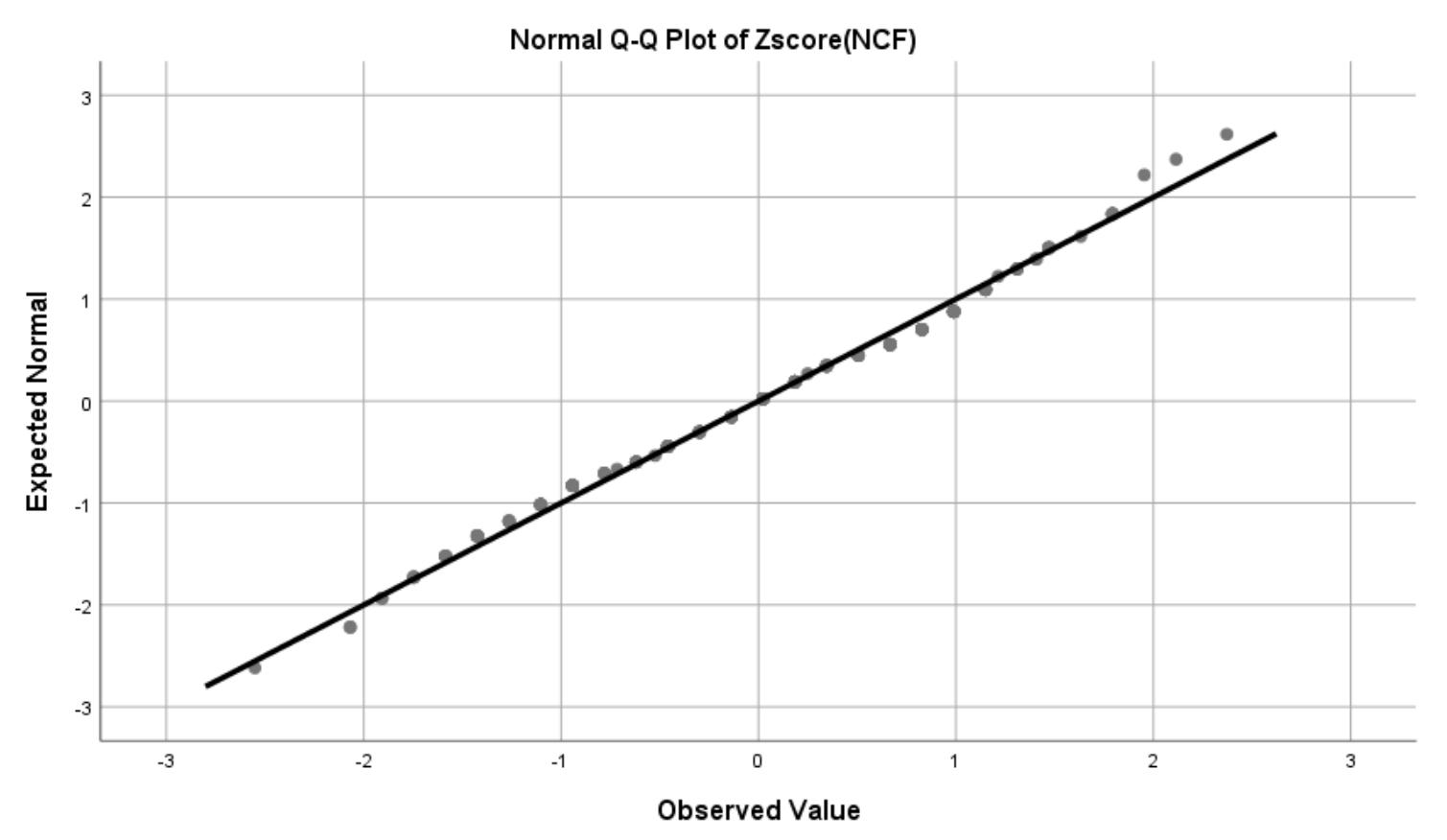

Figure 6. Normative Commitment Normality Plot 


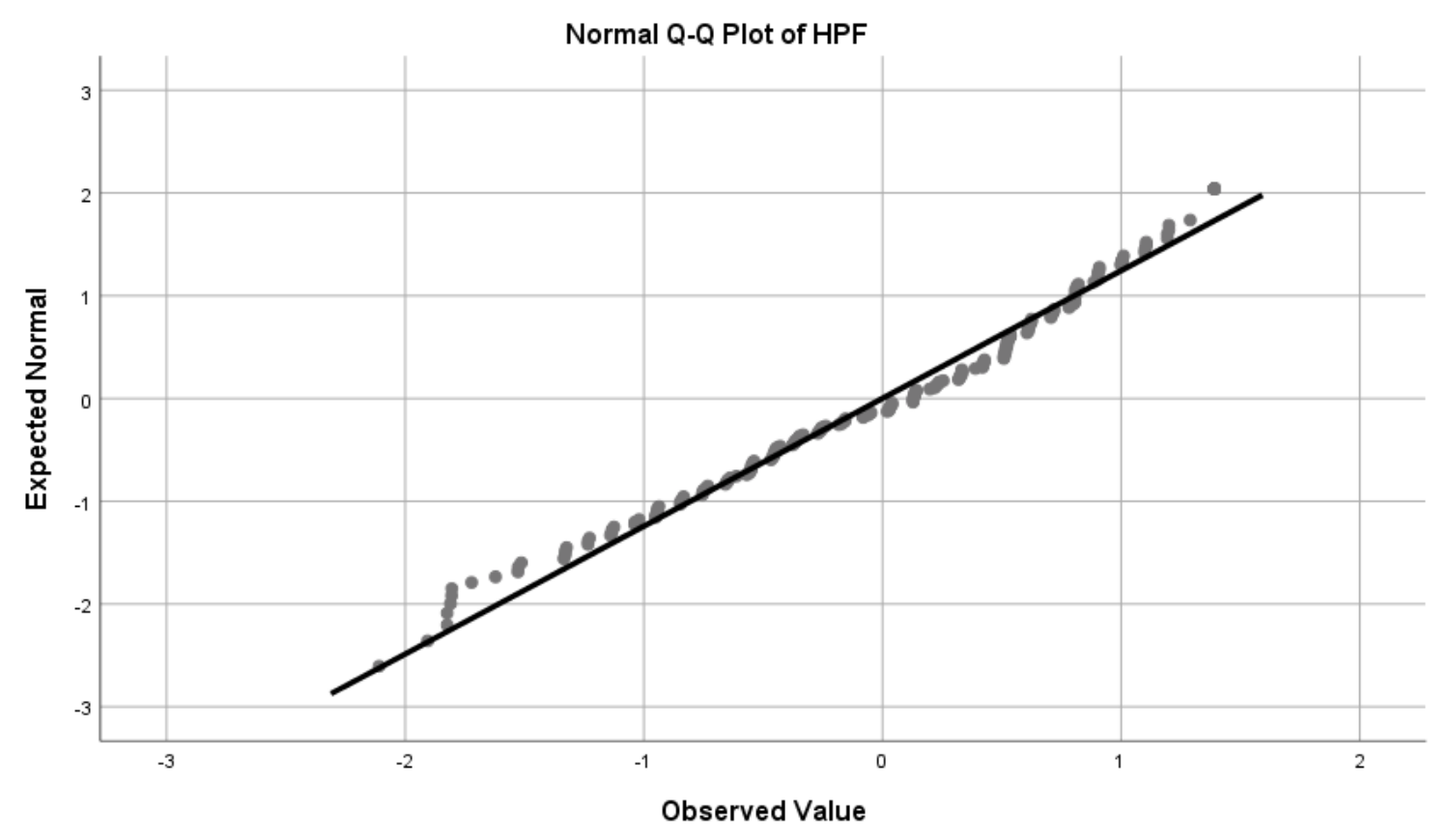

Figure 7. Harmonious Passion Normality Plot 


\section{REFERENCES}

Aarons, G. A., Fettes, D. L., Sommerfeld, D. H., \& Palinkas, L. A. (2011). Mixed methods for implementation research: Application to evidence-based practice implementation and staff turnover in community-based organizations providing child welfare services. Child Maltreatment, 17(1), 67-79.

doi: $10.1177 \% 2 F 1077559511426908$

Aarons, G. A., Sommerfeld, D. H., Hecht, D. B., Silovsky, J. F., \& Chaffin, M. J. (2009). The impact of evidence-based practice implementation and fidelity monitoring on staff turnover: Evidence for a protective effect. Journal of Consulting and Clinical Psychology, 77, 270-280. doi:10.1037/a0013223

Aarons, G. A., \& Sommerfeld, D. H. (2011). Leadership, innovation climate, and attitudes toward evidence-based practice during a statewide implementation. Journal of the American Academy of Child \& Adolescent Psychiatry, 51(4), 423431. doi:10.1016/j.jaac.2012.01.018

Aarons, G. A., Sommerfeld, D. H., \& Willging, C. E. (2011). The soft underbelly of system change: The role of leadership and organizational climate in turnover during statewide behavioral health reform. Psychological Services, 8(4), 269281. doi:10.1037/a002619

Agarwal, S., \& Mishra, P. C. (2016). Self-efficacy as predictor organizational commitment among revenue personnel. The International Journal of Indian Psychology, 3(4), 44-52. Retrieved from www.ijip.in/

Allen, N. J., \& Meyer, J. P. (1990). The measurement and antecedents of affective, continuance and normative commitment to the organization. Journal of 
Occupational and Organizational Psychology, 63(1), 1-18. doi:10.1111/j.20448325.1990.tb00506.x

Allen, N. J., \& Meyer, J. P. (1996). Affective, continuance, and normative commitment to the organization: An examination of construct validity. Journal of Vocational Behavior, 49, 252-276. doi:10.1006/jvbe.1996.0043

Allen, N. J., \& Meyer, J. P. (2000). Construct validation in organizational behavior research: The case of organizational commitment. In R. D. Goffin \& E. Helmes (Eds.), Problems and solutions in human assessment (pp. 285-314). Norwell, MA: Kluwer Academic.

Almalki, M. J., FitzGerald, G., \& Clark, M. (2012). The relationship between quality of work life and turnover intention of primary health care nurses in Saudi Arabia. BioMed Central Health Services Research, 12(314), 1-11. doi:10.1186/14726963-12-314

Amiot, C. E., Vallerand, R. J., \& Blanchard, C. M. (2006). Passion and psychological adjustment: A test of the person-environment fit hypothesis. Personality and Social Psychology Bulletin, 32(2), 200-229. doi:10.1177/0146167205280250

Atieno, O. (2016). An analysis of the strengths and limitation of qualitative and quantitative research paradigms. Problems of Education in the 21st Century, 6(13), 13-18. Retrieved from http://www.scientiasocialis.lt/pec/

Austin Research. (2014). The importance of representative samples and how to get them. Retrieved from http://austinresearch.co.uk/the-importance-of-representativesamples-and-how-to-get-them/ 
Aydogdu, S., \& Asikgil, B. (2011). An empirical study of the relationship among job satisfaction, organizational commitment and turnover intention. International Review of Management and Marketing (3), 43-55. Retrieved from: http://www.econjournals.com/index.php/irmm

Balfour, D. L., \& Neff, D. M. (1993). Predicting and managing turnover in human service agencies: A case study of an organization in crisis. Public Personnel Management, 22(3), 473-486. doi:10.1177/009102609302200310

Barak, M. E. M., Nissly, J. A., \& Levin, A. (2001). Antecedents to retention and turnover among child welfare, social work, and other human service occupations: What can we learn from past research? A review and meta-analysis. Social Service Review, 75, 625-661. Retrieved from http://www.journals.uchicago.edu/loi/ssr

Barlow, K. M., \& Zangaro, G. A. (2010). Meta-analysis of the reliability and validity of the Anticipated Turnover Scale across studies of registered nurses in the United States. Journal of Nursing Management, 18, 862-873. doi:10.1111/j.13652834.2010.01171.x

Barrett, K., \& Greene, R. (2016, November). Where Are All the Social Workers Going?, Governing The Sates and Localities. Retrieved from http://www.governing.com/columns/smart-mgmt/gov-social-workersturnover.html

Barth, R. P., Llyod, E. C., Christ, S. L., Chapman, M. V., \& Dickinson, N. S. (2008). Child welfare worker characteristics and job satisfaction: A national study. Social Work 53(3), 199-209. doi:10.1093/sw/53.3.199 
Bateman, T. S., \& Strasser, S. (1984). A longitudinal analysis of the antecedents of organizational commitment. Academy of Management Journal, 27(1), 95-112. doi: $10.2307 / 255959$

Becker, H. (1960). Notes on the concept of commitment. American Journal of Sociology, 66(1), 32-40. doi:10.1086/222820

Bent-Goodley, T. B. (2014). Social work: A profession of power, passion, and purpose. Social Work: A Journal of the National Association of Social Workers, 59(3), 197-199. doi:10.1093/sw/swu019

Berg, B. L., \& Lune, H. (2011). Qualitative research methods for the social sciences (8th ed). Upper Saddle River, NJ: Pearson Education.

Blankertz, L., \& Robinson, S. (1997). Turnover intentions of community mental health workers in psychosocial rehabilitation services. Community Mental Health Journal, 33(6), 517-529. doi:10.1023/A:1025000703487

Blau, G. J. (1986). Job involvement and organizational commitment as interactive predictors of tardiness and absenteeism. Journal of Management, 12, 577-584. doi:10.1177/014920638601200412

Boone, H. N., \& Boone, D. A. (2012). Analyzing Likert data. Journal of Extension, 50(2), p. 1-5. Retrieved from https://joe.org/

Borysenko, K. (2014). The cost of employee turnover. Retrieved from https://www.linkedin.com/pulse/20140701121556-17497251-the-cost-ofemployee-turnover

Boyas, J., Wind, L.H., \& Kang, S. (2012). Exploring the relationship between employment-based social capital, job stress, burnout, and intent to leave among 
child protection workers: An age-based path analysis model. Children and Youth Services Review, 34(1), 50-62. doi:10.1016/j.childyouth.2011.08.033

Bryman, A. (2012). Social Research Methods (4th ed.). Oxford, England: Oxford University Press.

Bureau of labor Statistics (2014). Occupational Outlook Handbook. Retrieved from http://www.bls.gov/ooh/Community-and-Social-Service/Social-workers.htm

Burke, R. J., Astakhova, M. N., \& Hang, H. (2014). Work passion through the lens of culture: Harmonious work passion, obsessive work passion, and work outcomes in Russia and China. Journal of Business and Psychology, 30(3), 457-471. doi:10.1007/s10869-014-9375-4

Burmeister, E., \& Aitken, L. M. (2012). Sample size: How many is enough? Aust Crit Care, 25(4), 271-274. doi:10.1016/j.aucc.2012.07.002

Callahan, D. G. (2014, December). Social worker turnover problematic. Retrieved from http://www.journal-news.com/

Campbell, D., \& Campbell, S. (2008). Statlab workshop introduction to regression and data analysis. Retrieved from http://statlab.stat.yale.edu/workshops/IntroRegression/StatLabIntroRegressionFa08.pdf

Carsten, J. M., \& Spector, P. E. (1987). Unemployment, job satisfaction, and employee turnover: A meta-analytic test of the Muchinsky model. Journal of Applied Psychology 72(3), 374-381. doi:10.1037/0021-9010.72.3.374

Casper, W. J., Harris, C., Taylor-Bianco, A., \& Wayne, J. H. (2011). Work-family conflict, perceived supervisor support and organizational commitment among 
Brazilian professionals. Journal of Vocational Behavior, 79(3), 640-652. doi:10.1016/j.jvb.2011.04.011

Caudroit, J., Boiche, J., Stephan, Y., Le Scanff, C., \& Trouilloud, D. (2011). Predictors of work/family interference and leisure-time physical activity among teachers: The role of passion towards work. European Journal of Work and Organizational Psychology, 20(3), 326-344. doi:10.1080/13594320903507124

Charmaz, K. (1990). Discovering chronic illness: Using grounded theory. Social Science and Medicine, 30(11), 1161-1172. doi:10.1016/0277-9536(90)90256-R

Charmaz, K. (2006). Constructing grounded theory: A practical guide through qualitative analysis. London, England: Sage.

Chen, Y., Park, J., \& Park, A. (2012). Existence, relatedness, or growth? Examining turnover intention of public child welfare caseworkers from a human needs approach. Children and Youth Services Review 34(10), 2088-2093. doi:10.1016/j.childyouth.2012.07.002

Child Welfare League of America. (2004). Child welfare workforce and training. Retrieved from http://66.227.70.18/advocacy/2004legagenda05.pdf

Cho, Y. J., \& Song, H. J. (2017). Determinants of turnover intention of social workers: Effects of emotional labor and organizational trust. Public Personnel Management, 46(1), 41-65. doi:10.1177/0091026017696395

Chuebang, P., \& Baotham, S. (2011). Voluntary turnover intentions: effects on perceived organizational support and organizational commitment of Thai employees in Rajabhat universities. International Academy of Business and Economics, 11(3). Retrieved from http://www.iabe.org/ 
Clark, D. B. (2013). Employee commitment and other factors that affect attraction and retention of employees in organizations: The examination of research and OPM practices (Doctoral dissertation). Available from ProQuest Dissertations and Theses database. (UMI No. 3596008)

Craigie, M., Slatyer, S., Hegney, D., Osserian-Moisson, R., Gentry, E., Davis, S., ... Rees, C. (2016). A pilot evaluation of a mindful self-care and resiliency (MSCR) intervention for nurses. Springer Science, 7(3), 764-774. doi:10.1007/s12671-0160516-X

Creswell, J. W. (2007). Qualitative inquiry and research design: Choosing among five approaches (2nd ed.). Thousand Oaks, CA: Sage.

Creswell, J. W. (2009). Research design: Qualitative, quantitative, and mixed methods approaches (3rd ed.). Los Angeles, CA: Sage.

Creswell, J. W. (2013). Qualitative inquiry \& research design: Choosing among five approaches (3rd ed.). Thousand Oaks, CA: Sage.

Creswell, J. W., \& Plano-Clark, V. L. (2011). Designing and conducting mixed methods research (2nd ed.). Thousand Oaks, CA: Sage.

Creswell, J. W., Plano-Clark, V. L., Gutmann, M. L., \& Hanson, W. E. (2003). Advanced mixed methods research designs. In A. Tashakkori \& C. Teddlie (Eds), Handbook on mixed methods in the behavioral and social sciences (pp. 209-240). Thousand Oaks, CA: Sage.

Compensation Force (2017). 2016 turnover rates by industry. Retrieved from http://www.compensationforce.com/2017/04/2016-turnover-rates-byindustry.html 
Coomber, B., \& Barriball, K. L. (2007). Impact of job satisfaction components on intent to leave and turnover for hospital-based nurses: A review of the research literature. International Journal of Nursing Studies, 44, 297-314. doi:10.1016/j.ijnurstu.2006.02.004

Culpepper, R. A. (2011). Three-component commitment and turnover: An examination of temporal aspects. Journal of Vocational Behavior, 79(2), 517-527. doi:10.1016/j.jvb.2011.03.004

Davis, L. (2014). Manager leadership behaviors, employee job satisfaction, and turnover within the federal government (Doctoral Dissertation). Available from ProQuest Dissertations and Theses database. (UMI No. 3617728)

Deci, E. L., \& Ryan, R. M. (1985). Intrinsic motivation and self-determination in human behavior. Rochester, NY: Plenum Press.

Deci, E. L., \& Ryan, R. M. (2014). Autonomy and need satisfaction in close relationships: Relationships motivation theory. In N. Weinstein (Ed.), Human motivation and interpersonal relationships: Theory, research, and applications (pp. 53-73). Dordrecht, Netherlands: Springer.

Denzin, N. (1978). The research act: A theoretical introduction to sociological methods. New York, NY: McGraw-Hill.

Denzin, N. K., \& Lincoln, Y. (2003). The landscape of qualitative research: Theories and issues (2nd ed.). London, England: Sage.

Dess, G. G., \& Shaw, J. D. (2001). Voluntary turnover, social capital, and organizational performance. Academy of Management Review, 26(3), 446-456. doi:10.2307/259187 
Dickter, D. N., Roznowski, M., \& Harrison, D. A. (1996). Temporal tempering: An event history analysis of the process of voluntary turnover. The Journal of Applied Psychology, 81, 705-716. doi:10.1037/0021-9010.81.6.705

Dillman, D. A. (2000). Mail and internet surveys: The tailored design method (2nd ed.). New York, NY: John Wiley.

Dworkin, S. L. (2012). Sample size policy for qualitative studies using in-depth interviews. Archives of Sexual Behavior, 41(6), 1319-1320. doi:10.1007/s10508012-0016-6

Ekety, C. A., \& Edeh, F. O. (2015). Social intelligence and employee intention to stay. International Journal of Novel Research in Marketing Management and Economics. 2(1), 27-34. Retrieved from www.noveltyjournals.com

Eisner, E. W. (1991). The enlightened eye: Qualitative inquiry and the enhancement of educational practice. New York, NY: MacMillian.

Eriksson, P. and Kovalainen, A. (2008). Qualitative methods in business research. London, Englad:Sage.

Equifax Workforce Solutions (2014). Employee Turnover Trends In 2013. Retrieved from http://insight.equifax.com/wp-content/uploads/2014/03/BenchmarkInfographic-FINAL-03.27.14.pdf

Field, Andy (2013). Discovering statistics using IBM SPSS statistics (4th ed.). Thousand Oaks, CA: Sage.

Fillenbaum, G., Heyman, A., Peterson, B. L., Pieper, C., \& Weiman, A. L. (2000). Frequency and duration of hospitalization with Alzheimer's disease based on 
Medicare data: CERAD XX. Neurology, 54(3), 740-743. Retrieved from http://www.neurology.org/

Finnemore, M. (1990). Unemployment and labor turnover in the Eastern Cape. IPM Journal, 8(9), 17-20. Retrieved from http://www.journals.elsevier.com/information-processing-and-management/ Fink, A. (2003). The survey handbook (2nd ed.). Thousand Oaks, CA: Sage. Fontana, A., \& Frey, J. H. (2005). The interview: From neutral stance to political involvement. In N. K., Denzin \& Y. S., Lincoln (Eds.), The Sage Handbook of Qualitative Research (pp. 695-728). Thousand Oaks, CA: Sage.

Forest, J., Mageau, G., Sarrazin, C., \& Morin, E. (2011). "Work is my passion”: The different affective, behavioral, and cognitive consequences of harmonious and obsessive passion toward work. Canadian Journal of Administrative Sciences, 28, 27-40. doi:10.1002/CJAS.170

Forest, J., Mageau, G. A., Crevier-Braud, L., Bergeron, E., Dubreuil, P., \& Lavigne, G. L. (2012). Harmonious passion as an explanation of the relation between signature strengths' use and well-being at work: Test of an intervention program. Human Relations, 65, 1233-1252. doi:10.1177/0018726711433134

Froese, F. J., \& Xiao, S. (2012). Work values, job satisfaction and organizational commitment in China. The International Journal of Human Resource Management, 23(10), 2144-2162. doi:10.1080/09585192.2011.610342

Frost, J. (May 2013). Regression Analysis: How Do I Interpret R-squared and Assess the Goodness-of-Fit? Retrieved from http://blog.minitab.com/blog/adventures-in- 
statistics-2/regression-analysis-how-do-i-interpret-r-squared-and-assess-thegoodness-of-fit

Fusch, P. I., \& Ness, L. R. (2015). Are we there yet? Data saturation in qualitative research. The Qualitative Report, 20(9), 1408-1416. Retrieved from http://tqr.nova.edu/

Gagné, M., \& Deci, E. L. (2005). Self-determination theory and work motivation. Journal of Organizational behavior, 26(4), 331-362. doi:10.1002/job.322

Gagné, M., \& Forest, J. (2008). The study of compensation systems through the lens of self-determination theory: Reconciling 35 years of debate. Canadian Psychological Association, 49(3), 225-232. doi:10.1037/a0012757

Geurts, S., Schaufeli, W., \& De Jonge, J. (1998). Burnout and intention to leave among mental health-care professionals: A social psychological approach. Journal of Social and Clinical Psychology, 17(3), 341-362. doi:10.1521/jscp.1998.17.3.341

Gieter, S., Hofmans, J., \& Pepermans, R. (2011). Revisiting the impact of job satisfaction and organizational commitment on nurse turnover intention: An individual differences analysis. International Journal of Nursing Studies, 48(12), 1562-1569. doi:10.1016/j.ijnurstu.2011.06.007

Gillet, N., Gagn, M., Sauvagre, S., \& Fouquereau, E. (2013). The role of supervisor autonomy support, organizational support, and autonomous and controlled motivation in predicting employees' satisfaction and turnover intentions. European Journal of Work and Organizational Psychology, 2(4), 450-460. doi:10.1080/1359432X.2012.665228 
Gong, Y., \& Chang, S. (2008). Institutional antecedents and performance consequences of employment security and career advancement practices: Evidence from the people's republic of China. Human Resources Management, 47, 33-48. doi:10.1002/hrm.20196

Graphic Art Monthly (2005, February). Employee Pride Goes Wide. Retrieved from http://www.verify360.com/background-verification-experts

Greenbank, P. (2003). The role of values in educational research: The case for reflexivity. British Educational Research Journal, 29(6), 791-801. doi:10.1080/0141192032000137303

Grimsley, S. (2003). Organizational commitment: Definition, theory \& types. Retrieved http://study.com/academy/lesson/organizational-commitment-definition-theorytypes.html

Gunnell, M. (2016). Research Methodologies: A comparison of quantitative, qualitative, and mixed methods. Retrieved from https://www.linkedin.com/pulse/researchmethodologies-comparison-quantitative-mixed-methods-gunnell

Guntert, S. T. (2014). The impact of work design, autonomy support, and strategy on employee outcomes: A differentiated perspective on self-determination at work. Motivation and Emotion, 39(1), 74-87. doi:10.1007/s11031-014-9412-7

Harter, J. K., Schmidt, F. L., Asplund, J. W., Killham, E. A., \& Agrawal, S. (2010). Causal impact of employee work perceptions on the bottom line of organizations. Perspectives on Psychological Science, 5(4), 378-389. doi:10.1177/1745691610374589 
Herscovitch, L., \& Meyer, J. P (2002). Commitment to organizational change: Extension of a three-component model. Journal of Applied Psychology, 87(3), 474-487. doi:10.1037/0021-9010.87.3.474

Hewitt Associates. (2004). Strategies for Cost Management of the HR Function. Retrieved from http://hrledger.com/library/HR_Costs_Hewitt_2004.pdf

Hinshaw, A., \& Atwood, J. (1982). Anticipated turnover: A pilot stage instrument. Communicating Nursing Research. Boulder, CO: Wiche Publications.

Ho, V., Wong, S., \& Lee, C. (2011). A tale of passion: Linking job passion and cognitive engagement to employee work performance. Journal of Management Studies, 48(1), 26-41. doi:10.1111/j.1467-6486.2009.00878.x

Houlfort, N., Fernet, C., Vallerand, R. J., Laframboise, A., Guay, F., \& Koestner, R. (2015). The role of passion for work and need satisfaction in psychological adjustment to retirement. Journal of Vocational Behavior, 88, 84-94. doi:10.1016/j.jvb.2015.02.005

Huck, S. W. (2008). Reading statistics and research (5th ed.). Boston, MA: Pearson. Human capital (2017). In Business Dictionary. Retrieved from http://www.businessdictionary.com/definition/human-capital.html

Jacob, S. A., \& Furgerson, S. P. (2012). Writing Interview Protocols and Conducting Interviews: Tips for Students New to the Field of Qualitative Research. The Qualitative Report, 17(42), 1-10. Retrieved from http://nsuworks.nova.edu/tqr

Kaufman, S. B. (2011, September). How to increase your harmonious passion. Psychology Today. Retrieved November 06, 2016 https://www.psychologytoday.com/ 
Kermish, I., \& Kushin, F. (1969). Why high turnover? Social work staff losses in a county welfare department. Public Welfare, 27, 134-139. Retrieved from http://www.tandfonline.com/loi/wpcw20

Khapova, S. N., \& Korotov, K. (2007). Dynamics of Western career attributes in the Russian context. Career Development International, 12(1), 68-95. doi:10.1108/13620430710724839

Koeske, G. F., \& Kirk, S. A. (1995). The effect of characteristics of human service workers on subsequent morale and turnover. Administration in Social Work, 19(1), 15-31. doi:10.1300/J147v19n01_02

Lapointe, E., \& Vandenberghe, C. (2017). Supervisory mentoring and employee affective commitment and turnover: The critical role of contextual factors. Journal of Vocational Behavior, 98, 97-107. doi:10.1016/j.jvb.2016.10.004

Larson, S. A., \& Hewitt, A. M. (2012). Staff recruitment, retention, training strategies for community human services organizations. Retrieved from https://ici.umn.edu/index.php?products/view_part/580/

Larson, S. A., Hewitt, A. S., \& Lakin, K. C. (2004). Multiperspective analysis of workforce challenges and their effects on consumer and family quality of life. American Journal on Mental Retardation, 109(6), 481-500. doi:10.1352/08958017(2004)109<481:MAOWCA>2.0.CO;2

Lewis, K. (2014). Rising Voluntary Turnover: Is It An Opportunity Or A Curse. Talent Management and HR. Retrieved from http://www.eremedia.com/tlnt/

Liederman, D. (2003). A critical look at the child welfare system caseworker turnover. Retrieved from http://www.liftingtheveil.org/turnover.htm 
Lin, V., Lin, J., \& Zhang, X. (2015). U.S. social worker workforce report card:

Forecasting nationwide shortages. A Journal of the National Association of Social Workers, 61(1), 7-15. doi:10.1093/sw/swv047

Lincoln, Y. S., \& Guba, E. G. (1985). Naturalistic Inquiry. Newbury Park, CA: Sage.

Liu, D., Chen, XP, \& Yao, X. (2011). From autonomy to creativity: A multilevel investigation of the mediating role of harmonious passion. Journal of Applied Psychology, 96(2), 294-309. doi:10.1037/a0021294

Llobet, J., \& Fito, M. A. (2013). Contingent workforce, organizational commitment and job satisfaction: Review, discussion and research agenda. Intangible Capital, 9(4), 1068-1079. doi:10.3926/ic.475

Long, C. S., Thean, L. Y., Ismail, W. K., \& Jusho, A. (2012). Leadership styles and employees' turnover intention: exploratory study of academic staff in a Malaysian College. World Applied Sciences Journal, 19(4), 575-581. doi:10.5829/idosi.wasj.2012.19.04.155

Loewenberg, F. M. (2014). The causes of turnover among social workers. The Journal Of Sociology \& Social Welfare, 6(5). Retrieved from http://scholarworks.wmich.edu/jssw/

Luh, D., \& Lu, C. (2012). From cognitive style to creativity achievement: The mediating role of passion. Psychology of Aesthetics, Creativity, and the Arts, 6, 282-288. doi:10.1037/a0026868

Mabengano, C. M. (2003). Factors that influence job turnover of social workers in the directorate of developmental social welfare services (DDSWS) in Namibia. 
University of Pretoria, South Africa. Retrieved from http://repository.up.ac.za/bitstream/handle/2263/27180/Complete.pdf?sequence=3

Mageau, G. A., \& Vallerand, R. J. (2007). The moderating effect of passion on the relation between activity engagement and positive affect. Springer Science Business Media, 31, 312-321. doi:10.1007/s11031-007-9071-z

Mageau, G. A., Vallerand, R. J., Charest, J., Salvy, S., Lacaille, N., Vouffard, T., \& Koestner, R. (2009). On the development of harmonious and obsessive passion: The role of autonomy support, activity specialization, and identification with the activity. Journal of Personality, 7(3), 601-646. doi:10.1111/j.14676494.2009.00559.x

Maia, L. G., Virgilio, A., Bastos, B., \& Solinger, O. N. (2016). Which factors make the difference for explaining growth in newcomer organizational commitment? A latent growth modeling approach. Journal of Organizational Behavior, 37(4), 537-557. doi:10.1002/job.2096

Marsh, H. W., Vallerand, R. J., Lafrenière, M. A. K., Parker, P., Morin, A. J., Carbonneau, N., ... Paguet, Y. (2013). Passion: Does one scale fit all? Construct validity of two-factor passion scale and psychometric invariance over different activities and languages. Psychological Assessment, 25, 796-809. doi:10.1037/a0032573

Mathieu, J. E., \& Zajac, D. M. (1990). A review and meta-analysis of the antecedents, correlates, and consequences of organizational commitment. Psychological Bulletin, 8(2), 171-194. doi:10.1037/0033-2909.108.2.171 
McGregor, E. B. (1988). The public sector human resources puzzle: Strategic management of a strategic resource. Public Administration Review, 4(6), 493-522. doi:10.2307/976989

Meld, M. B. (1974). The employment experience of community organization graduates: A pilot study. Journal of Education for Social Work, 10(1), 60-67. doi:10.1080/00220612.1974.10672334

Merhar, C. (2016, February 4). Employee Retention - The Real Cost of Losing an Employee Small Business Employee Benefits and HR Blog. Retrieved from http://www.zanebenefits.com/blog/bid/312123/Employee-Retention-The-RealCost-of-Losing-an-Employee

Meyer, J. P., \& Allen, N. J. (1991). A three-component conceptualization of organizational commitment. Human Resource Management Review, 1(1), 61-89. doi:10.1016/1053-4822(91)90011-Z

Meyer J. P., \& Allen, N. J. (1997). Commitment in the workplace: Theory, research, and application. Thousand Oaks, CA: Sage.

Meyer, J. P., \& Allen, N. J. (2004). TCM employee commitment survey academic users guide 2004. Retrieved from: http://employeecommitment.com/TCM-EmployeeCommitment-Survey-Academic-Package-2004.pdf

Meyer, J. P., Allen, N. J., \& Smith, C. A. (1993). Commitment to organizations and occupations: extension and test of a three-component conception. Journal of Applied Psychology, 78, 538-551. doi:10.1037//0021-9010.78.4.538 
Meyer, J. P., Becker, T. E., \& Vandenberghe, C. (2004). Employee commitment and motivation: A conceptual analysis and integrative model. Journal of Applied Psychology, 89, 991-1007. doi:10.1037/0021-9010.89.6.991

Meyer, J. P., \& Parfyonova, N. M. (2010). Normative commitment in the workplace: A theoretical analysis and re-conceptualization. Human Resource Management Review, 11(3), 299-326. doi:10.1016/j.hrmr.2009.09.001

Meyer, J. P., \& Smith, C. A. (2000). HRM practices and organizational commitment: test of a mediation model. Canadian Journal of Administrative Sciences, 17(4), 319331. doi:10.1111/j.1936-4490.2000.tb00231.x

Meyer, J. P., Stanley, D. J., Hersocovitch, L., \& Topolinytsky, L. (2002). Affective, continuance, and normative commitment to the organization: A meta-analysis of antecedents, correlates, and consequences. Journal of Vocational Behavior, 61, 20-62. doi:10.1006/jvbe.2001.1842

Meyer J. P., Stanley D. J., Jackson T. A., McInnis K. J., Maltin E. R., \& Sheppard L. (2012). Affective, normative and continuance commitment levels across cultures: A meta-analysis. Journal of Vocational Behavior, 80, 225-245. doi:10.1016/j.jvb.2011.09.005

Monette, D. R., Sullivan, T. J., \& Dejong, C. R. (2011). Applied social research: a tool for the human services. New York, NY: Brooks/Cole Cengage Learning.

Morse, J. M. (1994). Designing funded qualitative research. In N. Denzin \& Y. Lincoln (Eds.), Handbook of qualitative research (pp. 220-235). Thousand Oaks, CA: Sage. 
Morse, J. M. (1995). The significance of saturation. Qualitative Health Research, 5(3), 147-149. Retrieved from http://journals.sagepub.com/home/qhr

Mosadeghrad, A. M., \& Ferdosi, M. (2013). Leadership, job satisfaction and organizational commitment in healthcare sector: proposing and testing a model. Materia Socio Medica, 25(2), 121-126. doi:10.5455/msm.2013.25.121-126

Moss, S. (2013). The dualistic model of passion. Retrieved from Sico Tests, http://www.sicotests.com/psyarticle.asp?id=444

Mowday, R. T., Porter, L. W., \& Steers, R. M. (1982). Employee-organization linkages: The psychology of commitment, absenteeism and turnover. New York, NY: Academic Press.

Nehmeh, R. (2009). What is organizational commitment, why should managers want it in their workforce and is there any cost effective way to ensure it? Swiss Management Center. Retrieved from https://www.smcuniversity.com/working_papers/Ranya_Nehmeh__What_is_Organizational_commitment,_why_should_managers_want_it_in_their _workforce_and_is_there_any_cost_effective_way_to_secure_it.pdf

Newman, S., Ye, J., \& Leep, C. (2014). Workforce turnover at local health departments: Nature, characteristics, and implications. American Journal of Preventive Medicine. 47(5), 337-343. doi:10.1016/j.amepre.2014.07.023

Ng, T. W. H., Feldman, D. C., \& Lam, S. S. K. (2010). Psychological contract breaches, organizational commitment, and innovation related behavior: A latent growth modeling approach. Journal of Applied Psychology, 95, 744-751. doi:10.1037/a0018804 
NSI Nursing Solutions, Inc. (2016). 2016 National Healthcare Retention \& RN Staffing Report. Retrieved from http://www.nsinursingsolutions.com/Files/assets/library/retentioninstitute/NationalHealthcareRNRetentionReport2016.pdf

O’Neill, J. V. (2000, November). Larger doctoral enrollments sought: Few social workers follow path to PhD. NASW News. Retrieved from http://www.socialworkers.org/pubs/news/2000/11/phd.htm

Ocak, M. A. (2011). Why are faculty members not teaching blended courses? Insights from faculty members. Computers \& Education, 56, 689-699. doi:10.1016/j.compedu.2010.10.011

Patton, M. Q. (2001). Qualitative research and evaluation methods. Thousand Oaks, CA: Sage.

Peng, J., Dongdog, L., Zhenjian, Z, Tian, Y., Miao, D., Xiao, W., \& Zhang, J. (2016). How can core self-evaluations influence job burnout? The key roles of organizational commitment and job satisfaction. Journal of Health Psychology, 21(1), 50-59. doi:10.1177/1359105314521478

Phillippe, F. L., Vallerand, R. J., Houlfort, N., Lavigne, G. L., \& Donohue, E. G. (2010). Passion for an activity and the quality of interpersonal relationships: The mediating role of emotions. Journal of Personality and Social Psychology, 98, 917-932. doi:10.1037/a0018017

Phillips, P. P., Phillips, J. J., \& Aaron, B. (2013). Survey basics. Alexandria, VA: ASTD. 
Phillips, P. P., Phillips, J. J., \& Zuniga, L. (2013). Measuring the success of organization development: A step-by-step guide for measuring impact and calculating ROI. Alexandria, VA: ASTD.

Porter, L. W., Steers, R. M., Mowday, R. T., \& Boulian, P. V. (1974). Organizational commitment, job satisfaction, and turnover among psychiatric technicians. Journal of Applied Psychology, 59, 603-609. doi:10.1037/h0037335

Powell, D. M., \& Meyer, J. P. (2004). Side-bet theory and the three-component model of organizational commitment. Journal of Vocational Behavior 65(1), 157-177. doi: $10.1016 / \mathrm{S} 0001-8791(03) 00050-2$

QuestionPro (2018). Increase online survey response rates. Retrieved from https://www.questionpro.com/article/increase-response-rates-online-surveys.html Rafique, S. (2016, June). CPS attributes investigator turnover to stress, low pay. Lubbok Avalanche-Journal. Retrieved from http://www.lubbockonline.com/

Raosoft Sample Size Calculator. (n.d.). Retrieved from http://www.raosoft.com/samplesize.html

Reagh, R. (1994). Public child welfare professionals: Those who stay. Journal of Sociology and Social Welfare, 21(3), 69-78. Retrieved from https://scholarworks.wmich.edu/jssw/

Reichers, A. E. (1985). A review and reconceptualization of organizational commitment. Academy of Management Review, 10(3), 465-476. doi:10.5465/AMR.1985.4278960 
Richards, D.A., \& Schat, A.C.H. (2011). Attachment at (not to) work: Applying attachment theory to explain individual behavior in organizations. Journal of Applied Psychology, 96(1), 169-182. doi:10.1037/a0020372

Roberts, C. M. (2010). The dissertation journey: A practical and comprehensive guide to planning, writing, and defending your dissertation (2nd ed.). Thousand Oaks, CA: Corwin.

Rodrigo (2012, December). How can HRM practices influence employee commitment and overcome high employee turnover. The WritePass Journal. Retrieved from https://writepass.com/journal/

Rosenkranz, A. (2012). The influence of values and psychosocial job characteristics on intent to leave among hospital nurses. (Doctoral Dissertation). Retrieved from George Mason University http://digilib.gmu.edu/jspui/bitstream/handle/1920/8095/Rosenkranz_gmu_0883E _10185.pdf? sequence $=1$

Ryan, R. M., \& Deci, E. L. (2000). Self-determination theory and the facilitation of intrinsic motivation, social development, and well-being. American psychologist, 55(1), 68. doi:10.1037110003-066X.55.1.68

Savickas, M. L. (2004). Vocational psychology, overview. Encyclopedia of Applied Psychology, (3), 655-667. doi:10.1016/B0-12-657410-3/00610-3

Sayğan, F. N. (2011). Relationship between affective commitment and organizational silence: A conceptual discussion. International Journal of Social Sciences and Humanity Studies, 3(2), 219-227. Retrieved from http://www.sobiad.org/eJOURNALS/journal_IJSS/index.html 
Schlesinger, L. A., \& Heskett, J. L. (1991, October). The service-driven service company. Harvard Business Review. Retrieved December 06, 2016 https://hbr.org/

Scrima, F., Stefano, G., Guarnaccia, C., \& Lorito, L. (2015). The impact of adult attachment style on organizational commitment and adult attachment in the workplace. Personality and Individual Differences, 86, 432-437. doi:10.1016/j.paid.2015.07.013

Seguin-Levesque, C., Laliberte, M. L., Pelletier, L. G., Blanchard, C., \& Vallerand, R. J. (2003). Harmonious and obsessive passion for the internet: Their associations with couple's relationships. Journal of Applied Social Psychology, 33, 197-221. doi:10.1111/j.1559-1816.2003.tb02079.x

Sharma, B. R., Mohapatra, M., \& Rai, S. (2014). Organizational commitment as a measure of managerial motivation: Search for its predictors in a multinational organization. Management and Labour Studies, 38(3), 139-153. doi: $10.1177 / 0258042 X 13509735$

Shinan-Altman, S., Werner, P., \& Cohen, M. (2015). The connection between illness representations of Alzheimer's disease and burnout among social workers and nurses in nursing homes and hospitals: a mixed-methods investigation. Aging Mental Health, 20(4), 352-361. doi:10.1080/13607863.2015.1008983

Simon, M. K., \& Goes, J. (2013). Dissertation and scholarly research: Recipes for success. Retrieved from http://dissertationrecipes.com/wpcontent/uploads/2011/04/Role-of-the-Researcher.pdf

Slack, F., Orife, J., \& Anderson, F. (2010). Effects of commitment to corporate vision on employee satisfaction with their organization: An empirical study in the United 
States. International Journal of Management, 27(3), 421. Retrieved from http://www.theijm.com/

Social Worker (2015). Human Services. Retrieved from http://www.humanservicesedu.org/definition-social-work.html Social Worker (2014). International Federation of Social Workers. Retrieved from http://ifsw.org/policies/definition-of-social-work/

Society for Human Resource Management. (2008). Retaining talent: A guide to analyzing and managing employee turnover. Retrieved from https://www.shrm.org/about/foundation/research/documents/retaining\%20talent\%20final.pdf

Solinger, O. N., Hofmans, J., \& Van Olffen, W. V. (2015). The dynamic microstructure of organizational commitment. Journal of Occupational and Organizational Psychology, 88(4), 773-796. doi:10.1111/joop.12097

Solinger, O. N., Van Olffen, W. V., \& Roe, R. A. (2008). Beyond the three-component model of organizational commitment. The Journal of Applied Psychology, 93, 7383. doi:10.1037/0021-9010.93.1.70

Smith, H. (2014). How do we attract and retain social workers? Retrieved from http://www.peridotpartners.co.uk/attract-retain-social-workers/

Smith, K. G., \& Hitt, M. A. (Eds.). (2005). Great minds in management: The process of theory development. Oxford, England: Oxford University Press.

Spain, E., \& Groysberg, B. (2016, April). Making exit interviews count. Harvard Business Review. Retrieved January 07, 2017 https://hbr.org/ 
Starnes, B. J., \& Truhon, S. A. (n.d.). A primer on organizational commitment. American Society for Quality. Retrieved from http://asq.org/divisions-forums/hdl/qualityinformation/library/index.html?topic=24\&PageNumber=2\&StartRow=11

Stone, D. N., Deci, E. L., \& Ryan, R. M. (2009). Beyond talk: Creating autonomous motivation through self-determination theory. Journal of General Management, 34, 75-91. Retrieved from https://journals.sagepub.com/home/gem

Strand, V. C., \& Dore, M. M. (2009). Job satisfaction in a stable state child welfare workforce: Implications for staff retention. Children and Youth Services Review 31(3), 391-397. doi:10.1016/j.childyouth.2008.09.002

Strober, M. H. (1990). Human capital theory: Implications for HR managers. Industrial Relations, 29, 214-239. doi:10.1111/j.1468-232X.1990.tb00752.x

Strolin-Goltzman, J., Kollar, S., \& Trinkle, J. (2010). Listening to the voices of children in foster care: Youths speak out about child welfare workforce turnover and selection. Oxford Journals, 55(1), 47-53. doi:10.1093/sw/55.1.47

Sudeshna (2016). Limitations and weakness of quantitative research methods. Retrieved from https://www.projectguru.in/publications/limitations-quantitative-research/

Suma, S., \& Lesha, J. (2013). Job satisfaction and organizational commitment: The case of shkodra municipality. European Scientific Journal, 9(17), 41-51. Retrieved from eujournal.org/

Sutton, J., \& Austin, Z. (2015). Qualitative Research: Data Collection, Analysis, and Management. The Canadian Journal of Hospital Pharmacy, 68(3), 226-231. Retrieved from https://www.ncbi.nlm.nih.gov/pmc/articles/PMC4485510/ 
Tashakkori, A., \& Teddlie, C. (2010). Sage handbook of mixed methods in social \& behavioral research. Thousand Oaks, CA: Sage.

Teddlie, C., \& Tashakkori, A. (2009). Foundations of mixed methods research: Integrating quantitative and qualitative approaches in the social and behavioral sciences. Thousand Oaks, CA: Sage.

Testa, B. (2008). Early engagement, long relationships? Workforce Management, 87(15), 27-31. Retrieved from http://www.rand.org/topics/workforce-management.html

Tett, R. P., \& Meyer, J. P. (1993). Job satisfaction, organizational commitment, turnover intention, and turnover: path analyses based on meta-analytic findings. Personnel Psychology, 46(2), 259-293. doi:10.1111/j.1744-6570.1993.tb00874.x

Thomas, T. (2009). Voluntary turnover: Why it exists and what it costs. Thomas Concept the Leader in Healthcare Culture Transportation. Retrieved from http://www.thomasconcept.com/docs/Voluntary\%20TurnoverWhy\%20it\%20Exists\%20and\%20What $\% 20$ it $\% 20$ Costs.pdf

Tremblay, N., Want, Z., Ma, B., Belec, C., \& Vigneault, P. (2009). A comparison of crop data measured by two commercial sensors for variable-rate nitrogen application. Precision Agric, 10, 145-161. doi:10.1007/s11119-008-9080-2

Tollen, W. B. (1960). Study of staff losses in child welfare and family service agencies. Washington, DC: U.S. Department of Health, Education, and Welfare, Social Security Administration, Children's Bureau.

Tran, N. (2014, December). What is Self-Determination Theory? Positive Psychology. Retrieved from http://www.apa.org/pubs/journals/index.aspx 
Vallerand, R. J. (2008). On the psychology of passion: In search of what makes people's lives most worth living. Canadian Psychology, 49, 1-13. doi:10.1037/0708-5591.49.1.1

Vallerand, R. J. (2010). On passion for life activities: The dualistic model of passion. Advances in Experimental Social Psychology, 42, 97-193. doi:10.1016/S0065-2601(10)42003-1

Vallerand, R. J. (2012). The role of passion in sustainable psychological wellbeing. Psychology of Well-Being, 2(1), 1-21. doi:10.1186/2211-1522-2-1

Vallerand, R. J. (2015). The psychology of passion: On the Dualistic Model of Passion. New York, NY: Oxford University Press.

Vallerand, R. J., Blanchard, C., Mageau, G. A., Koestner, R., Ratelle, C., Léonard, M., \& Marsolais, J. (2003). Les passions de l'âme: On obsessive and harmonious passion. Journal of Personality And Social Psychology, 85(4), 756-767. doi:10.1037/0022-3514.85.4.756

Vallerand, R. J., Houlfort, N., \& Forest, J. (2014). Passion for work: Determinants and outcomes. In M. Gagné (Ed.), The Oxford Handbook of Work Engagement, Motivation, and Self-Determination Theory (pp. 85-105). Oxford, England: Oxford University Press.

Vinokur-Kaplan, D. (1991). Job satisfaction among social workers in public and voluntary child welfare agencies. Child Welfare, 70(1), 81-91. Retrieved from http://www.cwla.org/child-welfare-journal/ 
Wang, C., \& Chu, Y. (2007). Harmonious passion and obsessive passion in playing online games. Social Behavior and Personality: An International Journal, 35(7), 997-1006. doi:10.2224/sbp.2007.35.7.997

Wargo, W. G. (2015). Identifying assumptions and limitations for your dissertation. Academic Information Center. Retrieved from http://www.academicinfocenter.com/identifying-assumptions-and-limitations-foryour-dissertation.html

Weaver, D., Chang, J., \& Gil de Gibaja, M. (2006). The retention of public child welfare workers. Berkeley, CA: University of California at Berkeley, California Social Work Education Center.

Wharton University of Pennsylvania (n.d.). Declining Employee Loyalty: A Casualty of the New Workplace. Retrieved April 25, 2017, from http://knowledge.wharton.upenn.edu/article/declining-employee-loyalty-acasualty-of-the-new-workplace/

Wisdom, J., \& Creswell, J. (2013). Mixed Methods: Integrating Quantitative and Qualitative Data Collection and Analysis While Studying Patient-Centered Medical Home Models. Agency for Healthcare Research and Quality. Retrieved from https://pcmh.ahrq.gov/page/mixed-methods-integrating-quantitative-andqualitative-data-collection-and-analysis-while

Wong, A., \& Tong, C. (2014). Evaluation of organizational commitment models and their components in Asian cities. International Journal of Human Resource Studies 4(2), 66-96. doi:10.5296/ijhrs.v4i2.5601 
Yousef, D. A. (2016). Organizational commitment, job satisfaction and attitudes toward organizational change: A study in the local government. International Journal of Public Administration 40(1), 77-88. doi:10.1080/01900692.2015.1072217

Zeitlin, W. (2014). Factors impacting perceptions of organizational cultural competence in voluntary child welfare. Children and Youth Services Review, 44(1), 1-8. doi:10.1016/j.childyouth.2014.05.006

Zhang, J., Wu, Q., \& Miao, D. (2013). The impact of core self-evaluations on job satisfaction: The mediator role of career commitment. Social Indicators Research, 116(3). doi:10.1007/s11205-013-0328-5.

Zhao, Y., St-Louis, A., \& Vallerand, R. J. (2015). On the validation of the passion scale in Chinese. Psychology of Well-Being, 5(3), 1-11. doi:10.1186/s13612-015-00311

Zigarmi, D., Nimon, K., Houson, D., Witt, D., \& Diehl, J. (2009). Beyond engagement: Toward a framework and operational definition for employee work passion. Human Resource Development Review, 8, 300-326. doi: $10.1177 / 1534484309338171$

Zohrabi, M. (2013). Mixed method research: instruments, validity, reliability and reporting findings. Theory and practice in language studies 3(2), 254-262. doi:10.4304/tpls.3.2.254-26 